AGRICULTURAL EXPERIMENT STATION

RESEARCH BULLETIN 49

\title{
EXPERIMENTS IN FIELD PLOT TECHNIC FOR THE PRELIMINARY DETERMINATION OF COMPARATIVE YIELDS IN THE SMALL GRAINS
}

(Publication authorized December 2, 1921.)

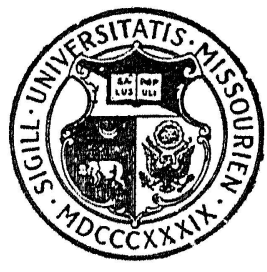




\title{
UNIVERSITY OF MISSOURI \\ COLLEGE OF AGRIGULTURE \\ Agricultural Experiment Station
}

BOARD OF CONTROL

THE CURATORS OF THE UNIVERSITY OF MISSOURI

EXECUTIVE BOARD OF THE UNIVERSITY
E. I,ANSING RAY,
P. E. BURTON,
Joplin
H. J. BLANTON,
St. Louis
Paris

\author{
ADVISORY COUNCIL \\ THE MISSOURI STATE BOARD OF AGRICUL,TURE
}

OFFICERS OF THE STATYON

F. B. MUMFORD, M. S., DIRECTOR

J. C. JONES, Ph. D., LL.D., PRESIDENT OF THE UNIVERSITY

STATYON STAFF

DECEMBER, 1921

AGRICULTURAL CHEMISTRY

C. R. MoulToN, Ph. D.

L. D. HAIGH, Ph. D.

W. S. RITCHIE, A. M.

E. E. VANATTA, M. S.

A. R. HAII, B. S. in Agr.

E. G. SIEVekiNG, B. S. in Agr.

AGRICULTURAL ENGINEERING

J. C. WOOLEY, B.S.

MACK M. JONES, B. S.

\section{ANIMAL HUSBANDRY}

E. A. Trowbridge, B. S. in Agr.

L. A. WEAVER, B. S. in Agr.

A. G. Hogan, Ph. D.

F. B. MUMFORD, M. S.

D. W. ChitTenden, B. S. in Agr.

A. T. EDINGER, B. S. in Agr.

H. D. Fox, B. S. in Agr.

W. J. RoBbins, Ph. D.

$$
\text { BOTANY }
$$

E. F. Hopkins, Ph. D.

\section{DAIRY HUSBANDRY}

A. C. RAGSDALE. B. S. in Agr.

W. W. SWETT, A. M.

Wis. H. E. REID, A. M.

SAMUEI BRODY, M. A.

C. W. TURNER, B. S. in Agr.

D. H. Nelson, B. S. in Agr.

\section{ENTOMOLOGY}

Leonard Haseman, Ph. D.

$\vec{K}$. C. Sullivan, A. $M$.

O. C. McBride,

\section{FIELD CROPS}

W. C. Ermeridge, Ph. D.

C. A. HELM, A. M.

I. J. STADLER, A. M.

O. W. LETSON, B. S. in Agr.

B. M. KrNG, B. S. in Agr.

A. C. HILI, B. S. in Agr.

Miss Bertha C. Hite, A. B.I

Miss PEARI DRUMMOND, A. A.
RURAL LIFE

O. R. Jorrnson, A. M.

S. D. GROMER, A. M.

E. L. Morgan, A. M.

BEN H. FRAME, B. S. in Agr.

\section{HORTICULTURE}

V. R. GARDNER, M. S. A.

H. D. HOOKER, JR., Ph. D.

J. T. ROSA, JR., M. S.

F. C. BRADFORD, M. S.

H. G. Swartwout, B. S. in Agr.

POULTRY HUSBANDRY

H. L. KEMPSTER, B. S.

EARI W. HENDERSON

\section{SOILS}

M. F. MILLER, M. S. A.

H. H. KRUSEKOPF, A. M.

W. A. AlBRECHT, Ph. D.

F. L. DULEY, A. M. ${ }^{2}$

R. R. HUDELSON, A. M.

WM. DEYounG, B. S. in Agr.

H. V. JORDAN, B. S. in Agr.

RICHARD BRADFIEID, A. B.

O. B. PRICE, B. S. in Agr.

\section{VETERINARY SCIENCE}

J. W. Connaway, D. V. S., M. D.

L. S. BACKUS, D. V. M.

O. S. CRISLER, D. V. M.

A. J. Durant, A. M.

H. G. NEWMaN, A. M.

\section{OTHER OFFICERS}

R. B. PrICE, M. S., Treasurer LESLIE COWAN, B. S., Sercretary S. B. SHIRKEY, A. M., Asst. to Director A. A. JEFFREY, A. B., Agricultural Editor J. F. BARHAM, Photographer MISS JANE FRODSHAM, Librarian E. E. Brown, Business Manager

IIn service of U. S. Department of Agriculture, Seed Testing Laboratory.

'On leave of absence. 


\section{CONTENTS}

Page

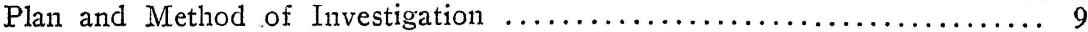

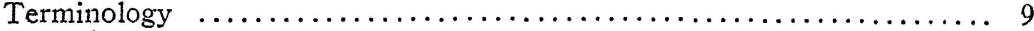

Procedure $\ldots \ldots \ldots \ldots \ldots \ldots \ldots \ldots \ldots \ldots \ldots \ldots \ldots \ldots \ldots \ldots \ldots \ldots, 11$

Work of 1919 ......................................... 12

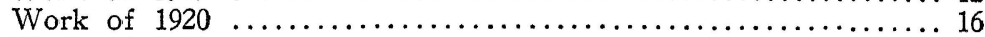

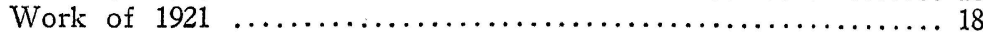

Competition as a Source of Error in Preliminary Tests $\ldots \ldots \ldots \ldots \ldots \ldots .23$

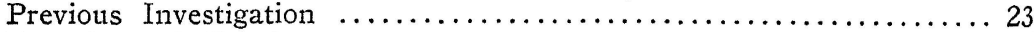

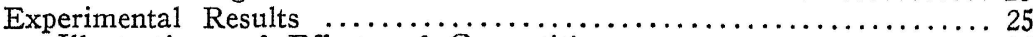

Illustrations of Effects of Competition ...................26

Relation of Competition to Various Characteristics of the Com-

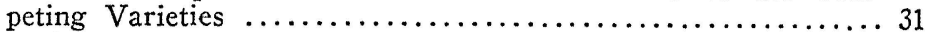

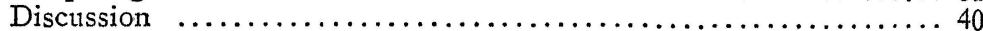

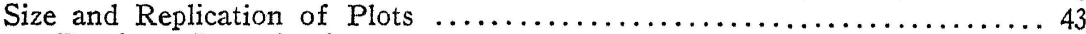

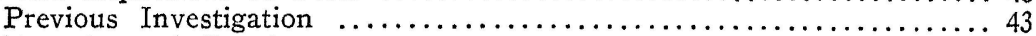

Experimental Results $\ldots \ldots \ldots \ldots \ldots \ldots \ldots \ldots \ldots \ldots \ldots \ldots \ldots \ldots, 44$

Size of Plots ........................................ 44

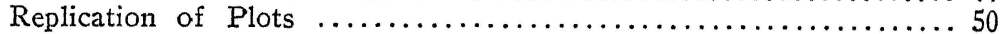

Adjustment of Yields by Means of Check Plots ..................... 54

Previous Investigation $\ldots \ldots \ldots \ldots \ldots \ldots \ldots \ldots \ldots \ldots \ldots \ldots \ldots \ldots, 54$

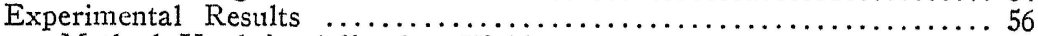

Method Used in Adjusting Yields ....................... 58

Relative Variability of Actual and Adjusted Yields .............. 60 .

Difference in Results Obtained by Adjustment with Different Check

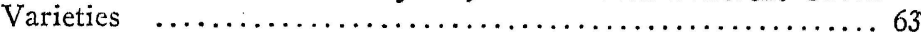

Value and Limitations of Adjusting Yields by Means of Check Plots 71

Concluding Remarks ............................................ 73

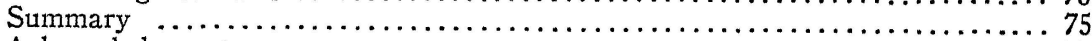

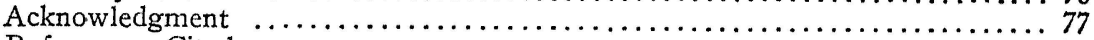

References Cited $\ldots \ldots \ldots \ldots \ldots \ldots \ldots \ldots \ldots \ldots \ldots \ldots \ldots \ldots \ldots \ldots \ldots, 78$

\section{TABLES}

Table

Number

Table

Page

1 Yields of Barley Varieties 1919 .............................. 13

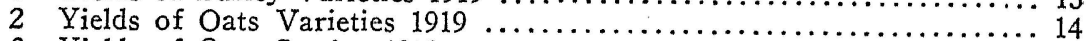

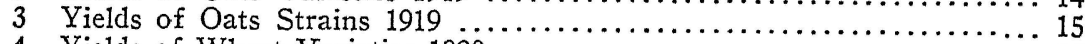

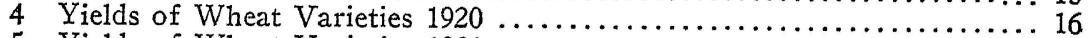

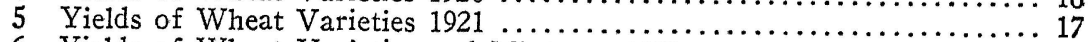

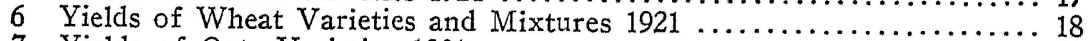

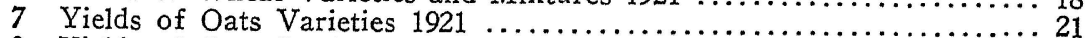

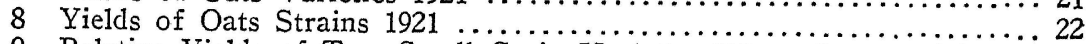

9 Relative Yields of Two Small Grain Varieties When Compared in $\mathrm{Ai}$ ternate Rows and in Blocks (Kiesselbach) ..................... 24

10 Correlation of Competition with Various Characteristics in Barley Va-

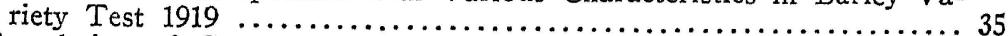

11 Correlation of Competition with Various Characteristics in Oats Variety Test 1919 
12 Correlation of Competition with Various Characteristics in Oats Strain Test 1919 ........................................ 36

13 Correlation of Competition with Various Characteristics in Wheat Va-

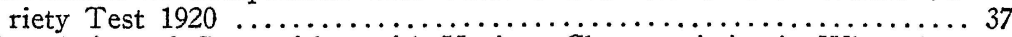

14. Correlation of Competition with Various Characteristics in Wheat Va-

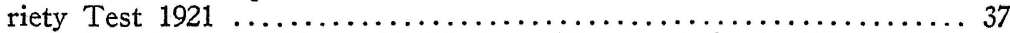

15 Correlation of Competition with Various Characteristics in Wheat Mixture Test 1921

16 Correlation of Competition with Various Characteristics in Oats Va-

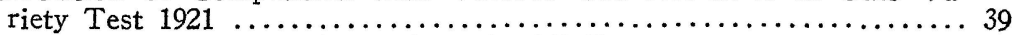

17 Summary of Effects of Competition in All Tests ................ 41

18 Correlation of Yield with Dates of Heading and Maturity in Variety

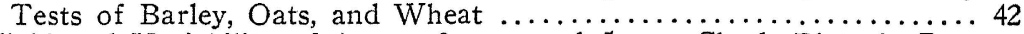

19 Yield and Variability of 1-row, 3-row, and 5-row Check Plots in Bar-

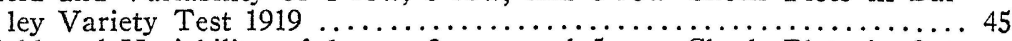

20 Yield and Variability of 1-row, 3-row, and 5-row Check Plots in Oats Variety Test 1919 ................................. 46

21 Yield and Variability of 1-row, 3-row, and 5-row Check Plots in Oats Strain Test 1919

22 Yield and Variability of 1 -row, 3 -row, and 5 -row Check Plots in Wheat

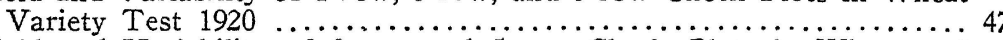

23 Yield and Variability of 3-row and 5-row Check Plots in Wheat and

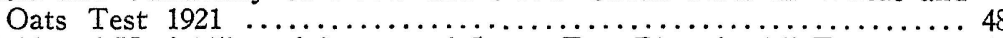

24 Yield and Variability of 3-row and 5-row Test Plots in All Tests .... 50

25 Relation of Plot Variability to Size of Experiment Field in Wheat Va-

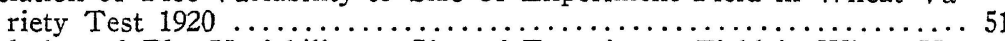

26 Relation of Plot Variability to Size of Experiment Field in Wheat Va-

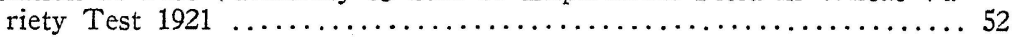

27 Relation of Plot Variability to Size of Experiment Field in Oats Va-

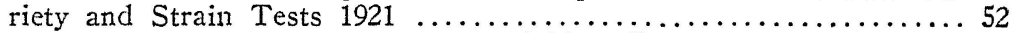

28 Soil Heterogeneity of an Experiment Field as Determined from Yields

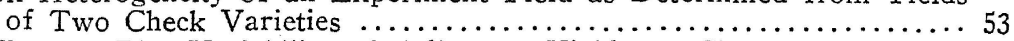

29 Effect on Plot Variability of Adjusting Yields by Check Plots (Kies-

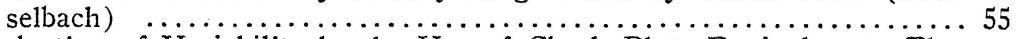

30 Reduction of Variability by the Use of Check Plots Equivalent to That Probably Attainable with the Same Number of Plots by Replication . 57

31 Relative Variability of Actual and Adjusted Yields in Barley Variety Test 1919 ............................................ 59

32 Relative Variability of Actual and Adjusted Yields in Oats Variety Test 1919 ......................................... 60

33 Relative Variability of Actual and Adjusted Yields in Oats Strain

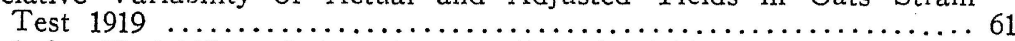

34 Relative Variability of Actual and Adjusted Yields in Wheat Variety

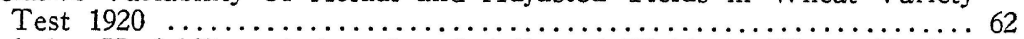

35 Relative Variability of Actual and Adjusted Yields in Wheat Variety

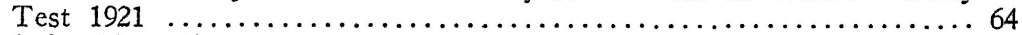

36 Relative Variability of Actual and Adjusted Yields in Wheat Mixture

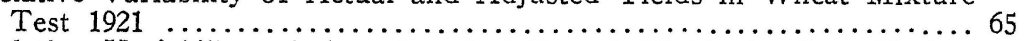

37 Relative Variability of Actual and Adjusted Yields in Oats Variety

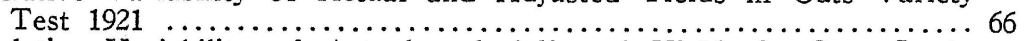

38 Relative Variability of Actual and Adjusted Yields in Oats Strain

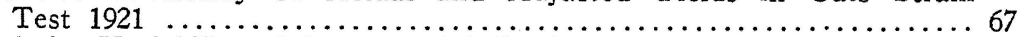

39 Relative Variability of Actual and Adjusted Yields of Kherson and Red Rustproof Oats Each in 120 Distributed Plots, in Oats Variety and

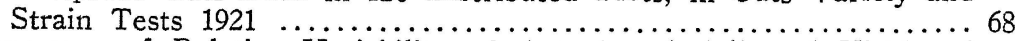

40 Summary of Relative Variability of Actual and Adjusted Yields of Interior Rows in All Tests 1921 ............................. 71 


\section{EXPERIMENTS IN FIELD PLOT TECHNIC FOR THE PRELIMINARY DETERMINA- TION OF COMPARATIVE YIELDS IN THE SMALL GRAINS*}

\section{J. Stadler}

During recent years the investigation of the reliability of field experiments has become an important phase of agronomic research. Field experiments as ordinarily conducted have been shown to be affected by many gross errors. In the light of these investigations it has become apparent that the results of many of the older experiments are inconclusive or even misleading. Various expedients have been suggested for counteracting experimental error. Some of these have been quite successful, while others have probably done more harm than good.

The pioneer investigations in this field have been of great value in directing attention to the important sources of error and in suggesting possible means for their control. Doubtless at the present time most of the major sources of error are recognized. But the true extent of the errors and the actual practical value of the methods of counteracting them can be determined only by numerous investigations of experimental methods under different conditions.

The present paper is concerned with experimental error and field plot technic in preliminary variety and strain tests with the small grains. The same type of test is extensively used in small grain improvement, not only in the preliminary testing of varieties, but also in the comparison of strains and selections. Although the small plot test is particularly subject to errors of certain sorts, it has a decided advantage over tests in larger plots in the possibility of extensive replication, which is probably the greatest single factor in the reduction of experimental error. It should be possible, consequently, to obtain extremely accurate results in small plot tests without the use of large experimental areas, when the errors peculiar to the small plot are understood and controlled.

\footnotetext{
*Also submitted as a thesis in partial fulfilment of the requirements for the degree of Doctor of Philosnphy.
} 


\section{THE PROBLEM.}

At present the type of plot most commonly used for the preliminary testing of small grain varieties and strains is probably the "rod-row." The methods of conducting rod-row tests described by Love and Craig" may be considered typical. The varieties or strains are sown by hand in rows one foot apart, usually opened and covered with a wheel hoe or similar implement. The seed for each row is weighed out in a quantity equivalent to ordinary rates of seeding in field practice. In harvesting, six inches or a foot at the end of the row is discarded, to prevent increase in yield by reason of the more favorable space conditions at the ends of the rows. The list of varieties is repeated in several series, and the results averaged to reduce the error from plot variability. A check variety is grown in every tenth row to indicate the variability of the field.

The use of rod-row tests involves several errors, derived principally from the modified conditions under which the plants are grown. The object of the test is to discover the relative value of the strains under field conditions, and therefore any modification of field conditions which may favor some sorts more than others introduces error. The wide spacing between rows, with consequently heavier seeding in the row for any given rate of planting; the hand seeding and covering, resulting usually in slightly ridged rather than slightly furrowed rows; and the growing of different varieties in single rows, in competition with other varieties rather than with their own kind, are examples of typical conditions which may be expected to favor some varieties more than others. Consequently the best varieties in the rod-row test are not necessarily the best varieties under field culture, even when soil and seasonal variability are reduced to the minimum by replication of plots and repetition of the test through a series of seasons.

Such sources of error as those mentioned do not necessarily affect the variability of the yields of replicate plots, as Kiesselbach ${ }^{5}$ has pointed out, and are therefore more likely to escape notice. They are systematic errors affecting the yields of replicate plots similarly. Marked superiority of Turkey wheat over Fulcaster in a variety test in Kansas does not indicate the superiority of Turkey over Fulcaster in Illinois, no matter how low plot variability in the variety test may be, because the growing conditions in Illinois are different from the growing conditions in Kansas. Similarly the superiority of Turkey wheat over Fulcaster in a rod-row test may not mean its superiority under field conditions in the same locality, because here again growing 
conditions are different. The error in applying the results, though of course much less in degree, is similar in kind. And, since the rod-row test has no purpose but to indicate the relative value of the strains tested, for field conditions, any pronounced tendency to favor some varieties at the expense of others is fatal to its object.

Ordinarily, however, the rod-row test is only the first stage in variety testing, and final recommendations are based upon results of tests under conditions which approach those of field culture more closely. When the elimination of varieties in the rod-row tests is not extremely strict a considerable latitude may be allowed, and under these conditions the rod-row test has served a valuable purpose. It is of course desirable nevertheless to reduce these errors to the greatest possible extent.

Probably the most important of the errors mentioned is that arising from the competition between different varieties, in the single-row test. Obviously a variety grown in a single row between two different varieties may yield considerably more or less than the same variety grown between two rows of its own kind. Various expedients for reducing varietal competition have been suggested. Sometimes the order of varieties is changed in each series to bring together different varieties and thus tend to equalize the effects of competition; sometimes an attempt is made to grow the varieties in such order as to bring together those of similar habit, and thus to reduce the effects of competition. Probably the most effective method is to grow border rows which may be discarded, and some investigators therefore use three-row or five-row blocks, in which the outer row on each side is discarded.

The principal objection to the use of border rows in the increased area required to test the same number of strains, and the large proportion of the crop which is not harvested for yield. This is particularly true when 3-row blocks are used, since in this case twothirds of the field is used for border protection. The border rows may be used for seed, but two-thirds of the field is of course much more than is required ordinarily for this purpose. When 5-row blocks are used the proportion of the crop harvested for yield is increased from one-third to three-fifths, though it is an increase in size of plot, with some decrease in replication, so that there may be no gain in accuracy. There is a possibility that the effect of competition on the yield of 5-row blocks may be slight enough to permit the harvesting of all five rows for yield, particularly if the varieties may be effectively arranged for the reduction of competition. At any rate, in such plots the error from competition may be expected to be much less than that in single- 
row plots, since only two of the five rows are subject to competition with a different variety, and each of these is subject to such competition on only one instead of on both sides.

Another phase of the question which should not be overlooked is the effect of adding border rows on the error from soil variability. If, for example, each rod-row is to be protected from competition by two border rows, the test will require three times as large a field as the same test without the border rows. This can hardly fail to increase materially the variability of the yields of replicate plots, to an extent which will vary with the uniformity of the field concerned. The use of border rows may thus necessitate the use of an even greater number of replications for the same degree of accuracy, as far as plot variability is concerned. It is possible that 3-row plots (whether or not provided with border rows) may require less replications for a given degree of accuracy than single-row plots, on account of their larger size. It is possible also that 5-row plots, because of their size, may have an advantage over 3 -row plots in reducing variability, great enough to justify in practice harvesting all five rows for yield, rather than harvesting the interior three rows and discarding the border rows.

The importance of any practice that will reduce the variability of the replicate plots is thus increased when border rows are introduced. A familiar method for this purpose is the adjustment of yields by means of distributed check plots. In following this method the yields of check plots are considered measures of the productivity of the soil, which is usually assumed to vary uniformly between them. The yields of the experimental plots are adjusted on the basis of uniform productivity of the field as a whole. Of late this method has rather lost favor among agronomists. In some cases the adjustment actually increases rather than decreases the variability of the replicate experimental plots. Check plots have not been used extensively in adjusting yields in rod-row tests, principally because of the great increase in computation necessary in adjusting the yields of such a large number of plots. 


\section{PLAN AND METHOD OF INVESTIGATION}

The experiments here reported were designed to obtain information on several factors affecting the accuracy of preliminary variety and strain tests, with a view to devising, if possible, an improved technic for this important phase of crop improvement work. The data obtained bear directly on the following points:

1. The extent of error from varietal competition in border rows, and the relation of such competition to the characteristics of the varieties,

2. The relative variability of plots of 1,3 , and 5 rows, and the number of replications necessary for a given degree of precision with plots of the three sizes, and

3 . The effect on variability of adjusting yields by means of check plots.

Terminology.-In this report the term plot will be used to designate an area on which a single varnety or strain is grown, in comparison with other varieties or strains, in other plots. The plot may consist of one or more rows. A plot of more than one row may also be referred to as a block. The single outside rows of the block are the border rows. A single-row plot protected from competition by border rows, which are to be discarded, will be spoken of as a protected single-row plot. A protected single-row plot is therefore a 3-row plot with border rows discarded, and a protected 3-row plot is a 5-row plot with border rows discarded. The phrase "3-row plots replicated five times" will be used to refer to 3-row plots in five systematically distributed locations, not in six. The area on which a complete variety or strain test is conducted is spoken of as an experiment field, or simply a field. A group of plots including one plot of each variety or strain tested is a series. When four replications are used there are four series of plots. The group of contiguous plots from one side of the field to the other constitutes a range. The ranges are separated by alleys.

Thus the field shown in figure 1 consists of sixteen ranges, each range including twenty-nine 5-row (or protected 3-row) plots. Ninetysix varieties were tested on this field, each replicated four times. Ranges I to IV, inclusive, make up the first series, V to VIII the second, IX to XII the third, and XIII to XVI the fourth. Each of the four strips running lengthwise of the field and separated by the check plots may also be considered a series.

All yields are expressed in bushels per acre by weight, computed on the basis of 60 pounds per bushel for wheat, 48 pounds for barley, 


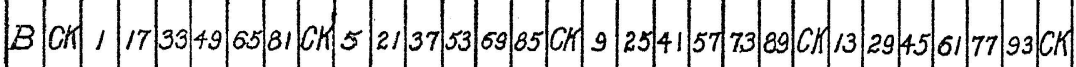

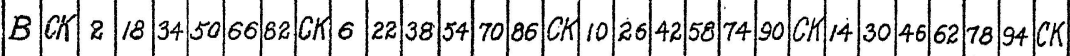

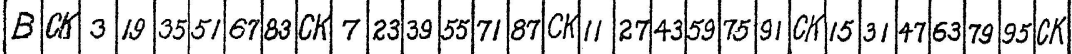

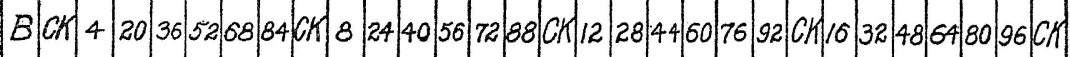

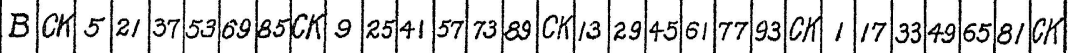

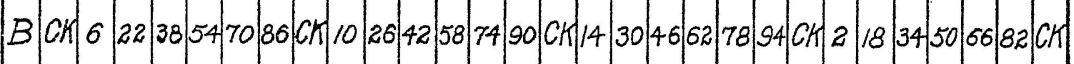

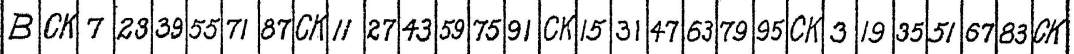

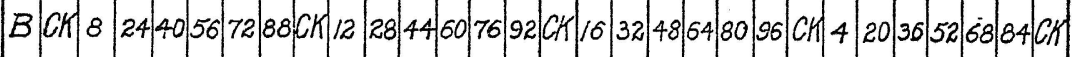

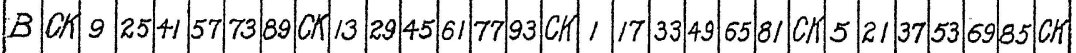

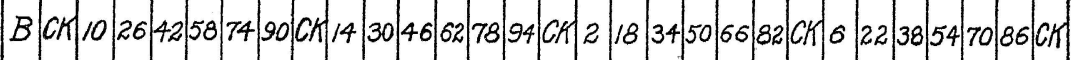

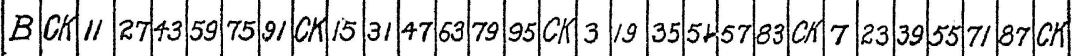

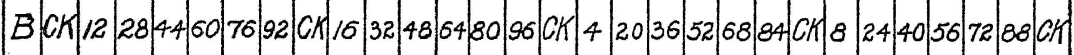

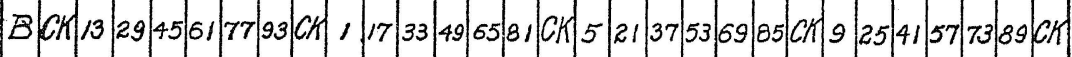

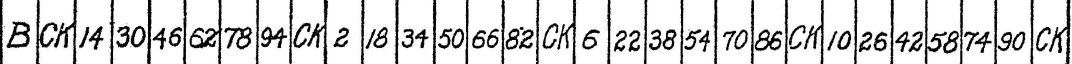

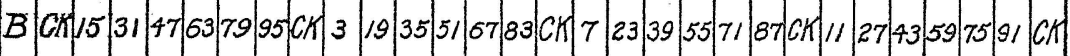

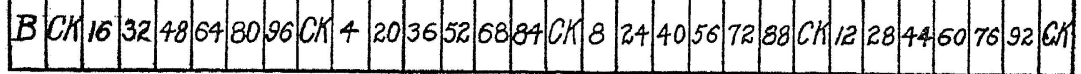

Figure 1.-Planting Plan of Wheat Variety Tests 1920 and 1921. Legend: B, border. CK, check. Numbers 1-96, planting numbers of varieties tested as given in Tables 4 and 5 . 
and 32 pounds for oats. The measures of variability used are the average deviation, the standard deviation, and the probable error. These were computed according to the following formula:

$$
\begin{aligned}
& \text { A.D }=\frac{\Sigma \mathrm{d}}{\mathrm{n}}, \\
& \sigma=\sqrt{\frac{\Sigma \mathrm{d}^{2}}{\mathrm{n}}}, \text { and } \\
& E=+6745 \sigma .
\end{aligned}
$$

in which A.D. = average deviation, $\sigma=$ standard deviation, $\mathrm{E}=$ probable error (of a single determination), $d=$ the deviation of a single variate from the mean, and $n=$ the number of variates. The correlation coefficient $r$ was determined by the formula

$$
\mathrm{r}=\left(\frac{\Sigma\left(\mathrm{d}_{\mathrm{x}} \mathrm{d}_{\mathrm{y}}\right)}{\mathrm{n}}\right)\left(\frac{1}{\sigma_{\mathrm{x}} \sigma_{\mathrm{y}}}\right)
$$

and the probable error of the correlation coefficient $E_{r}$ by the formula

$$
E_{r}= \pm \frac{.6745\left(1-r^{2}\right)}{\sqrt{n}}
$$

The tests reported are of two kinds, variety tests and strain tests. The variety tests were comparisons of commercial varieties, most of which were taxonomically distinct. A number of pure line selections were included in the wheat variety tests. The strain tests were comparisons of a considerable number of commercial lots of the same variety obtained from different sources. These strains, so-called for convenience, are not, except in a very few cases, pure lines. Some of them are possibly identical, and all the strains of any one variety are of course very similar, since they are taxonomically the same.

Procedure.-In the seasons of 1919, 1920, 1921, tests of varieties and strains of oats, barley, and wheat were conducted in blocks consisting of five rows ten inches apart and usually 18 feet long. From 24 to 96 varieties were included in each test, and from three to six (usually four) replications were used. The planting order in each case was designed on a plan similar to that illustrated in figure 1 . It will be noted that the check plots were in continuous strips, that each variety was represented in each quarter of the field, whether divided from east to west or from north to south, and that in all four series each variety occupied the same position with relation to the check plots, and had the same varieties adjoining it on either side. 
The rows in some cases ran east and west, and in some cases north and south.

All these plots were seeded with a 5-row nursery drill, built from plans furnished by Professor T. A. Kiesselbach of the Nebraska Station. This is a hoe drill designed for rapid and thorough cleaning between plots. Photographs of it have been published in reports of earlier work on field plot technic at the Nebraska Station (Montgomery ${ }^{14}$ page 57 , and Kiesselbach ${ }^{\circ}$ page 16). Its use resulted in uniform seeding and covering and accurate spacing between rows, with a close approach to ordinary field conditions in the state in which the field was left after seeding. Each field was seeded in a single day.

All plots were harvested by hand with sickles, a foot at each end of each row discarded, and the remainder (usually 16 feet) tied in a bundle and hung in a ventilated shed to dry. In 1919 and 1920 each row was bundled and threshed separately; in 1921 the border rows of each 5-row block were bundled separately and the three interior rows bundled together. Yields were determined by weighing in grams at the time of threshing. All final yields were converted to bushels per acre and are so expressed.

Work of 1919.-In 1919 tests were conducted with barley and oats. Thirty varieties of barley were grown, each in 3 replicate plots. The test comprised three ranges of 185 rows each, including 21 check plots, or one in every sixth plot. The barley was drilled at the rate of eight pecks per acre, on March 21, in rows running north and south. The rows were 14 feet long and 10 inches apart. They were cut to 12 feet in harvesting. The planting plan is shown in figure 2. Conditions

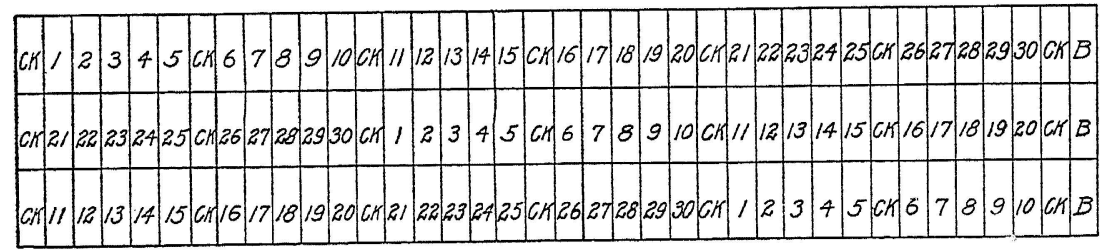

Figure 2.-Planting Plan of Barley Variety Test 1919. Legend: B, border. CK, check. Numbers 1-30, planting numbers of varieties tested, as given in Table 1.

were fairly favorable, and the yields of the adapted varieties were slightly higher than the average obtained under the conditions at Columbia. Two varieties, Italian and Australian White, gave extremely low yields and were excluded. Another, Sandrel, was represented only in two series, and was also excluded. The yields of the remain- 
ing 27 varieties are shown in Table 1 . The planting numbers given in this table correspond to those shown in the diagram of the field (figure 2.)

TABLE 1.-YIELDS OF BARLEY VARIETIES.

In Bushels per Acre. 1919.

\begin{tabular}{|c|c|c|c|}
\hline \multirow{2}{*}{$\begin{array}{l}\text { Planting } \\
\text { number }\end{array}$} & \multirow[b]{2}{*}{ Variety } & \multicolumn{2}{|c|}{ Average Yield } \\
\hline & & 3 interior rows & 5 rows \\
\hline 1 & Hanna 906 & 12.55 & 12.57 \\
\hline 2 & Steigum 907 & 19.90 & 19.65 \\
\hline 3 & Luth 908 & 23.65 & 23.40 \\
\hline 4 & Eagle 913 & 20.40 & 20.13 \\
\hline 5 & Italian $914^{*}$ & 6.70 & 6.57 \\
\hline 6 & Servian 915 & 19.85 & 19.86 \\
\hline 7 & Odessa 916 & 13.75 & 13.41 \\
\hline 8 & Lion 923 & 21.75 & 22.14 \\
\hline 9 & Australian White $925^{*}$ & 1.45 & 1.74 \\
\hline 10 & Horn 926 & 21.25 & 21.54 \\
\hline 11 & Odessa 927 & 20.80 & 19.53 \\
\hline 12 & Summit 929 & 23.05 & 24.03 \\
\hline 13 & Mariout 932 & 18.75 & 18.15 \\
\hline 14 & Odessa 934 & 10.30 & 9.84 \\
\hline 15 & Peruvian 935 & 22.25 & 20.55 \\
\hline 16 & Trebi 936 & 30.90 & 30.96 \\
\hline 17 & Sandrel $937 *$ & 35.90 & 33.48 \\
\hline 18 & Oderbrucker 940 & 23.35 & 23.79 \\
\hline 19 & Frankish 953 & 22.50 & 22.05 \\
\hline 20 & Manchuria 956 & 30.80 & 30.03 \\
\hline 21 & Oderbrucker $95 \%$ & 29.45 & 29.52 \\
\hline 22 & Manchuria $\mathrm{x}$ Champion of Vermont 959 & 18.30 & 17.49 \\
\hline 23 & Luth 972 & 25.05 & 26.28 \\
\hline 24 & Red River 973 & 27.25 & 28.14 \\
\hline 25 & Featherston 1118 & 28.25 & 27.00 \\
\hline 26 & Featherston 1119 & 25.80 & 25.83 \\
\hline 27 & Featherston 1120 & 34.35 & 35.49 \\
\hline 28 & Hanna $\mathrm{x}$ Champion of Vermont 1121 & 13.75 & 13.92 \\
\hline 29 & Manchuria 1125 & 20.35 & 20.94 \\
\hline 30 & Malting 1129 & 17.25 & 16.44 \\
\hline & Mean & 22.06 & 21.95 \\
\hline
\end{tabular}

Forty varieties of oats were compared in 1919, but only 24 of these could be replicated 4 times and the remaining 16 were duplicated. The planting plan was therefore arranged as for 32 varieties, and these 16 varieties grown in two plots each in place of eight varieties

*Italian 914 and Australian White 925 were omitted from all computations because of their extremely low yields, and Sandrel 937 because omitted in the third series. 


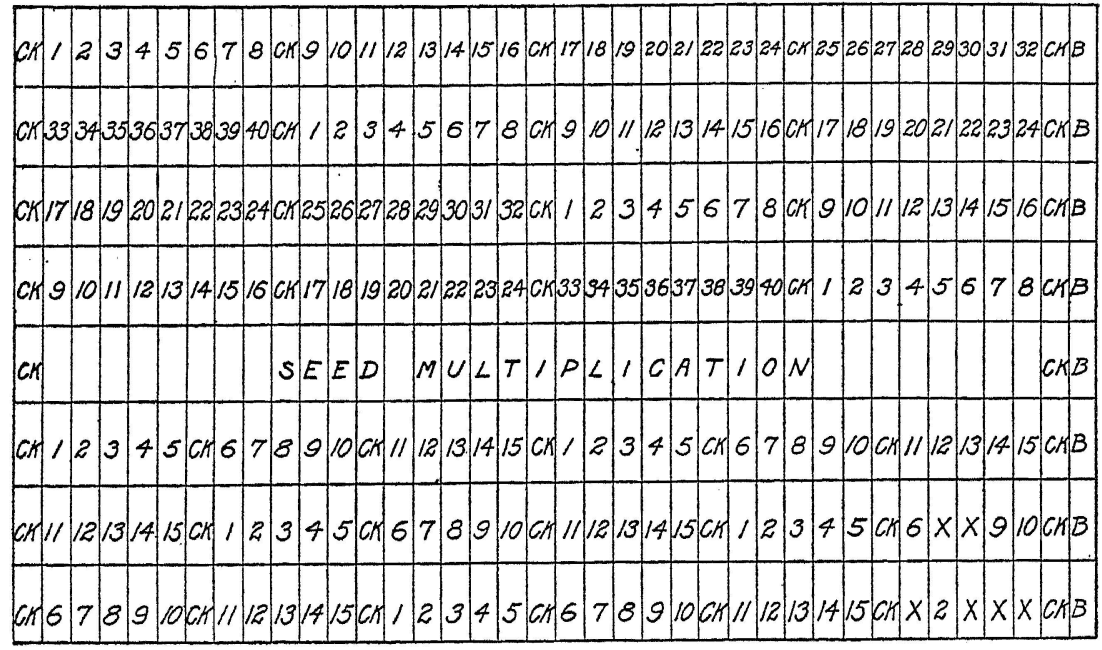

Figure 3.-Planting Plan of Oats Variety and Strain Tests 1919. Legend: $B$, border. $C K$, check. Numbers 1-40 in first four ranges, planting numbers of oats varieties, as given in Table 2. Numbers 1-15 in last three ranges, planting numbers of oats strains, as given in Table $3 . \mathrm{X}$, test plots planted to check variety becatse of insufficient supply of seed.

TABLE 2.-YIELDS OF OATS VARIETIES.

In Bushels per Acre. 1919.

\begin{tabular}{|c|c|c|c|}
\hline $\begin{array}{l}\text { Planting } \\
\text { number }\end{array}$ & Variety & \multicolumn{2}{|c|}{ Average yield in interior rows } \\
\hline 1 & A. Sterilis nigra & 30.0 & 31.7 \\
\hline 2 & Black Mesdag & 44.2 & 44.7 \\
\hline 3 & C. I. 602 & 35.4 & 38.1 \\
\hline 4 & C. I. 603 & 53.9 & 55.1 \\
\hline 5 & C. I. 620 & 13.1 & 14.1 \\
\hline 6 & Early Champion & 55.5 & 53.9 \\
\hline 7 & Early Gothland & 54.1 & 52.8 \\
\hline 8 & Garton 473 & 30.6 & 31.7 \\
\hline 9 & Garton 585 & 21.7 & 23.0 \\
\hline 10 & Golden Giant & 42.0 & 44.9 \\
\hline 11 & Irish Victor & 69.6 & 70.2 \\
\hline 12 & Japan Selection & 47.9 & 50.9 \\
\hline 13 & June & 43.1 & 44.5 \\
\hline 14 & Kherson Selection & 67.2 & 63.1 \\
\hline 15 & Fulghum 042 & 60.9 & 57.1 \\
\hline 16 & Lincoln & 51.5 & 50.3 \\
\hline 17 & Monarch & 56.0 & 53.4 \\
\hline 18 & North Finnish & 51.0 & 49.5 \\
\hline 19 & Scottish Chief & 59.3 & 60.1 \\
\hline 20 & Sparrow bill (Missouri) & 39.8 & 41.3 \\
\hline 21 & Sparrow bill (Cornell) & 42.3 & 45.7 \\
\hline 22 & Tobolsk 1 & 52.6 & 57.3 \\
\hline 23 & Tobolsk 2 & 46.1 & 51.9 \\
\hline 24 & White Tartar & 49.7 & 50.3 \\
\hline & Mean & 46.6 & 47.3 \\
\hline
\end{tabular}


in four plots each, as shown in figure 3. The rows were 14 feet long and were cut to 12 feet in harvesting. This is a convenient size of plot for oats tests with 10 inches distance between rows, when the border rows are discarded, since the total yield of three rows in grams, divided by 10 , gives the yield in bushels per acre. The oats were planted at the rate of 10 pecks per acre, on March 18, in rows running north and south. The season was favorable and a good yield of the better varieties was obtained. The yields of the 24 varieties replicated four times are shown in Table 2.

The oats strain test was conducted on the same field, as shown in figure 3 , directly south of the oats variety test. In planting, these two tests were handled as one; and the rate, date, and method of planting were the same. The strains tested were 15 strains of oats obtained under the name Red Rustproof from various experiment stations and seedsmen. Three of these strains, 0121, 0124, and 0127, were not true to name, but the remainder were taxonomically Red Rustproof oats, as described by Etheridge. The oats strains were tested in six series, with check plots in every sixth plot. The line of check plots on the west, however, gave abnormally low yields, probably because they were located partly on a dead furrow at the edge of the experiment field. On account of shortage of seed some of the varieties could not be planted in the last series. The first and last series were therefore dis-

TABLE 3.-YIELdS of OATS Strains (Red RUstproof). In Bushels per Acre. 1919.

\begin{tabular}{rccc}
\hline $\begin{array}{c}\text { Planting } \\
\text { number }\end{array}$ & $\begin{array}{c}\text { Accession } \\
\text { number }\end{array}$ & 3 interior Rows & 5 Rows \\
\hline 1 & 0119 & 49.58 & 49.41 \\
2 & 0120 & 45.83 & 44.51 \\
3 & $0121^{*}$ & 49.43 & 53.01 \\
4 & 0122 & 47.85 & 49.59 \\
5 & 0123 & 53.55 & 53.47 \\
6 & 0125 & 50.18 & 49.19 \\
7 & 0126 & 44.85 & 45.81 \\
8 & $0127^{*}$ & 38.55 & 36.67 \\
9 & $0124^{*}$ & 63.90 & 67.46 \\
10 & 0133 & 48.00 & 46.49 \\
11 & 0128 & 53.55 & 53.15 \\
12 & 0129 & 49.35 & 49.01 \\
13 & 0130 & 52.73 & 51.89 \\
14 & 0131 & 48.60 & 47.84 \\
15 & 0132 & 55.13 & 55.44 \\
& Mean & 50.07 & 50.20
\end{tabular}

*Not taxonomically Red Rustproof. 
carded. The average yields of the 15 strains in the four remaining series are shown in Table 3.

Work of 1920.-Wheat varieties were grown in 5-row blocks in 1919-20. Ninety-six varieties were included in the test, four replications being used. Fultz wheat was grown as a check in every sixth plot. The rows were 18 feet long and were cut to 16 feet in harvesting. The direction of the rows was east and west. The planting plan is shown in figure 1. The wheat was sown October 15, at the rate of 6 pecks per acre. There was considerable winter injury in the plots and the condition of the wheat in early spring was rather poor. The yields obtained are shown in Table 4.

TABLE 4.-YIELDS OF WhEAT VARIETIES.

In Bushels per Acre 1920.

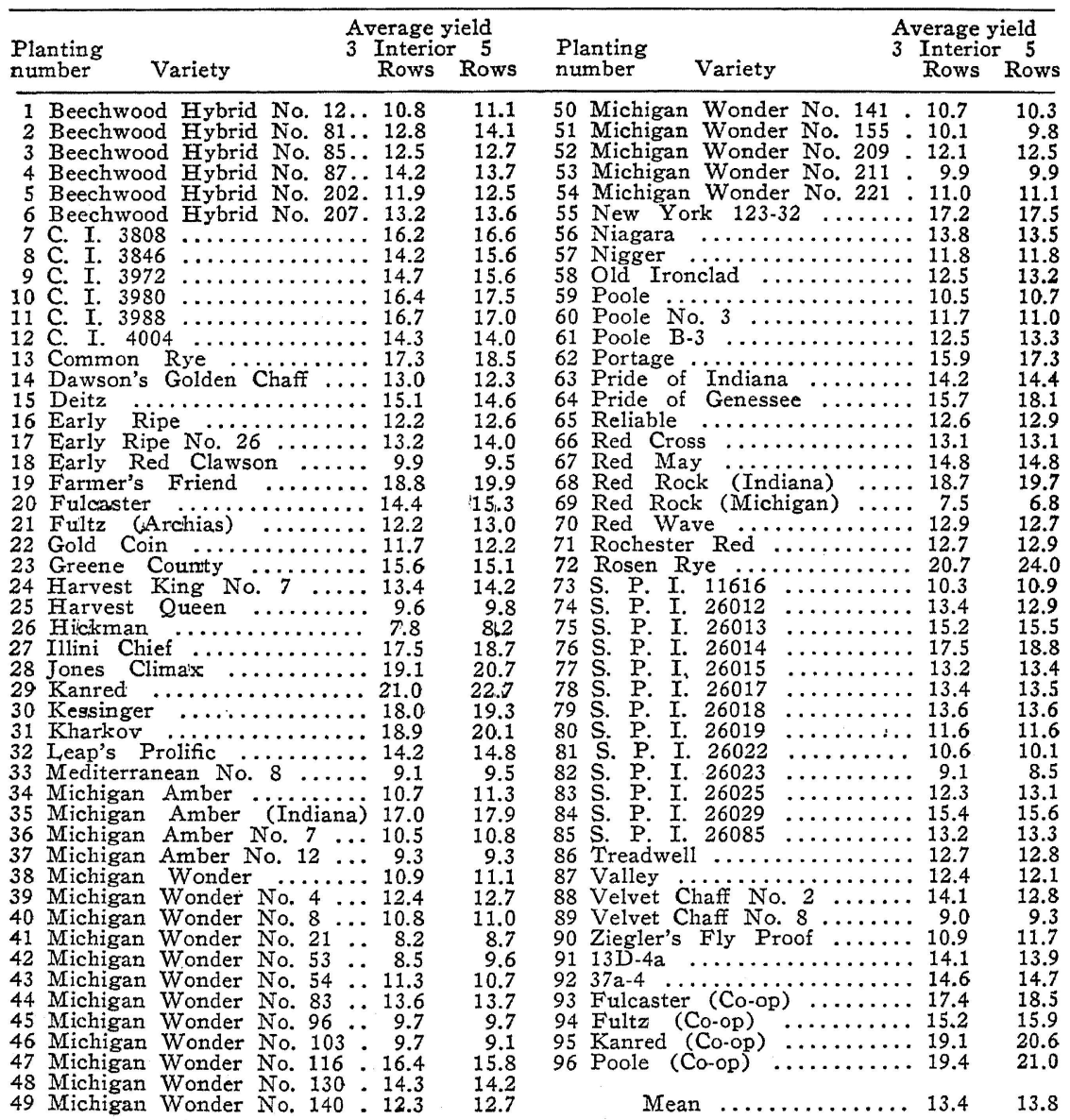


TABLE, 5.-YIELDS OF WheAT VARTETIES.

In Bushels per Acre. 1921.

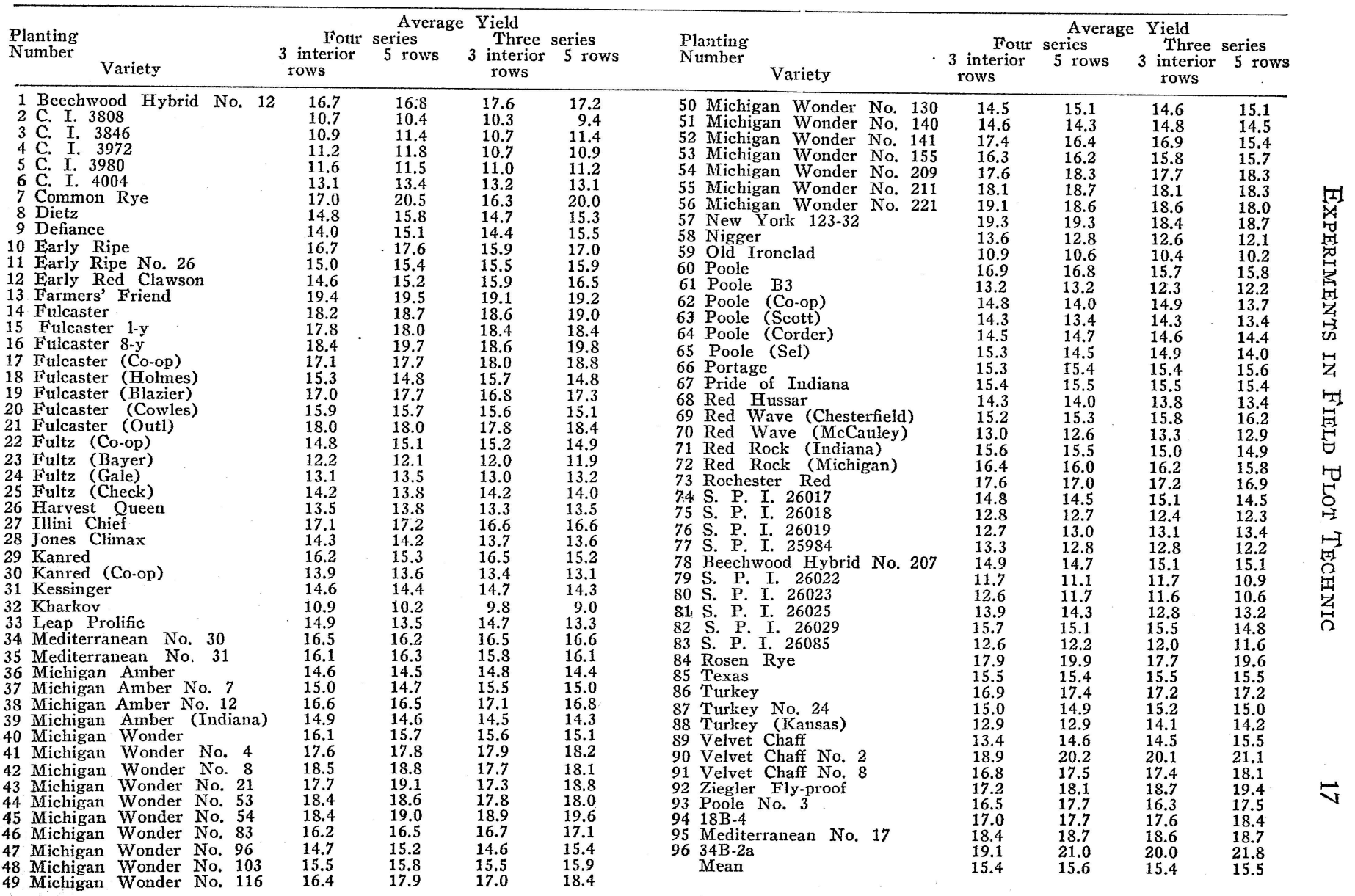


Work of 1921.-In 1920-21 ninety-six varieties of wheat were again tested by this method. Many of the varieties were the same as those tested in the preceding year, about 20 varieties being eliminated and a corresponding number added. The planting plan was the same as that of the preceding season. Poole wheat was used as a check variety. The wheat was drilled at the rate of 5 pecks per acre, October 6 , in rows running east and west. The season was favorable, but yields were reduced by the very rapid ripening of the wheat caused by the hot dry weather in the second and third weeks of June. The yields are shown in Table 5 .

\section{TABLE 6.-Yields of WheAT VARIE'TES AND MixTURES \\ In Bushels per Acre. 1921.}

\begin{tabular}{|c|c|c|c|}
\hline \multirow{2}{*}{$\begin{array}{l}\text { Planting } \\
\text { number }\end{array}$} & \multirow[b]{2}{*}{ Variety } & \multicolumn{2}{|c|}{ Average yield } \\
\hline & & 3 Interior Rows & 5 Rows \\
\hline 1 & Fulcaster & 17.3 & 18.6 \\
\hline 2 & Harvest Queen & 14.2 & 14.5 \\
\hline 3 & Mixture No. $1(1,2,4,5)$ & 15.9 & 16.2 \\
\hline 4 & Michigan Wonder & 16.8 & 17.8 \\
\hline 5 & Nigger & 10.8 & 10.8 \\
\hline 6 & Michigan Wonder No. 21 & 19.8 & 20.8 \\
\hline 7 & Michigan Wonder No. 54 & 18.9 & 19.3 \\
\hline 8 & Mixture No. $2(6,7,9,10)$ & 20.8 & 21.3 \\
\hline 9 & Michigan Wonder No. 96 & 18.5 & 18.9 \\
\hline 10 & Michigan Wonder No. 209 & 21.7 & 22.6 \\
\hline 11 & Beechwood Hybrid No. 12 & 17.4 & 18.8 \\
\hline 12 & Beechwood Hybrid No. 85 & 16.5 & 17.3 \\
\hline 13 & Mixture No. $3(11,12,14,15)$ & 17.6 & 18.4 \\
\hline 14 & Beechwood Hybrid No. $8 \%$ & 19.9 & 19.9 \\
\hline 15 & Beechwood Hybrid No. 207 & 17.4 & 17.9 \\
\hline 16 & Michigan Wonder No. 221 & 18.6 & 20.3 \\
\hline 17 & Kanred & 13.6 & 13.8 \\
\hline 18 & Mixture No. $4(16,17,19,20)$ & 17.8 & 18.0 \\
\hline 19 & New York 123-32 & 19.6 & 19.7 \\
\hline 20 & Red Rock & 17.6 & 17.4 \\
\hline 21 & Red Hussar & 16.3 & 17.8 \\
\hline 22 & Turkey (Kansas) & 10.8 & 10.5 \\
\hline 23 & Mixture No. $5(21,22,24,25)$ & 15.7 & 15.9 \\
\hline 24 & Michigan Amber & 19.2 & 19.6 \\
\hline 25 & Nigger & 14.1 & 13.4 \\
\hline 26 & Fulcaster (Co-op) & 20.4 & 21.2 \\
\hline 27 & Fulcaster (Outl) & 20.1 & 20.6 \\
\hline 28 & Mixture No. $6(26,27,29,30)$ & 20.1 & 21.0 \\
\hline 29 & Fulcaster (Blazier) & 20.6 & 21.5 \\
\hline 30 & Fulcaster (Cowles) & 20.6 & 20.6 \\
\hline & Mean & 17.6 & 18.2 \\
\hline
\end{tabular}


On another field in 1921, a test of mixtures of varieties and strains of wheat in comparison with their pure constituents was conducted. Each mixture was made up of four varieties or strains, in equal quantities of seed by weight. The composition of the mixtures and the yields obtained are shown in Table 6 . The planting plan is shown in figure 4 . This wheat was drilled at the rate of 5 pecks per

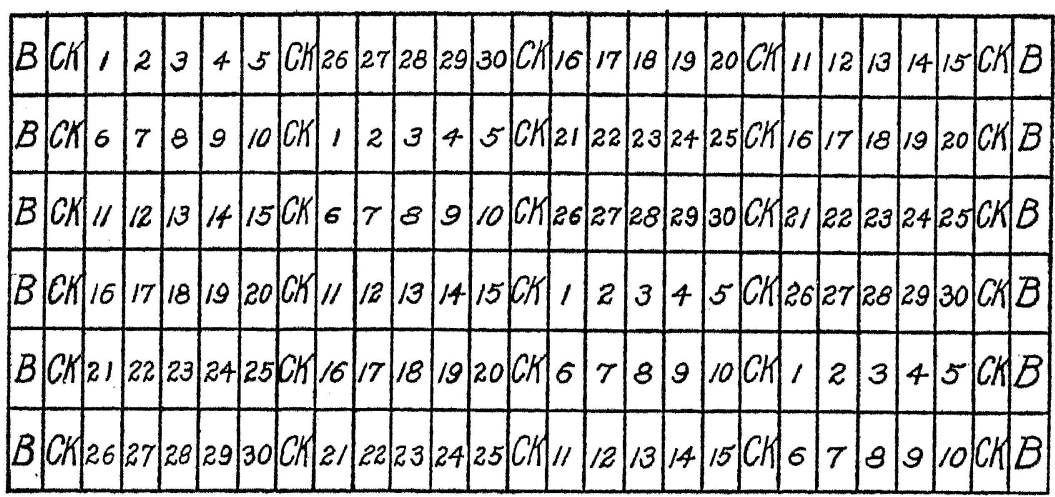

Figure 4.-Planting Plan of Wheat Mixture Test 1921. Legend: B, border. CK, check. Numbers 1-30, planting numbers of varieties and mixtures tested, as given in Table 6 .

acre in rows running north and south, on October 8, 1920. This test will be referred to as the wheat mixture test.

In 1921 tests of oats varieties and of oats strains were also conducted in 5-row blocks. Thirty-two strains of Red Rustproof, including many of those tested in 1919 and a number of others, and 32 strains of Kherson oats, obtained in the same way, were included in the oats strain test. The Kherson and Red Rustproof strains were arranged alternately, and both Kherson and Red Rustproof checks were grown, as shown in figure 5 . The test of these 64 strains, in four series, occupied 16 ranges. The next eight ranges on the same plot were used for an oats variety test in which 32 varieties of oats were compared, each in four replicate plots. In this part of the field the Kherson and Red Rustproof check plots were continued. There are thus available the yields of 120 plots each of Kherson and Red Rustproof oats, or five strips of 24 plots of each arranged in pairs side by side. In both of these experiments the rows ran east and west, and were 18 feet long, cut to 16 feet in harvesting. The oats were drilled on March 12, at the rate of 10 pecks per acre. The yields of oats, particularly of the later-maturing varieties, were materially reduced by the hot dry weather in the middle of June. The yields of the oats varieties are shown in Table 7 , and those of the strains in Table 8. 


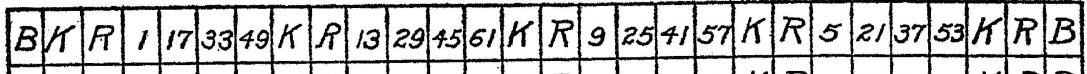

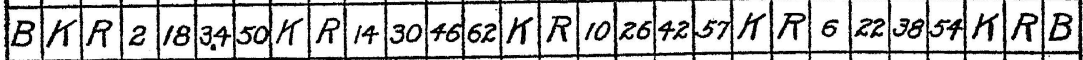

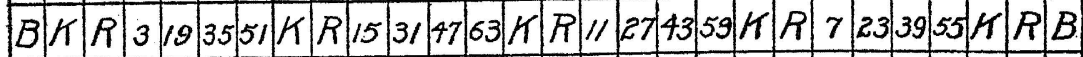

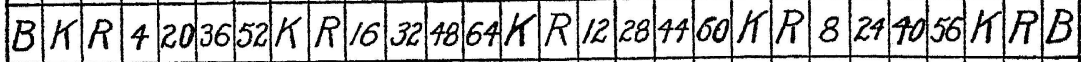

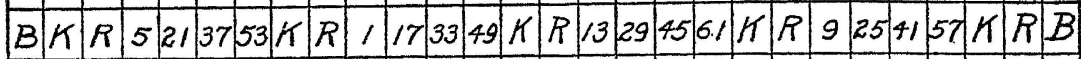

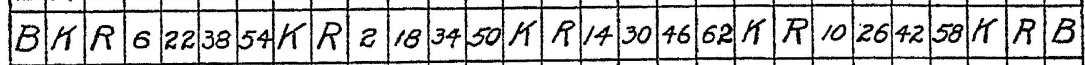

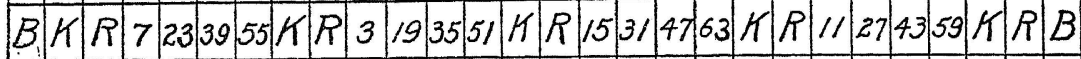

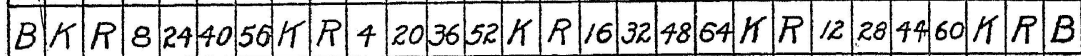

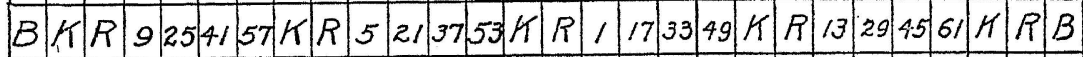

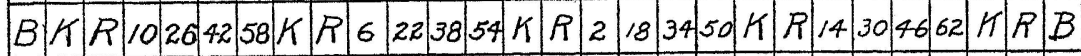

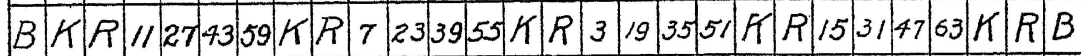

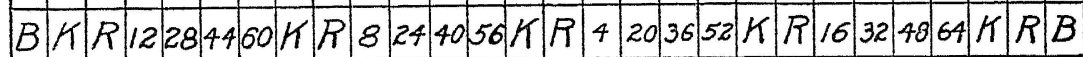

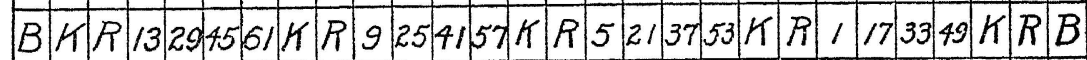

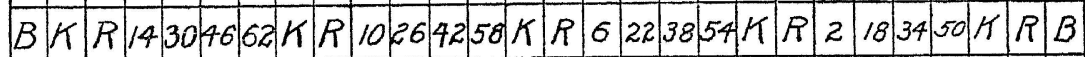

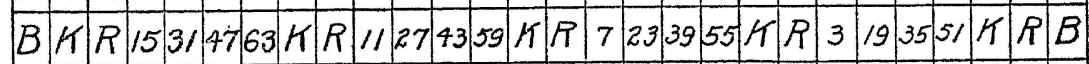

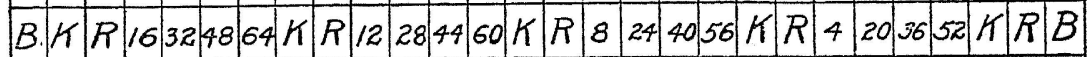

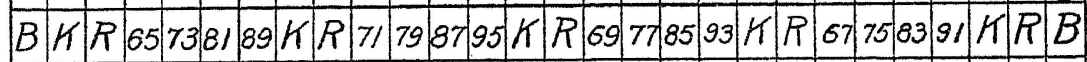
B KR $66748290 K R 72808896 K R \quad 70788694 K$ R $68768492 K R B$

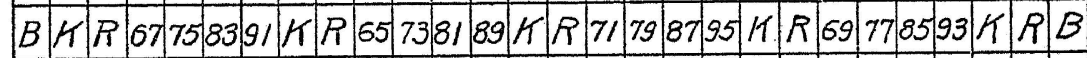

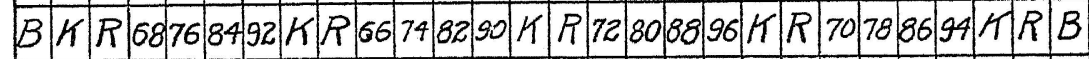

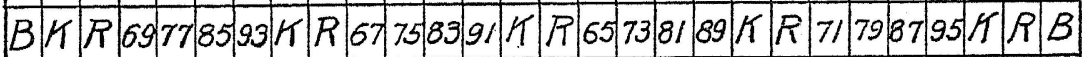

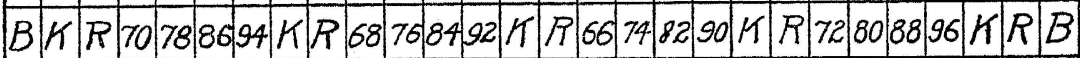
B K R 71798795K R 69778593 KR 67758391 K $R$. $65738189 K R B$

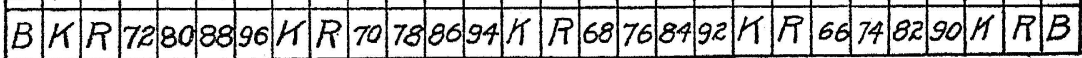

Figure 5.-Planting Plan of Oats Varietry and Strain Tests 1921. Legend: $\mathrm{B}$, border. $\mathrm{K}$, Kherson check. R, Red Rustproof check. Numbers 1-64, planting numbers of oats strains, as given in Table 8 . Numbers 65-96, planting numbers of oats varieties, as given in Table $\%$ 
TABLE 7.-YIELDS OF OA'S Varieties.

In Bushels per Acre. 1921.

\begin{tabular}{|c|c|c|c|}
\hline \multirow{2}{*}{$\begin{array}{l}\text { Planting } \\
\text { number }\end{array}$} & \multirow[b]{2}{*}{ Variety } & \multicolumn{2}{|c|}{ Average yield } \\
\hline & & 3 Interior Rows & 5 Rows \\
\hline 65 & Burt & 49.13 & 51.94 \\
\hline 66 & Canadian & 25.31 & 25.13 \\
\hline 67 & C. I. 603 & 22.50 & 23.06 \\
\hline 68 & Culberson & 24.75 & 25.13 \\
\hline 69 & Danish Island & 19.69 & 19.13 \\
\hline 70 & Early Dakota & 21.56 & 21.56 \\
\hline 71 & Early Gothland & 23.44 & 22.13 \\
\hline 72 & Garton 748 & 21.00 & 20.81 \\
\hline 73 & Green Russian & 26.06 & 26.25 \\
\hline 74 & Irish Victor & 29.81 & 32.06 \\
\hline 75 & Joanetfe & 19.31 & 19.69 \\
\hline 76 & Fulghum 042 & 45.19 & 47.44 \\
\hline 77 & Monarch & 29.63 & 31.88 \\
\hline 78 & Monarch Selection & 35.63 & 36.38 \\
\hline 79 & Scottish Chief & 26.63 & 27.38 \\
\hline 80 & Silvermine 050 & 31.69 & 32.06 \\
\hline 81 & Silvermine Selection & 22.13 & 24.94 \\
\hline 82 & Sparrowbill (C) & 15.38 & 14.63 \\
\hline 83 & Sterilis Selection & 38.63 & 36.94 \\
\hline 84 & Storm King & 20.06 & 17.63 \\
\hline 85 & Swedish Select 057 & 21.00 & 19.50 \\
\hline 86 & Fulghum 065 & 42.00 & 44.81 \\
\hline 87 & Fulghum 0113 & 42.00 & 45.38 \\
\hline 88 & Silvermine 0115 & 25.13 & 24.94 \\
\hline 89 & Silvermine 0117 & 21.75 & 22.69 \\
\hline 90 & Fulghum 0124 & 45.38 & 48.38 \\
\hline 91 & Fulghum 0145 & 39.19 & 41.81 \\
\hline 92 & Fulghum 0149 & 42.75 & 47.06 \\
\hline 93 & Fulghum 0151 & 39.75 & 43.88 \\
\hline 94 & Fulghum 0152 & 39.75 & 42.38 \\
\hline 95 & Silvermine 0.165 & 28.31 & 26.81 \\
\hline 96 & Swedish Select 0165 & 20.81 & 18.56 \\
\hline & Mean & 29.85 & 30.70 \\
\hline
\end{tabular}


Table 8.-Yields of Oats Strains (Red Rustproof and Kherson). In Bushels per Acre. 1921.

\begin{tabular}{|c|c|c|c|c|c|c|c|}
\hline \multicolumn{4}{|c|}{$\begin{array}{l}\text { Red Rustproof strains } \\
\text { Average yields }\end{array}$} & \multicolumn{4}{|c|}{ Kherson strains } \\
\hline Planting & Strain & 3 Interior & $\stackrel{5}{R o w s}$ & $\begin{array}{l}\text { Planting } \\
\text { Number }\end{array}$ & Strain & $\begin{array}{l}3 \text { Interior } \\
\text { Rows }\end{array}$ & $\begin{array}{c}\mathbf{5} \\
\text { Rows }\end{array}$ \\
\hline 1 & 066 & 24.00 & 23.25 & 2 & 023 & 35.25 & 36.38 \\
\hline 3 & 067 & 24.00 & 21.75 & 4 & 040 & 36.57 & 37.50 \\
\hline 5 & 068 & 23.25 & 23.44 & 6 & 041 & 36.56 & 38.81 \\
\hline 7 & 069 & 19.31 & 18.00 & 8 & 052 & 38.06 & 38.81 \\
\hline 9 & 072 & 18.38 & 18.75 & 10 & 053 & 39.75 & 42.00 \\
\hline 11 & 074 & 22.31 & 20.63 & 12 & 079 & 32.63 & 34.88 \\
\hline 13 & 075 & 24.19 & 22.13 & 14 & 080 & 35.44 & 38.25 \\
\hline 15 & 0118 & 16.50 & 16.31 & 16 & 082 & 40.88 & 41.44 \\
\hline 18 & 0119 & 22.31 & 21.38 & 17 & 083 & 35.44 & 38.25 \\
\hline 20 & 0120 & 21.19 & 19.69 & 19 & 085 & 38.25 & 41.81 \\
\hline 22 & 0122 & 19.13 & 17.81 & 21 & 086 & 36.75 & 37.69 \\
\hline 24 & 0125 & 21.00 & 19.88 & $23 \mathrm{M}$ & Gixture** & 33.75 & 36.38 \\
\hline 26 & 0126 & 25.31 & 22.50 & 25 & $088 * * *$ & 27.00 & 27.56 \\
\hline 28 & 0128 & 20.44 & 20.25 & 27 & 089 & 30.94 & 31.69 \\
\hline 30 & 0129 & 21.94 & 21.56 & 29 & 090 & 36.38 & 38.06 \\
\hline 32 & 0130 & 21.75 & 20.25 & 31 & 091 & 30.19 & 31.88 \\
\hline 33 & 0131 & 24.56 & 23.25 & 34 & 094 & 31.69 & 33.56 \\
\hline 35 & 0132 & 17.63 & 19.13 & 36 & 095 & 38.81 & 39.75 \\
\hline 37 & 0133 & 18.94 & 18.75 & 38 & 096 & 36.38 & 38.06 \\
\hline 39 & 0134 & 16.50 & 15.75 & 40 & 097 & 31.31 & 32.25 \\
\hline 41 & 0135 & 17.63 & 15.65 & 42 & 098 & 38.63 & 39.19 \\
\hline 43 & $0136^{*}$ & 32.44 & 33.19 & 44 & 099 & 38.81 & 38.25 \\
\hline 45 & 0141 & 21.94 & 21.19 & 46 & 0100 & 40.13 & 42.75 \\
\hline 47 & 0163 & 13.88 & 12.94 & 48 & 0155 & 37.50 & 38.63 \\
\hline 50 & 0169 & 15.38 & 14.44 & 49 & 0157 & 43.69 & 45.00 \\
\hline 52 & 0181 & 19.88 & 18.00 & 51 & 0158 & 34.69 & 35.25 \\
\hline 54 & 0182 & 19.88 & 19.13 & 53 & 0159 & 33.38 & 33.94 \\
\hline 56 & $0183^{*}$ & 41.44 & 43.31 & 55 & 0160 & 30.19 & 31.13 \\
\hline 58 & 0383 & 23.63 & 24.00 & 57 & 0161 & 34.69 & 36.00 \\
\hline 60 & 0391 & 29.44 & 30.19 & 59 & 0162 & 25.31 & 25.69 \\
\hline 62 & 0394 & 22.31 & 21.56 & 61 & 0167 & 40.69 & 39.94 \\
\hline 64 & 0395 & 23.25 & 21.94 & 63 & 0174 & 36.75 & 38.25 \\
\hline \multicolumn{2}{|l|}{ Mean } & 21.00 & 20.12 & \multicolumn{2}{|c|}{ Mean } & 35.79 & 37.14 \\
\hline \multicolumn{4}{|c|}{$\begin{array}{l}\text { *Not taxonomically Red Rustproof. Ex- } \\
\text { cluded from average. }\end{array}$} & \multicolumn{4}{|c|}{$\begin{array}{l}* * \text { Mixture of strains } 082,094,0100 \text {, } \\
0174 \text {. } \\
\text { ***Not taxonomically Kherson. Ex- } \\
\text { cluded from average. }\end{array}$} \\
\hline
\end{tabular}




\section{COMPETITION AS A SOURCE OF FRROR IN PRELIMINARY TESTS.}

Previous Investigation.-The possibility of error from competition in single-row tests was noted by Montgomery ${ }^{14}$ in 1913, in the following passage:

"In 1908 it was observed that a certain strain of early wheat in a series of row plats made a very poor appearance at harvest time, while the same strain planted in centgeners made a much better comparative showing. Apparently the larger and faster growing strains on each side, the rows being only 8 inches apart, exercised some competitive effect. This effect of competition has been noted for two years since. Also in certain variety tests of oats, grown in row plats 10 inches apart, the same effect was noted. Exact data cannot be given on this point, as the results from the series of plats planted in 1909 and in 1910 for this purpose were seriously impaired by unfavorable conditions; but Table XVIII, giving results from adjacent row plats sown at different rates, shows that the 800 -seed rate made a marked increase over the 700-seed rate, while in a similar series of blocks (Table XIX), sown at the same rate, this marked increase was not noted. Since the 800 -seed row was always adjacent to the 400 -seed row, it may have had some advantage on this account. Danger from this source can probably be avoided if care is taken to plant only similar varieties in adjacent rows. Where the block plat is used this source of error is eliminated."

Hayes \& Arny ${ }^{4}$ found considerable competition between rod-rows grown one foot apart. Three-row plots were used in variety tests of winter wheat, spring wheat, barley, and oats, and the yields of each row determined separately, in 1916. The comparative yield of the border rows in each plot was then correlated with the comparative height and yield of the adjacent rows. There was some effect on the yield of border rows due to the height of adjacent rows in the case of barley and winter wheat. The results were variable in different plots. In the case of oats the effect of height was rather obscure, and in the case of spring wheat it was not apparent. The yield of adjacent rows appeared to be of some importance in the barley tests and in some of the spring wheat tests. These results led to the adoption of 3-row plots with discarded border rows for preliminary testing at the Minnesota Station.

Love and Craig' in describing the methods used in cereal investigations at the Cornell Station describe the single-row test and add: "In order to prevent any effect which may be caused by two unlike sorts growing together the different strains are arranged according to earliness and other characters so as to reduce this source of error to a minimum." 
Kiesselbach $^{5,7}$ has published rather extensive data on the competition between adjacent rod-rows. In his experiments the crops were compared in alternating single-row plots and in alternating 5-row blocks, each replicated fifty times. In some cases the border rows of 5-row plots were discarded. The deviation of the result in the test in single-row plots from that of the test in 5-row plots is regarded as the measure of the effect of competition. The comparative yields of varieties of wheat and oats in alternating single rows and in alternating 5-row plots are shown in Table 9, from Kiesselbach?.

Table 9.-Relative Yields of Two Smali Grain Varieties When Compared in Alternating Rows and in Alternating 5-Row Plats (Kiesseibach).

\begin{tabular}{|c|c|c|c|c|c|}
\hline \multicolumn{3}{|c|}{ Wheat } & \multirow{2}{*}{\multicolumn{3}{|c|}{$\frac{\text { Oats }}{\text { Average yield of } 50 \text { plats }}$}} \\
\hline \multicolumn{3}{|c|}{ Average yield of 50 plats } & & & \\
\hline $\begin{array}{l}\text { Year and } \\
\text { variety }\end{array}$ & $\begin{array}{c}\text { Alternating } \\
\text { single rows } \\
\%\end{array}$ & $\begin{array}{l}\text { Alternating } \\
\text { 5-row blocks* } \\
\%\end{array}$ & $\begin{array}{c}\text { Year and } \\
\text { Variety }\end{array}$ & $\begin{array}{c}\text { Alternating } \\
\text { single rows } \\
\%\end{array}$ & $\begin{array}{l}\text { Alternating } \\
\text { 5-row blocks* } \\
\%\end{array}$ \\
\hline $\begin{array}{l}1913 \\
\text { Turkey }\end{array}$ & 100 & 100 & $\begin{array}{l}1913 \\
\text { Kherson }\end{array}$ & 100 & 100 \\
\hline $\begin{array}{l}\text { Big: Frame } \\
1914\end{array}$ & 107 & 97 & $\begin{array}{l}\text { Burt } \\
1914\end{array}$ & 130 & 112 \\
\hline Turkey & 100 & 100 & Kherson & 100 & 100 \\
\hline $\begin{array}{l}\text { Big Frame } \\
1913\end{array}$ & 85 & 97 & $\begin{array}{l}\text { Burt } \\
1913\end{array}$ & 139 & 101 \\
\hline Turkey & 100 & 100 & Kherson & 100 & 100 \\
\hline $\begin{array}{l}\text { Neb. No. } \\
28 \\
1914\end{array}$ & 107 & 107 & $\begin{array}{l}\text { Swedish } \\
\text { Select } \\
1914\end{array}$ & 82 & 77 \\
\hline Turkey & 100 & 100 & Kherson & 100 & 100 \\
\hline $\begin{array}{c}\text { Neb. No. } \\
28\end{array}$ & 63 & 85 & $\begin{array}{l}\text { Swedish } \\
\text { Select }\end{array}$ & 89 & 93 \\
\hline
\end{tabular}

*Yield based on 3 inner rows of 5-row plats in 1914.

Kiesselbach also submits interesting data on the competition of pure line selections of the same variety. It might be supposed that such strains, being similar in varietal characteristics, would be little affected by competition, and could therefore be safely compared in single-row plots. The average relative yields of three strains of Turkey wheat in single rows and in blocks for two seasons, however, showed that the two better strains were favored approximately 20 per cent and 15 per cent, respectively, at the expense of the poorer strain, in the single-row test. A strain which yielded 26 per cent more than another in the single-row test yielded only 6 per cent more in the block 
test. Kiesselbach has therefore adopted the practice of testing such strains in 5-row blocks replicated ten times instead of in single-row plots.

Love ${ }^{8}$ has criticized these results because in some cases at least the rows ran east and west rather than north and south. He states that in experiments at Ithaca, New York, there is little competition between varieties grown in single rows, when the rows run north and south. "In order to obviate any criticism of this method," he adds, "it might be well to follow the plan of arranging varieties so that late sorts are grown together and the earlier ones together. In other words, the different sorts could be so arranged that they grade into one another as regards yield, earliness, and the like." To this Kiesselbach ${ }^{\circ}$ replies that in some of his competition studies the rows ran north and south and in others east and west, and that striking competition occurred in both cases. He adds that although error resulting from row competition would undoubtedly be reduced by grouping varieties of similar growth habits together, it appears that varieties fairly similar in growth habit may vary for some reason in relative competitive quality.

Experimental Results.-Some further evidence on competition as a source of error in plot experiments is afforded by a study of the relative yields of border rows and interior rows in the 5-row blocks used in these preliminary tests. It should be remembered, of course, that the effect on yield would be decidedly greater in single rows exposed to competition on both sides than in these border rows, which compete with another sort on only one side. The extent of the error from competition in such border rows is of interest in determining whether it is necessary to discard the border rows of small blocks. When 5-row blocks are used, even if the border rows are not discarded, the relative effect of competition is greatly reduced, since only two of the five rows are subject to varietal competition and these are exposed only on one side. If this results in reducing the error from competition to a low point, or if varieties can be so arranged as to give this result, it may be advisable in practice to harvest 5-row blocks entire, thus avoiding the principal objection to the use of border rows-the loss of a considerable portion of the experimental area.

Competition is particularly important as a source of error because of the fact that it tends to affect replicate plots similarly, and consequently does not necessarily increase plot variability. For this reason it is likely to escape detection, and, when it is involved in an experiment, its effect cannot be measured. There is no great objection to a considerable experimental error from plot variability in field experi- 
ments, if the experimenter determines the extent of the error and draws his conclusions accordingly. But a preliminary variety test in which error from competition is not controlled may be very nearly worthless as an indication of the relative value of varieties for field conditions, because actually the relative values of the varieties tested may frequently differ by 50 or 100 per cent from the values determined in the test, without the slightest indication in the experimental results.

Illustrations of Effects of Competition.-The error from competition may be illustrated by numerous examples from each of the eight tests here reported. An extreme case is the effect of competition on the relative yield of wheat and rye. Two varieties of rye, common rye and Rosen rye, were included in the wheat variety test, for comparison with wheat. The average yields of Rosen rye and of the varieties of wheat adjoining it on either side, in interior rows and competing border rows of the four series, were as follows:

\begin{tabular}{|c|c|c|c|c|c|}
\hline \multirow[t]{2}{*}{ Seaso } & \multirow[t]{2}{*}{ Variety } & \multicolumn{2}{|c|}{$\begin{array}{l}\text { Yield in } \\
\text { interior rows }\end{array}$} & \multicolumn{2}{|c|}{$\begin{array}{c}\text { Yield in competing } \\
\text { border rows }\end{array}$} \\
\hline & & Bushels & Relative & Bushels & Relative \\
\hline \multirow{4}{*}{$1920\}$} & \multirow[t]{2}{*}{ Niagara (Wheat) } & 13.8 & 67 & 10.0 & 33 \\
\hline & & & & $\int 30.4$ & 100 \\
\hline & Rosen (Rye) & 20.7 & 100 & & - \\
\hline & Velvet Chaff No. 2 (Wheat & 14.1 & 68 & $\begin{array}{r}27.7 \\
9.8\end{array}$ & $\begin{array}{r}100 \\
35\end{array}$ \\
\hline \multirow{5}{*}{$1921\}$} & \multirow[t]{2}{*}{ Red Hussar (Wheat) } & 14.3 & 80 & 11.6 & 59 \\
\hline & & & & $(19.7$ & 100 \\
\hline & \multirow[t]{2}{*}{ Rosen (Rye) } & 17.9 & 100 & & - \\
\hline & & & & 25.4 & 100 \\
\hline & Poole (ck) (Wheat) & 11.8 & 66 & 11.2 & 44 \\
\hline
\end{tabular}

The disturbance of the true comparative value of the varieties by competition may be determined by comparing their relative yields in interior rows and in border rows. Thus Niagara wheat in 1920 yielded 67 per cent as much as Rosen rye in plots protected from competition, but only 33 per cent as much in rows not protected from competition. Similarly the yield of Velvet Chaff No. 2 wheat was reduced from 68 per cent to 35 per cent by competition with Rosen rye. In the following season the reduction in yield of the two varieties of wheat adjoining Rosen rye (Red Hussar and Poole) was not so great, but was still decidedly significant. This clear case of compe- 
tition serves to illustrate the phenomenen, although the competition between wheat and rye has little significance in itself as regards variety tests in general, since wheat and rye are not commonly included in the same test.

Ordinarily the competition between varieties of the same crop is not so extreme. There are, however, a number of cases in which a variety of wheat or oats profited almost as extremely in competition with other varieties of the same crop as did the rye in competition with wheat in the cases cited above. The wheat variety, Michigan Wonder No. 116, which grew between two other wheat varieties, Leap's Prolific and Poole Selection, in 1921, gave the following results, as an average of the four series:

\begin{tabular}{|c|c|c|c|c|}
\hline \multirow[t]{2}{*}{ Variety } & \multicolumn{2}{|c|}{$\begin{array}{c}\text { Yield in } \\
\text { interior rows }\end{array}$} & \multicolumn{2}{|c|}{$\begin{array}{c}\text { Yield in competing } \\
\text { border rows }\end{array}$} \\
\hline & Bushels & Relative & Bushels & Relative \\
\hline Ireap's Prolific & 14.9 & 91 & $\begin{array}{r}9.9 \\
(188\end{array}$ & $\begin{array}{r}53 \\
100\end{array}$ \\
\hline Michigan Wonder No. 116 & 16.4 & 100 & 21.7 & $\overline{100}$ \\
\hline Poole Selection & 15.3 & 93 & 11.5 & 53 \\
\hline
\end{tabular}

The effect of competition in this case is almost as pronounced as in the case of the rye, although the three wheat varieties concerned, when protected from competition, gave almost equal yields and differed little in date of heading, date of maturity, and height. In this case a small difference in actual value between the varieties, as indicated by their yields when protected from competition, is greatly increased when their yields in adjacent single rows are compared.

A striking case of competition in the oats variety test of 1921 was that of the three varieties Sterilis Selection, Fulghum, and Kherson, the check variety. Their average yields were as follows:

\begin{tabular}{|c|c|c|c|c|}
\hline \multirow[t]{2}{*}{ Variety } & \multicolumn{2}{|c|}{$\begin{array}{c}\text { Yield in } \\
\text { interior rows }\end{array}$} & \multicolumn{2}{|c|}{$\begin{array}{l}\text { Yield in competing } \\
\text { border rows }\end{array}$} \\
\hline & Bushels & Relative & Bushels & Relative \\
\hline Sterilis Selection & 38.63 & 99 & 28.50 & 58 \\
\hline Fulghum & 39.19 & 100 & 48.75 & 100 \\
\hline Kherson (check) & 40.69 & 104 & $\begin{array}{l}42.94 \\
34.18\end{array}$ & $\begin{array}{r}100 \\
70\end{array}$ \\
\hline
\end{tabular}


These three varieties, which gave almost equal yields in rows protected from competition, differed decidedly in their yields in adjacent rows. Although Kherson outyielded Fulghum 4 per cent in plots protected from competition, its yield was 30 per cent less than that of Fulghum in single rows not protected from competition.

Extreme effects of competition were shown in very numerous cases in the tests of Kherson and Red Rustproof strains in 1921. An example from this plot is the following:

\begin{tabular}{|c|c|c|c|c|}
\hline \multirow[t]{2}{*}{ Strain } & \multicolumn{2}{|c|}{$\begin{array}{c}\text { Yield in } \\
\text { interior rows }\end{array}$} & \multicolumn{2}{|c|}{$\begin{array}{l}\text { Yield in competing } \\
\text { border rows }\end{array}$} \\
\hline & Bushels & Relative & Bushels & Relative \\
\hline 0169 (Red Rustproof check) & 18.38 & 77 & $\begin{array}{r}22.31 \\
\int 18.75\end{array}$ & $\begin{array}{l}119 \\
100\end{array}$ \\
\hline 067 (Red Rustproof) & 24.00 & 100 & 17.44 & $\overline{100}$ \\
\hline 085 (Kherson) & 38.25 & 159 & 51.94 & 298 \\
\hline
\end{tabular}

The extreme advantage of the Kherson strain in competition with the Red Rustproof, increasing its margin of superiority from 59 per cent to 198 per cent, is particularly striking. Probably even more significant is the effect of competition between the two Red Rustproof strains, resulting in the conversion of a 23 per cent loss to a 19 per cent gain.

All of the cases cited above are taken from plots in which the rows ran east and west. Some examples of varietal competition from tests in rows running north and south are the following:

In the barley variety test, the variety Featherston 1118 occurred between Red River 973 and Oderbrucker (the check variety). The average yields of these three varieties in the three series were as follows:

\begin{tabular}{|c|c|c|c|c|}
\hline \multirow[t]{2}{*}{ Variety } & \multicolumn{2}{|c|}{$\begin{array}{l}\text { Yield in } \\
\text { interior rows }\end{array}$} & \multicolumn{2}{|c|}{$\begin{array}{l}\text { Yield in competing } \\
\text { border rows }\end{array}$} \\
\hline & Bushels & Relative & Bushels & Relative \\
\hline Red River 973 & 27.25 & 96 & $\begin{array}{r}31.20 \\
(24.60\end{array}$ & $\begin{array}{l}127 \\
100\end{array}$ \\
\hline Featherston 1118 & 28.25 & 100 & 25.65 & $\frac{}{100}$ \\
\hline Oderbrucker (ck) & 34.87 & 123 & 42.19 & 164 \\
\hline
\end{tabular}


In this case the advantage of Oderbrucker over Featherston was almost tripled by competition, and Red River, which yielded less than Featherston in the interior rows, excelled it materially in yield in the border rows.

The oats varieties tested in rows running north and south in 1919 showed marked effects of competition in several cases. The following will serve as an example:

\begin{tabular}{|c|c|c|c|c|}
\hline \multirow{2}{*}{ Variety } & \multicolumn{2}{|c|}{$\begin{array}{l}\text { Yield in } \\
\text { interior rows }\end{array}$} & \multicolumn{2}{|c|}{$\begin{array}{l}\text { Yield in competing } \\
\text { border rows }\end{array}$} \\
\hline & Bushels & Relative & Bushels & Relative \\
\hline Kherson Selection & 61.3 & 111 & $\begin{array}{r}84.7 \\
(49.4\end{array}$ & $\begin{array}{l}171 \\
100\end{array}$ \\
\hline Fulghum 042 & 57.1 & 100 & & $\overline{100}$ \\
\hline Lincoln & 50.3 & 88 & 57.5 & 113 \\
\hline
\end{tabular}

In this case Lincoln, yielding 12 per cent less than Fulghum in interior rows, yielded 13 per cent more than Fulghum in border rows; while the advantage of Kherson Selection over Fulghum was increased from 11 per cent to 71 per cent.

Marked competition is hardly to be expected in the oats strain test of 1919, regardless of the direction of the rows, because of the similarity of the strains in varietal characters. Three strains which proved to be taxonomically unlike Red Rustproof were included in this test, and each of these shows clearly the effects of competition. For example, strain 0124, which was classified as Fulghum, gave the following yields in comparison with the adjoining strains, 0127, classified as Kherson, and 0133, classified as Red Rustproof:

\begin{tabular}{|c|c|c|c|c|}
\hline \multirow[t]{2}{*}{ Strain } & \multicolumn{2}{|c|}{$\begin{array}{l}\text { Yield in } \\
\text { interior rows }\end{array}$} & \multicolumn{2}{|c|}{$\begin{array}{l}\text { Yield in competing } \\
\text { border rows }\end{array}$} \\
\hline & Bushels & Relative & Bushels & Relative \\
\hline 0.127 (Kherson) & 38.55 & 60 & $\begin{array}{r}32.40 \\
66.83\end{array}$ & $\begin{array}{r}48 \\
100\end{array}$ \\
\hline 0124 (Fulghum) & 63.90 & 100 & 78.75 & 100 \\
\hline 0133 (Red Rustproof) & 48.00 & 75 & 43.20 & 55 \\
\hline
\end{tabular}


Moreover, the Red Rustproof strains showed competitive effects among themselves to some extent, though not so conspicuously as different varieties. For example the strains 0122 and 0123 , which were taxonomically identical, yielded as follows:

\begin{tabular}{l|r|r|r|r}
\hline \multirow{2}{*}{ Strain } & \multicolumn{2}{|c|}{$\begin{array}{c}\text { Yield in } \\
\text { interior rows }\end{array}$} & $\begin{array}{r}\text { Yield in competing } \\
\text { border rows }\end{array}$ \\
\hline 0122 (Red Rustproof) & Bushels & Relative & Bushels & Relative \\
0123 (Red Rustproof) & 47.85 & 89 & 55.13 & 112 \\
& 53.55 & 100 & 49.28 & 100 \\
\hline
\end{tabular}

Strain 0122 which was apparently 11 per cent inferior to strain 0123 in the yields of interior rows, appeared to be 12 per cent superior to the same strain in the yields of their adjacent border rows.

In the wheat mixture test of 1920 also the rows ran north and south. An example of competition from this test is the following:

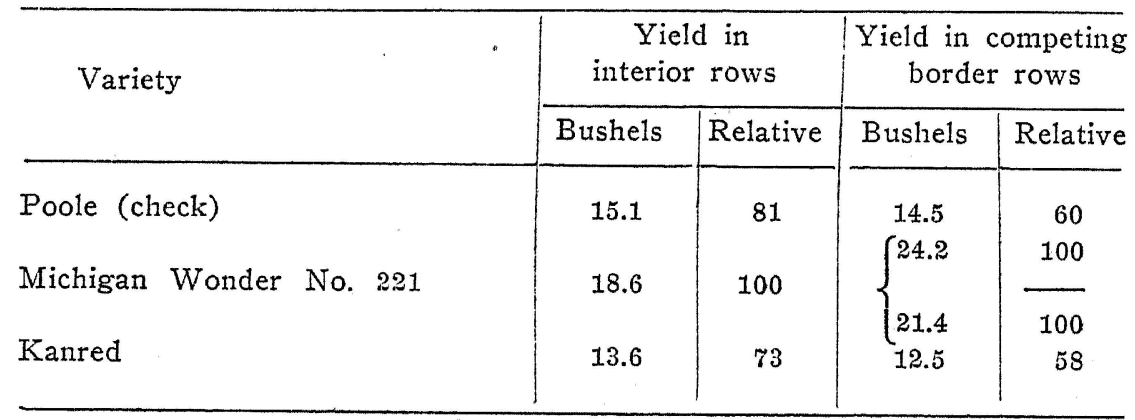
tition.

In this case also differences in yield were increased by compe-

The individual cases cited above will serve to show the existence of competition as a source of error in these tests. As a result of competition the differences between varieties may be increased or decreased, and in some cases a material advantage in yield may be converted to a material disadvantage. The phenomenon occurs, under conditions at Columbia, whether the rows run north and south or east and west. Of course it is not true that all of the difference in yield between border rows and interior rows is necessarily caused by varietal competition. Some variation in the yield of adjacent rodrows will occur regardless of competition. When the means of only 
four determinations are compared the effect of this variability may be considerable. If a field uniformly seeded to a single strain were harvested in rod-rows and assumed to be made up of several different varieties each in four distributed plots, doubtless the average border yield would differ materially from the average interior yield in several "varieties." It is not however, likely, that such differences as those cited above would be caused by chance variability. Nevertheless, no final conclusions regarding competition as a source of error should be drawn from such individual cases. The extent of error from competition is better shown in the average differences between border yields and interior yields, and in the mean coefficients of competition for complete tests. They are given in the next section.

Relation of Competition to Various Characteristics of the Competing Varieties.-It is essential that competition be eliminated by the use of border rows, or counteracted by some such means as grouping varieties. The latter is decidedly the preferable method, from the standpoint of economy, if satisfactory results may be obtained by its use. But competition cannot be effectively controlled by grouping varieties unless there is a close correlation between competitive value and some character like earliness or height, which may be known in advance. Determinations of the correlation between competitive effects and various characteristics of the varieties have therefore been made for each of the tests. The prelininary determinations were made as follows:

(1) The average yield in interior rows and the average yield in the border rows on each side for all replicate plots of each variety or strain was determined. The replicate plots thus averaged were grown between the same varieties in each series, and it may be assumed therefore that their border rows were strbject to the same competition. In the following discussion of competition each individual case represents the mean of all the replicate plots of the test in question. For example, when it is stated that the correlation between competition and yield is determined in a test in which one hundred cases of competition are involved, each of the hundred cases represents the mean of three or four determinations in replicate plots. In most cases the number of replicate plots was four. In the barley test of 1919 only three series were grown, and in the oats variety test of 1919, though four series were grown, only three could be used because one border row of each variety in the first series was harvested for seed and laboratory material.

(2) Corresponding average yields were determined for check plots, those adjoining the same variety being averaged together. For 
example, in the wheat variety test diagrammed in figure 1 the four check plots which adjoined variety 1 (one in each series) were averaged together, the four adjoining variety 2 , the four adjoining variety 3 , etc. The four check plots adjoining varieties $89,90,91$, etc. were similarly averaged.

(3) The average yield of each border row for each variety was converted to the percentage of the average yield of the same variety in its interior rows. These yields of border rows in percentage will be referred to as "relative border yields." The relative border yield gives a rough indication of the effect of competition on the variety. When it is above 100, the variety yielded more in border rows (subject to competition) that in interior rows (protected from competition). When it is below 100, the border yield was less than the interior yield, in proportion.

(4) An approximate measure of the competition between each pair of adjacent varieties was obtained by dividing the higher relative border yield by the lower, in the case of their adjacent border rows, and substracting 100 from the result. When the variety on the left has a higher relative border yield, this is given a positive sign; in the reverse case a negative sign. This figure is simply the predominance of the more strongly competing variety over the other in percentage of relative border yield. It will be referred to, for convenience, as the coefficient of competition.

(5) This measure of competition was correlated with various characteristics of the competing varieties, including the relative yields in interior rows, the relative grain-straw ratios, the relative dates of heading and of maturity, and the relative heights. In correlating competition with the relative yield of the interior rows, the relative yield was determined by dividing the higher yield by the lower, subtracting 100 , and assigning a positive or negative sign, as before. The correlation determined, therefore, is the correlation between the percentage advantage of one variety over another in competition, and the difference in yield of the two varieties, expressed in percentage, when protected from competition. Relative grain-straw ratios were determined similarly, the ratios being first obtained by dividing the yield of straw by the yield of grain. Relative dates of heading and maturity and relative heights were determined simply by subtracting the value for one variety from the value for the other. In each case, of course, the sign was determined in the same way.

A simple example explained in detail may serve to make this method clear. In the wheat variety test of 1921 the varieties Fultz (Bayer), Michigan Amber, and Michigan Wonder No. 211 occurred 
in the order named in four distributed sections of the field. The average yields of these varieties in the four series, in bushels per acre, for border rows and for interior rows, are shown below, together with the average dates of heading, dates of maturity, and heights, also determined for the four series.

\begin{tabular}{|c|c|c|c|c|c|c|c|c|c|}
\hline & \multicolumn{3}{|c|}{ 23. Fultz (Bayer) } & \multicolumn{3}{|c|}{ 39. Michigan Amber } & \multicolumn{3}{|c|}{$\begin{array}{l}\text { 55. Michigan Wonder } \\
\text { No. } 211\end{array}$} \\
\hline & Row $_{1}$ & $\begin{array}{l}\text { Row } \\
2,3,4\end{array}$ & $\underset{5}{\text { Row }}$ & $\underset{1}{\text { Row }}$ & $\begin{array}{l}\text { Row } \\
2,3,4\end{array}$ & $\begin{array}{l}\text { Row } \\
5\end{array}$ & $\underset{1}{\text { Row }}$ & $\begin{array}{l}\text { Row } \\
2,3,4\end{array}$ & $\underset{5}{\text { Row }}$ \\
\hline $\begin{array}{l}\text { Average } \\
\text { yields }\end{array}$ & $\begin{array}{l}10.8 \\
\text { bu. }\end{array}$ & $\begin{array}{l}12.2 \\
\text { bu. }\end{array}$ & $\begin{array}{l}13.1 \\
\text { bu. }\end{array}$ & $\begin{array}{l}13.3 \\
\text { bu. }\end{array}$ & $\begin{array}{l}14.9 \\
\text { bu. }\end{array}$ & $\begin{array}{l}14.5 \\
\text { bu. }\end{array}$ & $\begin{array}{l}19.8 \\
\text { bu. }\end{array}$ & $\begin{array}{l}18.1 \\
\text { bu. }\end{array}$ & $\begin{array}{l}19.4 \\
\text { bu. }\end{array}$ \\
\hline $\begin{array}{l}\text { Average } \\
\text { tate of } \\
\text { heading }\end{array}$ & & $21^{*}$ & & & $21 *$ & & & $19 *$ & \\
\hline $\begin{array}{l}\text { Average } \\
\text { date of } \\
\text { maturity }\end{array}$ & & $47^{*}$ & & & $48^{*}$ & & & $47^{*}$ & \\
\hline $\begin{array}{l}\text { Average } \\
\text { height }\end{array}$ & & $43 \mathrm{in.}$ & & & $42 \mathrm{in.}$ & & & 43 in. & \\
\hline
\end{tabular}

* Dates of heading and maturity are the numbers of days after April 30 . Thus 1 is May 1,32 is June 1,47 is June 16 , etc.

Now dividing the yields in border rows by the yields of the same varieties in interior rows, we obtain the relative border yields, which are substituted in the table below for the border yields in bushels. To determine the degree of competition between the varieties Fultz and Michigan Amber we divide the larger relative border yield (107) by the smaller (89) and subtract 100 , giving 20 per cent. Since in this case the relative border yield of the variety on the left is higher, the difference is given a minus sign. Similarly a value of +12 per cent is obtained for the competition between Michigan Amber and Michigan Wonder No. 211. These figures mean that the relative border yield of Fultz exceeded that of Michigan Amber by 20 per cent in their competing border rows, while that of Michigan Wonder exceeded that of Michigan Amber by 12 per cent.

The relative yields of these varieties are obtained similarly,in the first case by dividing 14.9 by $12.2(+22 \%)$ and in the second case by dividing 18.1 by $14.9(+21 \%)$. Both values are positive because in each case the yield of the variety on the left is higher than that of the variety on the right. The difference in dates of heading, maturity, and height are obtained simply by subtraction, being positive when the value of the variety on the right is greater and negative when 
the value of the variety on the left is greater. The figures ready for correlation study will then appear as follows:

\begin{tabular}{|c|c|c|c|c|c|c|c|c|c|c|c|}
\hline & $\underset{1}{\text { Row }}$ & $\begin{array}{c}\text { 23. Ful } \\
\text { (Bayer) } \\
\text { Row } \\
2,3,4\end{array}$ & $\begin{array}{c}\mathrm{tz} \\
\text { Row } \\
5\end{array}$ & $\begin{array}{c}\text { Compe- } \\
\text { tition } \\
\text { data }\end{array}$ & $\begin{array}{c}\text { Row } \\
1\end{array}$ & $\begin{array}{l}\text { 9. Mich } \\
\text { Amber } \\
\text { Row } \\
2,3,4 \\
\end{array}$ & $\begin{array}{l}\text { gan } \\
\text { Row } \\
5\end{array}$ & $\begin{array}{c}\text { Compe- } \\
\text { tition } \\
\text { data }\end{array}$ & $\begin{array}{c}55 . \mathrm{Mi} \\
\text { Row } \\
1\end{array}$ & $\begin{array}{l}\text { chigan } \\
\text { No. } 21 \\
\text { Row } \\
2,3,4\end{array}$ & $\begin{array}{c}\text { onder } \\
\text { Row } \\
5\end{array}$ \\
\hline $\begin{array}{l}\text { Average } \\
\text { yield }\end{array}$ & 89 & 12.2 & 107 & $\begin{array}{r}-20 \% \\
+22 \% \\
\end{array}$ & 89 & 14.9 & 97 & $\begin{array}{l}+12 \% \\
+21 \% \\
\end{array}$ & 109 & 18.1 & 107 \\
\hline $\begin{array}{l}\text { Average } \\
\text { date of } \\
\text { heading }\end{array}$ & & 21 & & 0 & & 21 & & -2 & & 19 & \\
\hline $\begin{array}{l}\text { Average } \\
\text { date of } \\
\text { maturity }\end{array}$ & & 47 & & +1 & & 48 & & 0 & & 47 & \\
\hline $\begin{array}{l}\text { Average } \\
\text { height }\end{array}$ & & 43 & & -1 & & 42 & & +1 & & 43 & \\
\hline
\end{tabular}

The columns headed "competition data" show the relation of the effect of competition to the yield, earliness, and height of the competing varieties. For example, Michigan Amber was at a disadvantage of 20 per cent in competition with Fultz, though it was 22 per cent superior in yield when protected from competition. It headed the same day, matured one day later, and was one inch shorter. After corresponding data had been prepared for all the 96 varieties in this test, correlation tables with the coefficient of competition as subject and relative yield, date of heading, date of maturity, and height as relative were constructed. Correlations were determined similarly in the other tests. One of these correlation tables is shown in figure 6. In general, merely

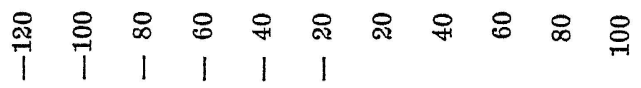

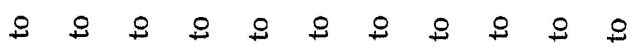

$$
\begin{aligned}
& \text { 육 } \\
& \begin{array}{rrr}
-40 & \text { to } & -60 \\
-20 & \text { to } & -40 \\
0 & \text { to } & -20 \\
0 & \text { to } & 20 \\
20 & \text { to } & 40 \\
40 & \text { to } & 60 \\
60 & \text { to } & 80
\end{array} \\
& \text { Total }
\end{aligned}
$$

\begin{tabular}{|rrrrrrrrrrrrr|r}
\hline 2 & 1 & 1 & 2 & 4 & 2 & 2 & & & & & 1 \\
& & 1 & 1 & 7 & 10 & 5 & 2 & & & & \\
& & 1 & 2 & 6 & 10 & 8 & 3 & 5 & & & 26 \\
& & & & 2 & 3 & 4 & 11 & 2 & 1 & 1 & 35 \\
& & & & 1 & & 1 & & & 3 & & 24 \\
& & & & & & 1 & & 1 & 1 & & 5 \\
& & & & & & 1 \\
\hline 2 & 1 & 3 & 5 & 20 & 26 & 21 & 16 & 8 & 5 & 1 & 112
\end{tabular}

Figure 6.-Correlation Between CoffFicient of Competition and RelaTIVE YIELD, IN WhEAT VARIETY TEST 1920.

$$
\mathrm{r}=+.582 \pm .043
$$


the coefficient of correlation and its probable error are given, for lack of space.

In the barley variety test, 1919 , the effect of competition was quite marked. The average yield of border rows differed from the average yield of interior rows by 11.13 per cent, and the mean coefficient of competition was 21.30 per cent. Attempts were made to correlate competition with relative date of heading, date of maturity, grain-straw ratio, and yield. The correlation coefficients determined are shown in Table 10, together with the mean differences between competing

Table 10.-Corretation of Competition With Various Characteristics in Barley Varety TEST 1919.

Character

\begin{tabular}{|c|c|}
\hline $\begin{array}{l}\text { Mean difference be- } \\
\text { tween competing } \\
\text { varieties }\end{array}$ & $\begin{array}{c}\text { Coefficient of correlation } \\
\text { with competition }\end{array}$ \\
\hline
\end{tabular}

Date of heading

Date of maturity

Grain-straw ratio

Yield

$\begin{array}{ll}4.0 \text { days } & -.153 \pm .120 \\ 2.6 \text { days } & -.063 \pm .123 \\ 38.0 \% & +.072 \pm .122 \\ 52.3 \% & +.442 \pm .099\end{array}$

varieties in the characters whose relation to competition was studied. Although none of these correlations is statistically significant, in the strictest sense, it is noticeable that the correlation between competition and yield is much greater than any of the others, and is equal to about four and one-half times its probable error. There was apparently some tendency for the better yielding varieties to profit by competition with the poorer yielders. On account of the relatively small number of cases involved in this and the other 1919 tests, the probable errors are high, and a fairly high coefficient of correlation

Table 11.-Corritation of Competition With Vartous Characteristrcs in OATS VarIETy TEST 1919.

\begin{tabular}{|c|c|c|}
\hline Character & $\begin{array}{l}\text { Mean difference be- } \\
\text { tween competing } \\
\text { varieties }\end{array}$ & $\begin{array}{c}\text { Coefficient of correlation } \\
\text { with competition }\end{array}$ \\
\hline Date of maturity & 3.56 days & $-.456 \pm .103$ \\
\hline Grain-straw ratio & $50.2 \%$ & $-.091 \pm .129$ \\
\hline Yield & $53.5 \%$ & $+.314 \pm .117$ \\
\hline
\end{tabular}


The oats variety test of 1919 also showed distinctly the effects of competition. The border rows in this test differed in yield from the interior rows by 12.78 per cent, on the average, and the mean coefficient of competition was 27.67 per cent. Correlations were determined for competition and relative yield, date of maturity, and grain-straw ratio. Unfortunately the dates of heading are not available for all varieties in this test. The correlation coefficients are shown in Table 11.

Again no correlations of statistical significance are found, but the relation of yield and earliness of maturity to competing strength is at least suggestive. There was a tendency for early and high-yielding varieties to profit by competition at the expense of later and lower-yielding varieties, but the number of varieties was too small to permit the drawing of positive conclusions.

The oats strains grown on the same field showed much less strikingly the effects of competition. The mean difference in yield between border rows and interior rows in these 15 strains was only 6.50 per cent and the mean coefficient of competition only 13.11 per cent. This is undoubtedly accounted for by the fact that the differences between competing strains were so much less than in the oats variety test. When the three strains taxonomically unlike Red Rustproof are eliminated, leaving 12 strains of the same variety, the average deviation of border yields from interior yields is reduced to 4.69 per cent and the average coefficient of competition to 8.69 per cent. It is noteworthy that the competition between these strains of the same variety is decidedly less than that between different varieties. No sig-

Table 12.-Correlation of Competition With Various Characteristics in Oats Strain Test 1919.

\begin{tabular}{lcc}
\hline Character & $\begin{array}{c}\text { Mean difference be- } \\
\text { tween competing } \\
\text { strains }\end{array}$ & $\begin{array}{c}\text { Coefficient of correlation } \\
\text { with competition }\end{array}$ \\
\hline Date of heading & 2.67 days & $-.376 \pm .136$ \\
Date of maturity & 1.56 days & $-.244 \pm .149$ \\
Grain-straw ratio & $14.2 \%$ & $+.012 \pm .159$ \\
Yield & $17.1 \%$ & $+.316 \pm .143$
\end{tabular}

nificant correlation was found between these minor effects of competition (for the 15 strains) and the relative time of heading, time of maturity, grain-straw ratio or yield, as is shown in Table 12, though in this case again the early strains and the high-yielding strains showed some tendency to profit by competition. 
In the wheat variety test of 1920 the average yield of border rows differed from the average yield of interior rows by 12.30 per cent and the mean coefficient of competition was 19.79 per cent. These figures represent the average determinations when the two varieties of rye and the border yields of the varieties of wheat adjoining them were eliminated. The correlation between competition and relative yield, date of heading, and date of maturity were determined for this test and the coefficients of correlation are shown in Table 13.

Table 13.-Correlation of Competition With Various Characteristics in WhEAT VARIETY TEST 1920.

\begin{tabular}{lcc}
\hline Character & $\begin{array}{c}\text { Mean difference be- } \\
\text { tween competing } \\
\text { varieties }\end{array}$ & $\begin{array}{c}\text { Coefficient of correlation } \\
\text { with competition }\end{array}$ \\
\hline Date of heading & 2.3 days & $-.515 \pm .048$ \\
Date of maturity & 2.7 days & $-.552 \pm .045$ \\
Yield & $28.9 \%$ & $+.582 \pm .043$
\end{tabular}

Competition in this test was negatively correlated with earliness of heading and maturity and positively with yield. All of the correlation coefficients are clearly significant. In other words, there was a rather pronounced tendency for the early and high-yielding varieties to profit in competition. To a considerable extent the early varieties were the high yielding varieties in this test, as indicated by the fact that the correlation coefficient for date of heading and yield was -.511 \pm .051 , and that for date of maturity and yield was $-.642 \pm .041$. A1though it is clear from these results that early, high-yielding varieties excelled in competition, it is not clear whether they did so chiefly as a result of their earliness or chiefly as a result of their yield.

TAbLE 14.-Correlation OF Competition With Various Characteristics in WhEAT VARIETY TEST 1921.

\begin{tabular}{|c|c|c|}
\hline Character & $\begin{array}{c}\text { Mean difference be- } \\
\text { tween competing } \\
\text { varieties }\end{array}$ & $\begin{array}{c}\text { Coefficient of correlation } \\
\text { with competition }\end{array}$ \\
\hline
\end{tabular}

\begin{tabular}{lcr}
\hline Date of heading & 2.1 days & $-.271 \pm .060$ \\
Date of maturity & 1.6 days & $-.222 \pm .062$ \\
Height & 3.3 inches & $+.347 \pm .057$ \\
Yield & $19.5 \%$ & $+.294 \pm .059$
\end{tabular}

Similar results were obtained in the wheat variety test of 1921 in which the difference between the average yield of border and interior rows was 12.89 per cent and the mean coefficient of competition 
was 18.85 per cent. Correlations were determined for competition and relative yield, date of maturity, date of heading, and height in this test. The coefficients of correlation thus determined are shown in Table 14.

In this case, as in the wheat variety test of the preceding season, dates of heading and maturity were correlated negatively and yield was correlated positively with competition. The coefficients of correlation were materially lower, and in fact are hardly significant. It is interesting that in this case height was correlated more closely with competition than were either earliness or yield. In this season again earliness was correlated to some extent with yield, the coefficients of correlation, for date of heading and yield being - $-331 \pm .062$ and for date of maturity and yield $-.419 \pm .057$.

In the wheat mixture test of 1921 the varieties were grouped roughly in respect to earliness, and in only three cases was there a greater difference than two days in heading or maturity between adjacent varieties. The rows in this test ran north and south. The conditions may be considered favorable in this test for the reduction of competition. Nevertheless the average yield of border rows differed from that of interior rows by 10.07 per cent and the mean coefficient of competition was 14.28 per cent. The coefficients of correlation determined for competition and date of heading, date of maturity, and yield, are shown in Table 15.

Table 15.-Correlation of Competition With Various Characteristics in WheAT Mixture TEST 1921.

\begin{tabular}{lcc}
\hline Character & $\begin{array}{c}\text { Mean difference be- } \\
\text { tween competing } \\
\text { varieties }\end{array}$ & $\begin{array}{c}\text { Coefficient of correla } \\
\text { with competitio }\end{array}$ \\
\hline Date of heading & 1.2 days & $-.514 \pm .083$ \\
Date of maturity & 0.8 days & $-.613 \pm .070$ \\
Yield & $19.2 \%$ & $+.554 \pm .078$
\end{tabular}

In this test significant negative correlations between competition and dates of heading and maturity and a significant positive correlation between competition and yield are shown. The tendency for early, high-yielding varieties to profit by competition was about as strong as in the wheat variety test of the preceding season, though the extent of competitive effect was considerably reduced.

The effects of competition in the oats variety test in 1921 were extreme. The yields of border rows differed by 16.74 per cent, on the average, from the yields of interior rows, and the mean coefficient of competition was 39.15 per cent. The extreme effects of compe- 
tition in this test are probably accounted for by the fact that the varieties differed very widely in varietal type and in yield. Differences of as much as 17 days in date of heading, 13 days in date of maturity, and almost 200 per cent in yield, were involved. The correlations determined between competition and relative date of heading, date of maturity and yield, are shown in Table 16.

TABLE 16.-Correlation OF Competition With Various Characteristics in OATS VARIETY TEST 1921.

Character

\section{Mean difference be- tween competing}

varieties
Date of heading

Date of maturity

Yield

$\begin{array}{ll}4.8 \text { days } & -.648 \pm .060 \\ 4.1 \text { days } & -.860 \pm .028 \\ 51.1 \% & +.484 \pm .082\end{array}$

A remarkably high negative correlation between date of maturity and competition is shown. The negative correlation between date of heading and yield is also quite high, while the positive correlation between yield and competition is barely significant. In this test, in which extreme differences in time of maturity occurred, the early-maturing varieties had a very distinct advantage in competition with the later varieties. Earliness was very closely correlated with yield in the oats variety test of this season, the coefficient of correlation for date of heading and yield being $-.750 \pm .052$ and that for date of maturity and yield being $-.894 \pm .024$. Considering the close correlation of earliness and yield, and the relatively low correlation of yield and competition, it would seem that the latter may be merely a by-product of the relation of earliness to competition. Since the early varieties were the leaders both in competition and in yield, some correlation of yield and competition is inevitable.

In the oats strains test of 1921 Kherson and Red Rustproof strains were alternated and both a Kherson and a Red Rustproof check were grown. In most cases therefore the competing border rows represented these two varieties, though in some cases two Red Rustproof or two Kherson plots occurred together, as is shown in the planting plan in figure 5. The effects of competition in this plot were quite distinct, as is to be expected, though they were not so extreme as in the oats variety test discussed above, which was located on the same field. The average yield of border rows differed from the average yield of interior rows by 11.76 per cent. The mean coefficient of competition was 23.85 per cent.

When we exclude the competition between the three strains not true to name and the strains adjacent to each, that between the Kher- 
son and Red Rustproof check plots, and that between adjacent strains of the same variety, 58 cases of competition between different strains of Kherson and Red Rustproof remain. In these the mean yield of border rows differed from that of interior rows by 14.06 per cent and the mean coefficient of competition was 30.86 per cent. In every case the Kherson strain outyielded the adjacent Red Rustproof strain, though the advantage in yield varied from 27 per cent to 165 per cent. Similarly, the Kherson strains were earlier in maturity and heading, . and taller, in each case, but with a rather wide variation in the extent of their advantage. In all but three of the 58 cases the Kherson strains showed a greater advantage in yield over the adjacent Red Rustproof strains in their competing border rows than in their interior rows. The average yields of the 30 Red Rustproof strains and 29 Kherson strains, in interior rows and competing border rows, were as follows:

\begin{tabular}{l|c|c|c|c}
\hline & $\begin{array}{c}\text { Average yield in } \\
\text { interior rows }\end{array}$ & $\begin{array}{c}\text { Average yield in } \\
\text { competing border } \\
\text { rows }\end{array}$ \\
\cline { 2 - 5 } & Bushels & Relative & Bushels & Relative \\
\hline Red Rustproof strains & 21.00 & 100 & 18.59 & 100 \\
Kherson strains & 35.79 & 170 & 41.00 & 222 \\
\hline
\end{tabular}

The Kherson strains outyielded the Red Rustproof strains by 70 per cent in their interior rows and by 122 per cent in their competing border rows. The coefficients of competition, like the relative yield, earliness, and height, varied rather widely. Correlations were therefore measured for the advantage of the Kherson strain of each adjacent pair in competition and its advantages in yield, date of heading, date of maturity, and height. The coefficient of correlation in each case was insignificant.

Discussion.-In each of these tests, with the exception of the oats strain test of 1919 , in which most of the strains compared belonged to the same variety, border rows differed from interior rows in yield by more than 10 per cent. Differences as great as this will change materially the relative standing of varieties. In single-row tests the effects of competition would be considerably greater than in these border rows, affected by competition on only one side. Furthermore, in each test, of course, there were many cases in which competition caused much larger differences in yield than are shown by average figures. 
The relation of the direction of rows to the effects of varietal competition is not clearly shown by these experiments. The tests which showed least the effect of competition, the oats strain test of 1919 and the wheat mixture test of 1921, were in rows running north and south. But relatively little effect from competition is to be expected in these tests, regardless of the direction of the rows, because of the similarity of adjacent strains. In the oats strain test 12 of the 15 strains were taxonomically identical, and it has been shown that the effects of competition among these was much less than among the strains of different varieties. In the wheat mixture test the varieties making up each mixture, which were grown side by side in the test, were chosen partly for their similarity in time of maturity, and the differences between adjacent varieties were therefore considerably less than in the wheat variety test of the same season. It cannot be stated definitely, therefore, from the results of these tests, that tests in rows running north and south are either more or less subject to error from competition than tests in rows running east and west. It is clear, however, that a considerable error from varietal competition may occur in tests in which the rows run north and south, as is evidenced particularly by the barley and oats variety tests of 1919 .

The relation of competition to relative date of heading, date of maturity, grain-straw ratio, height, and yield, insofar as it was investigated in these experiments, is shown in summary form in Table 17. Although none of these characteristics shows a significant rela-

Table 17.-Summary of Efreters of Competrtion in Ali, Tests.

\begin{tabular}{|c|c|c|c|c|c|c|c|c|}
\hline \multirow{2}{*}{ T'est } & \multirow{2}{*}{ 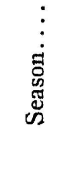 } & \multirow{2}{*}{ 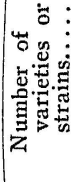 } & \multirow{2}{*}{ 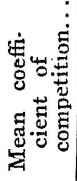 } & \multirow[b]{2}{*}{$\begin{array}{l}\text { Date of } \\
\text { Heading. }\end{array}$} & \multicolumn{4}{|c|}{ Coefficient of Correlation between Competition and- } \\
\hline & & & & & $\begin{array}{l}\text { Date of } \\
\text { Maturity. }\end{array}$ & $\begin{array}{c}\text { Grain-Straw } \\
\text { Ratio. }\end{array}$ & Height. & Yield. \\
\hline Barley variety & 1919 & 27 & 21.30 & $-.153 \pm .120$ & $-.063 \pm .123$ & $+.072 \pm .122$ & & $+.442 \pm .099$ \\
\hline Oats variety & 1919 & 24 & 27.67 & $\ldots \ldots$ & $-.456 \pm .103$ & $-.091 \pm .129$ & & $+.314 \pm .117$ \\
\hline Oats strain & 1919 & 15 & 13.11 & $-.376 \pm .136$ & $-.244 \pm .157$ & $+.012 \pm .159$ & & $+.316 \pm .143$ \\
\hline Wheat variety & 1920 & 94 & 19.79 & $-.515 \pm .048$ & $-.552 \pm .045$ & $\ldots \ldots \ldots$ & n........ & $+.582 \pm .043$ \\
\hline Wheat variety & 1921 & 94 & 18.85 & $-.271 \pm .060$ & $-.222 \pm .062$ & $\ldots$ & $+.347 \pm .057$ & $+.294 \pm .059$ \\
\hline Wheat mixture & 1921 & 30 & 14.28 & $-.514 \pm .083$ & $-.613 \pm .070$ & .. & $\ldots \ldots \ldots \ldots$ & $+.554 \pm .078$ \\
\hline Oats variety & 1921 & 32 & 39.15 & $-.648 \pm .060$ & $-.860 \pm .028$ & n......... & $\ldots \ldots \ldots$ & $+.484 \pm .082$ \\
\hline
\end{tabular}

tion to competition in every case, the results of the tests are fairly consistent. The correlation of competition with yield is always positive, and is fairly high in every case, the lowest coefficient being +.294 \pm .059 . From these results there can be no doubt that the higher yielding varieties are those which in general have profited by competition. The date of heading and the date of maturity show a negative correla- 
tion with competition in each case, though some of the coefficients are insignificant. It is clear therefore that early varieties are, in general, able to compete more strongly, but the extent of this relation is quite variable. The grain-straw ratio showed no significant relation to competition in any of the experiments of 1919, and was not determined for the succeeding tests. Height was correlated positively with competition in the one test in which height was determined, the wheat variety test of 1921 . In this test height was more closely related to competition than were date of heading, date of maturity, or yield.

In the oats variety tests, the relation of early maturity to competion is particularly marked, the coefficients of correlation in both oats variety tests being distinctly greater for date of maturity and competition than for yield and competition. In the wheat tests there was little difference in the degree of relation to competition between earliness and yield. In the one test of barley varieties conducted, yield was more closely correlated with competition than was either the date of heading or date of maturity, but none of the three showed a clearly significant correlation.

It is clear that in these trials the early, high-yielding varieties profited by competition. To a considerable extent these may be the same varieties, for the correlation of earliness and yield was high in most of the tests conducted. The relation of earliness and other characters to yield under Missouri conditions will be considered more fully in another paper, but data of interest in this connection are appropriate here. The coefficients of correlation of yield with date of heading and date of maturity in the variety tests discussed in this paper are shown in Table 18.

Table 18.-Correlation of Yield With Dates of Heading and Maturity in VARIETY TESTS OF BARLEY, OATS, ANd WhEAT

\begin{tabular}{lcccc}
\hline Crop & Season & $\begin{array}{l}\text { Number of } \\
\text { varieties }\end{array}$ & Date of heading & $\begin{array}{c}\text { Coefficient of correlation of } \\
\text { yield }\end{array}$ \\
\hline Barley & 1919 & 27 & $-.281 \pm .120$ & $-.271 \pm .120$ \\
Oats & 1919 & 40 & $-.627 \pm .065$ \\
Oats & 1921 & 32 & $-.750 \pm .052$ & $-.894 \pm .024$ \\
Wheat & 1920 & 94 & $-.511 \pm .051$ & $-.642 \pm .041$ \\
Wheat & 1921 & 94 & $-.331 \pm .062$ & $-.419 \pm .057$
\end{tabular}

When a very high correlation exists between earliness and yield it is likely that a character closely correlated with one may show a high degree of correlation with the other, which might not be shown were it not for the first correlation. For example, suppose earliness 
of maturity is largely responsible for strong competitive value. Then in a season when earliness is closely correlated with yield a close correlation of competition and yield is likely to be found, not because high yield makes for strong competition but because the high-yielding varieties are early. Conversely, the competing value may be dependent on the yield and the correlation with earliness may be incidental, under the same conditions. If the relation of earliness and yield were constant, such a question would have little practical importance, but when the relation is reversed, as it may be in different localities and even in different seasons in the same locality, the relation of competition to the two characteristics may be very different. The relation of competition to earliness and yield in these tests, therefore, may be due primarily to the predominating influence of either of these two characteristics, or to the influence of both.

General conclusions regarding competition should not be drawn from these tests. The problem of competition is complicated by many factors, and will require numerous and extensive investigations for its solution. These results, however, indicate that gross errors from this source are commonly involved in variety tests, that such errors occur both in rows running east and west and in rows running north and south, that the error is less when the varieties and strains compared are structurally similar than when they are widely different, and that the error may be reducible to some extent by the grouping of varieties according to the time of maturity and possibly other characters, when the relation of such characters to competition is more fully studied. In the present state of knowledge regarding the relation of competition to the characteristics of the varieties compared, the use of border rows is highly desirable, since by their use the error from competition can be practically eliminated.

\section{SIZE AND REPLICATION OF PLOTS.}

Previous Investigation.-Most of the direct evidence reported on replication and size of plots has been obtained in experiments in which a field of a uniformly handled crop is harvested in a large number of small sections. These sections are grouped to form plots of different shapes and sizes, and systematically distributed sections are averaged to represent replicate plots. The relative variability of the yields determined by each plot arrangement is the criterion of experimental accuracy. Such experiments have been reported by Morgan ${ }^{15}$ with wheat and fodder corn, Wood and Stratton ${ }^{18}$ with mangels, Mercer and Hall ${ }^{12}$ with wheat and mangels, Hall and Russel1 ${ }^{3}$ with wheat, 
Montgomery ${ }^{13}$, ${ }^{14}$ with wheat, Kiesselbach ${ }^{5}$ with oats, and Day $^{1}$ with wheat.

The general conclusions drawn from these experiments are in harmony, though the specific size and shape of plot and number of replications found most desirable vary rather widely. In general, plot variability was reduced by increasing the size of the individual plot, up to a certain limit, but it was reduced much more effectively by replication of plots. For a given area a large number of small plots was always found more accurate than a small number of large plots.

But the size of the plot cannot be reduced indefinitely for several reasons. As the plot becomes smaller the proportion subject to "border effect" rapidly becomes greater. This border effect may be due to the modified growth of plants adjoining an alley or to the influence of the competition of different varieties in adjacent rows. If the borders are not discarded an important systematic error is involved; if they are discarded a considerable portion of the land and labor is lost. In either case the disadvantage is increased as the size of the plot is decreased. When single rod-row plots are used the whole plot is subject to border effect. The importance of this error has already been discussed. Another disadvantage of the extremely small plot is that slight differences in stand and small mechanical errors have a marked effect on the yields. The increased labor involved in handling a large number of small plots rather than a small number of large plots is also an important disadvantage.

The length of the so-called rod-row has usually been determined by convenience. Commonly used lengths when the rows are a foot apart are 16 feet for wheat, 20 feet for barley, and 15 feet for oats, since with these lengths yields in grams per row may easily be converted to bushels per acre. In other cases the most convenient length is determined by the dimensions of experiment fields. Although increasing the length of the row would doubtless reduce variability, a greater gain could be made on the same area by further replication. Ordinarily it is preferable, therefore, to retain the most convenient length and to make any desired increase in size of plot in the width, for widening the plots will rapidly reduce the proportion subject to border effect.

Experimental Results. - Size of Plots.-By comparing the standard deviations of single rows and blocks consisting of three and five rows each, in the check plots, it is possible to determine the relative value of plots of the three sizes in counteracting plot variability. In this comparison the single-row and three-row plots correspond respectively to 3 -row and 5-row plots in which the border rows are dis- 
carded, since they are made up of rows protected from varietal competition by border rows. In each of the computations summarized below each check plot is represented by only one yield. For example, in determining the yield and standard deviation of single rows in the 20 check plots of the oats variety test of 1919 , the constants for single rows are the average of determinations made independently for Row 2 of each of the 20 plots, for Row 3, and for Row 4 . The determinations for 3-row plots are similarly made from the computed yields of the three interior rows of each check plot, and those for 5-row plots from the computed yields of the entire plots. Thus each determination represents the same number of plots and the same area, the only difference being in the size of the individual plot. It would be possible, of course, to test 40 per cent more varieties with the same number of replications or to increase the number of replications by 40 per cent for the same number of varieties on the same area, if 3 -row blocks were used rather than 5-row blocks.

The yield and variability of check plots of different sizes in the barley variety test of 1919 are shown in Table 19. The variety grown in these check plots was Oderbrucker, seeded at the rate of 8 pecks per acre. The check variety was grown in every sixth plot.

TABLE 19.-YIEID AND VARIability of Check Plóts.

Single-row, Three-row, and Five-row-Barley Variety Test 1919.

\begin{tabular}{l|c|c|c|c}
\multicolumn{1}{r|}{ Size of plot } & $\begin{array}{c}\text { Number } \\
\text { of plots }\end{array}$ & $\begin{array}{r}\text { Yield } \\
\text { per acre }\end{array}$ & \multicolumn{2}{|c}{ Standard deviation } \\
\cline { 2 - 4 } Single-row & & bu. & bu. & $\%$ \\
Row 1 & 21 & 41.26 & 7.95 & 19.26 \\
Row 2 & 21 & 36.71 & 8.30 & 22.61 \\
Row 3 & 21 & 37.15 & 8.48 & 22.84 \\
Row 4 & 21 & 35.82 & 10.37 & 28.96 \\
Row 5 & 21 & 42.12 & 11.86 & 28.16 \\
Mean of three & 21 & 36.56 & 9.05 & 24.80 \\
interior rows & 21 & 38.61 & 9.39 & 24.37 \\
Mean of & & & & \\
five rows & 21 & 36.56 & 8.11 & 22.18 \\
Three-row Plot & & & & \\
$\quad$ (Interior rows) & 21 & 38.61 & 8.29 & 21.47 \\
Five-row Plot & & & & \\
\hline
\end{tabular}

The variability of the single-row plots is 12 per cent higher on the average than that of the 3-row plots. That is, 3-row plots with 
borders discarded would have given in this case somewhat more variable results than 5 -row blocks with borders discarded. The same 5row blocks harvested entire (with borders retained) gave slightly less variable yields than when the borders were discarded.

The same comparison may be made in the check plots of the oats variety test of 1919 . The check variety was Red Rustproof, drilled at the rate of 10 pecks per acre in every ninth plot. The results are shown in Table 20.

TABLe 20.-Yield and Variability of Check Plots.

Single-row, Three-row, and Five-row-Oats Variety Test 1919.

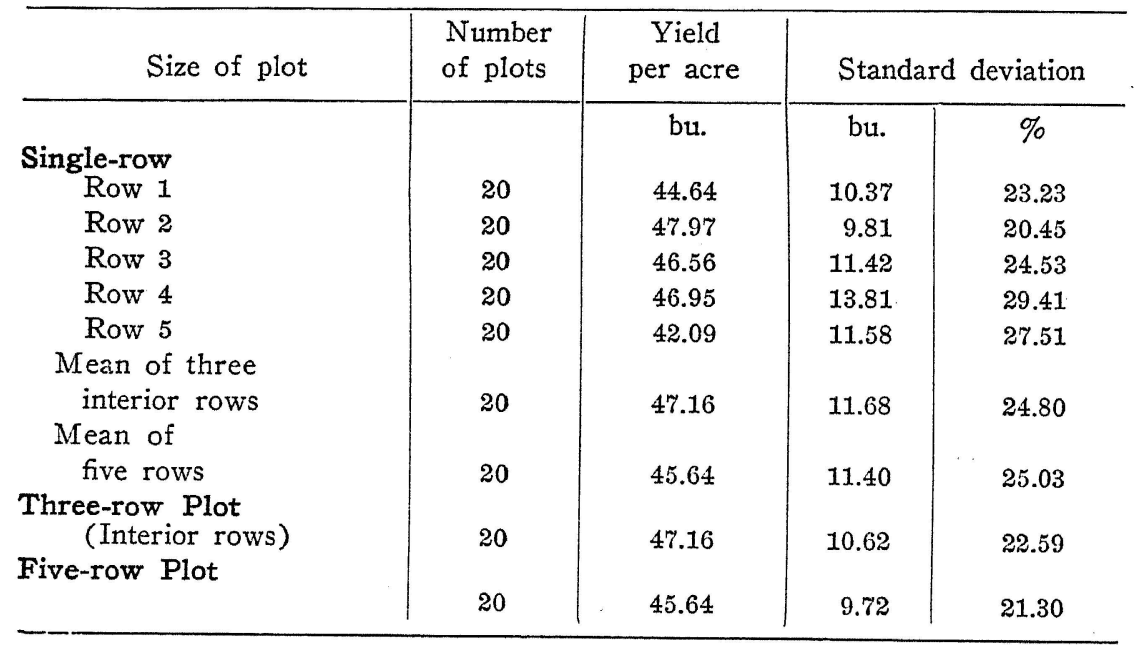

The results in this case are practically identical with those of the barley variety test. Protected single rows were 10 per cent more variable than protected 3-row blocks, while the latter were only 6 per cent more variable than unprotected 5-row blocks.

In the test of strains of Red Rustproof oats, conducted on the same field in 1919, adjoining the oats variety test, the same variety was used as check, and the crop was seeded on the same day with the same machine, but the check plots were in every sixth instead of every ninth plot. The corresponding data for these check plots are given in Table 21.

Although the variability of these plots is lower, the relative variability of plots of different sizes is similar to that of the variety test. The single interior rows are on the average 24 per cent more variable than the 3-row block. The 3-row plot is only very slightly more variable than the 5 -row plot. 
Table 21.-Yield and Variability of Cheick Plots.

Single-row, Three-row, and Five-row.-Oats Strain Test 1919.

\begin{tabular}{|c|c|c|c|c|}
\hline Size of plot & $\begin{array}{l}\text { Number } \\
\text { of plots }\end{array}$ & $\begin{array}{c}\text { Yield } \\
\text { per acre }\end{array}$ & Stanc & deviation \\
\hline & & bu. & bu. & $\%$ \\
\hline \multicolumn{5}{|l|}{ Single-row } \\
\hline Row 1 & 18 & 41.87 & 6.35 & · $\quad 15.15$ \\
\hline Row 2 & 18 & 40.88 & 5.52 & 13.51 \\
\hline Row 3 & 18 & 43.50 & 5.81 & 13.37 \\
\hline Row 4 & 18 & 45.00 & 7.31 & 16.25 \\
\hline Row 5 & 18 & 41.50 & 6.37 & 15.35 \\
\hline \multicolumn{5}{|l|}{ Mean of three } \\
\hline \multicolumn{5}{|l|}{ Mean of } \\
\hline five rows & 18 & 42.55 & 6.27 & 14.73 \\
\hline \multirow{2}{*}{\multicolumn{5}{|c|}{$\begin{array}{l}\text { Three-row Plot } \\
\text { (Interior rows) } \\
\text { Five-row Plot }\end{array}$}} \\
\hline & & & 4.86 & 11.41 \\
\hline
\end{tabular}

In the wheat variety test of 1920 the check variety was Fultz, which was seeded at the rate of six pecks per acre in.every seventh plot. The results of interest in this connection are shown in Table 22.

Table 22.-YIeld and Variability of Chiscks Plots.

Single-row, Three-row, and Five-row.-Wheat Variety Test 1920

\begin{tabular}{|c|c|c|c|c|}
\hline Size of plot & $\begin{array}{l}\text { Number } \\
\text { of plots }\end{array}$ & $\begin{array}{c}\text { Yield } \\
\text { per acre }\end{array}$ & Stand & viation \\
\hline & & bu. & bu. & $\%$ \\
\hline \multicolumn{5}{|l|}{ Single-row } \\
\hline Row 1 & 80 & 20.74 & 6.58 & 31.72 \\
\hline Row 2 & 80 & 17.28 & 5.02 & 29.05 \\
\hline Row 3 & 80 & 18.34 & 4.50 & 24.52 \\
\hline Row 4 & 80 & 17.29 & 5.10 & 29.48 \\
\hline Row 5 & 80 & 19.37 & 6.00 & 30.97 \\
\hline \multicolumn{5}{|l|}{ Mean of three } \\
\hline interior rows & 80 & 17.64 & 4.87 & 27.68 \\
\hline \multicolumn{5}{|l|}{ Mean of } \\
\hline five rows & 80 & 18.60 & 5.44 & 29.15 \\
\hline \multicolumn{5}{|l|}{$\begin{array}{l}\text { Three-row Plot } \\
\text { (Interior rows) }\end{array}$} \\
\hline \multicolumn{5}{|l|}{ Five-row Plot } \\
\hline & 80 & 18.63 & 4.77 & 25.60 \\
\hline
\end{tabular}


Again the single rows are distinctly more variable than the 3-row plot, in this case to the extent of 10 per cent. The 5-row and the 3 -row plots are about equally variable, the slight advantage in this case being in favor of the latter.

To summarize, it is evident that the protected 3-row plot is somewhat less subject to plot variability than the protected single-row, but the relative value of the 5-row plot harvested entire and the same plot harvested as a protected 3-row block is not clear. Some further comparison of these two methods was made in 1921. The variability of the check plots in both the wheat and oats tests was computed as protected 3-row and as unprotected 5-row plots. In the wheat tests the check variety was Poole, seeded at 5 pecks per acre in every seventh plot in the variety test, and in every sixth plot in the mixture test. In the oats tests the check variety was Kherson, seeded at 10 pecks per acre in every sixth plot. The results are shown in Table 23.

Table 23.-Yield and Variability of Check Plots. Three-row and Five-row.-Wheat and Oats Tests, 1921.

\begin{tabular}{|c|c|c|c|c|}
\hline Size of plot & $\begin{array}{l}\text { Number } \\
\text { of plots }\end{array}$ & $\begin{array}{c}\text { Yield } \\
\text { per acre }\end{array}$ & \multicolumn{2}{|c|}{ Standard deviation } \\
\hline & & bu. & bu. & $\%$ \\
\hline $\begin{array}{l}\text { Wheat Variety Test } \\
\text { Three-row Plots } \\
\text { (Interior rows) }\end{array}$ & 80 & 14.89 & 2.16 & 14.50 \\
\hline $\begin{array}{l}\text { Five-row Plots } \\
\text { Wheat Mixture Test }\end{array}$ & 80 & 13.98 & 1.90 & 13.61 \\
\hline $\begin{array}{l}\text { Three-row Plots } \\
\text { (Interior rows) }\end{array}$ & 30 & 15.48 & 3.25 & 20.98 \\
\hline $\begin{array}{l}\text { Five-row Plots } \\
\text { Oats Variety and Strain Tests }\end{array}$ & 30 & 15.78 & 3.55 & 22.49 \\
\hline $\begin{array}{l}\text { Three-row Plots } \\
\text { (Interior rows) }\end{array}$ & 120 & 37.95 & 4.61 & 12.15 \\
\hline Five-row Plots & 120 & 38.37 & 4.70 & 12.25 \\
\hline
\end{tabular}

In no case are the differences very great. The variability of 3-row blocks is slightly greater in the mixture test and that of 5-row blocks in the variety test of wheat. There is practically no difference between the two in the oats tests.

Apparently there is no constant material gain in plot uniformity obtained by the inclusion of the border rows of the 5-row plot, even though the size of the plot is materially increased by this procedure. Even if variability were decreased by their inclusion, the practice would be of doubtful value in most tests, for the reasons given in the last section; but with practically no decrease in variability there is left no 
reason for the harvesting of these rows. They are not wasted because they are not harvested, for they serve a valuable purpose; the waste would be involved rather in harvesting them, for the added labor and expense would contribute nothing to the accuracy of the experiment.

Although protected 3-row plots are less variable than protected single-row plots, they are not necessarily preferable. Three protected 3 -row plots require the same area as five protected single-row plots, and the harvesting of almost twice as large a crop (nine rows in the first case for every five in the second). If the mean yield of five single rows has as low a probable error as the mean yield of three 3 -row plots, the protected single-row plot will ordinarily be preferable, because of the reduction of labor in harvesting and threshing. When the standard deviation of the check plot yields is known, the probable error of the mean of any number of replicate plots can be computed and the number of replications for any given degree of accuracy determined. If single-row plots were 29 per cent more variable than 3-row plots, the probable errors of the mean of three 3 -row plots and of five single-row plots would be equal, since the probable error of the mean is equal to the probable error of a single determination divided by the square root of the number of determinations, and since the square root of 5 is 29 per cent greater than the square root of 3 . In the cases herein cited the advantage of the 3-row plots was considerably less than 29 per cent in every case, and we may confidently expect therefore that protected single-row plots repeated five times will be less variable than protected three-row plots repeated three times, which would require the same area and more labor.

Some further evidence on the relative variability of the protected 3 -row plot and the unprotected 5-row plot, or, in other words, of 5 -row plots, harvested with and without their border rows, may be obtained from the yields of the tested varieties and strains. Since the number of replications of each strain is small, average deviations are given instead of standard deviations. The inclusion of border rows in the 5-row plots should not increase variability, since the adjacent varieties are the same in each series, and the competitive effect should be no more variable than would be that of the same variety. A clear-cut comparison of 5-row and 3-row plots is therfore available in this case. In the case of the check plots this comparison was somewhat obscured by the competitive effect of different varieties on the border rows, which might be expected to increase variability and thus to conceal a possible advantage of the 5-row plot.

The average variability of 3 -row and 5-row plots in the strains tested in these experiments is shown in Table 24 . In each case the 
figure given is the mean of the average variabilities determined for all of the varieties or strains in the experiment.

\section{TABLe 24.- Yield and Variability of Test Plots. \\ Three-row and Five-row.}

\begin{tabular}{l|c|c|c|c|c|r|r}
\hline & Season & $\begin{array}{c}\text { Number } \\
\text { of vari- } \\
\text { eties }\end{array}$ & $\begin{array}{c}\text { Number } \\
\text { of Repli- } \\
\text { cations }\end{array}$ & $\begin{array}{c}\text { Three-row Plots } \\
\text { Yield } \\
\text { bu. per } \\
\text { acre }\end{array}$ & $\begin{array}{c}\text { Average } \\
\text { Devia- } \\
\text { tion } \\
\%\end{array}$ & $\begin{array}{c}\text { Five-row Plots } \\
\text { Yield } \\
\text { bu. per } \\
\text { acre }\end{array}$ & $\begin{array}{c}\text { Aver- } \\
\text { age } \\
\text { Devia- } \\
\text { tion } \\
\%\end{array}$ \\
\hline Barley varieties & 1919 & 27 & 3 & 22.06 & 15.35 & 21.95 & 15.44 \\
Oats strains & 1919 & 15 & 4 & 50.07 & 5.96 & 50.20 & 5.10 \\
Wheat varieties & 1920 & 96 & 4 & 13.39 & 24.27 & 13.78 & 24.36 \\
Wheat varieties & 1921 & 96 & 4 & 15.42 & 10.30 & 15.57 & 9.74 \\
Wheat mixtures & 1921 & 30 & 4 & 17.62 & 9.84 & 18.15 & 10.03 \\
Oats varieties & 1921 & 32 & 4 & 29.85 & 10.86 & 30.70 & 10.14 \\
Oats strains & 1921 & 64 & 4 & 28.40 & 10.82 & 28.63 & 10.58 \\
\hline
\end{tabular}

There is no consistent difference in variability between the 3-row plots and the 5-row plots. In some cases the former are more variable; in others the latter; and in no case is the difference in variability great. These results are contrary to the general impression that variability decreases with increase in size of plots. Apparently, in tests of this kind, the 3-row plot is large enough to give a fair sample and nothing is gained by adding the other two rows. When it is considered that the addition of these two rows undoubtedly introduces systematic error from competition to a greater or less extent, and involves a very considerable increase in the labor of harvesting and threshing, there remains little doubt that the border rows of 5-row plots are best discarcled in experiments of this sort.

Replication of Plots.-It is generally considered that the error from soil variability may be reduced to any desired point by replication in sufficient degree. For any given degree of precision the number of replications required is dependent on the variability of the replicate plots. When every plot in a single-row test is provided with two border rows the area required for the test is tripled, the replicate plots are separated more widely, and variability is usually increased, since the range of soil variability will usually be greater when a larger area is included.

The removal of border effect from the rows harvested for yield may in some cases reduce variability more than enough to balance this increase, but when the unprotected single rows are grown in the same order in each series, variability will not be much affected by competition, as before stated. Consequently more replications of single-row 
plots protected by borders than of the single-row plots not so protected may actually be required for a given degree of plot variability. Similarly, more replications may be required in a test of a large number of strains than in a test of a small number, as Montgomery ${ }^{14}$ has suggested.

The number of replications required may be determined with a fair degree of accuracy from the variability of the check plots. The variability of the check plots in parts of the large fields used as compared with the variability of the check plots in the whole fields shows the importance of this point. In Table 25 are given the standard de-

Table 25.-Relation of Plot Variability to Size of Experiment Field. Check Plots in Wheat Variety Test 1920.

\begin{tabular}{lcccc}
\hline Size of field & $\begin{array}{c}\text { No. of } \\
\text { Plots }\end{array}$ & $\begin{array}{c}\text { Yield } \\
\text { bur acre }\end{array}$ & $\begin{array}{c}\text { Standard deviation } \\
\text { bu. }\end{array}$ & $\%$ \\
\hline Four ranges (1st)* & 20 & 14.79 & 3.789 & 25.62 \\
Four ranges (2nd) & 20 & 18.35 & 4.073 & 22.20 \\
Four ranges (3rd) & 20 & 16.67 & 3.659 & 21.94 \\
Four ranges (4th) & 20 & 20.74 & 3.876 & 18.69 \\
$\quad$ Mean & 20 & 17.64 & 3.849 & 22.11 \\
Eight ranges (1st) & 40 & 16.57 & 4.316 & 26.05 \\
Eight ranges (2nd) & 40 & 18.71 & 4.285 & 22.90 \\
$\quad$ Mean & 40 & 17.64 & 4.302 & 24.48 \\
Sixteen ranges & 80 & 17.64 & 4.430 & 25.11 \\
\hline
\end{tabular}

*The four-range and eight-range sections are in order from west to east.

viations of the yields of the check plots in the wheat variety test of 1920. The yields of the three interior rows of the check plots were used in computing these constants.

Twenty-four varieties could have been replicated four times in the four ranges comprising any quarter of the field. As the probable error of a single plot yield is 14.92 per cent we may conclude that the probable error of the mean of four such yields would be about 7.46 per cent. But when 96 varieties must be tested, as they were in this test, four replications require 16 ranges. and the probable error of the mean yield becomes 8.47 per cent. A degree of precision which could be attained with four replications in a test covering four ranges could hardly be attained with five replications in a test covering sixteen ranges.

Corresponding data for the wheat variety test of 1921 are given in Table 26. Although the variability in this experiment was much lower, the relative variability of large and small experiment fields was 
TABLE 26.-RELAtion of Plot Variability to Size of Experiment Field. Check Plots in Wheat Variety Test 1921.

\begin{tabular}{lcccc}
\hline Size of field & $\begin{array}{c}\text { No. of } \\
\text { Plots }\end{array}$ & $\begin{array}{c}\text { Yield } \\
\text { ber acre }\end{array}$ & $\begin{array}{c}\text { Standard } \\
\text { bu. }\end{array}$ & $\begin{array}{c}\text { Deviation } \\
\%\end{array}$ \\
\hline Four ranges (1st)* & 16 & 15.78 & 1.584 & 10.04 \\
Four ranges (2nd) & 16 & 15.48 & 1.586 & 10.25 \\
Four ranges (3rd) & 16 & 15.28 & 2.099 & 13.74 \\
Rour ranges (4th) & 16 & 13.01 & 2.091 & 16.07 \\
$\quad$ Mean & 16 & 14.89 & 1.840 & 12.53 \\
Eight ranges (1st) & 32 & 15.63 & 1.592 & 10.19 \\
Eight ranges (2nd) & 32 & 14.14 & 2.383 & 16.85 \\
$\quad$ Mean & 32 & 14.89 & 1.988 & 13.52 \\
Sixteen ranges & 64 & 14.89 & 2.159 & 14.50 \\
\hline
\end{tabular}

*The four-range and eight-range sections are in order from west to east.

similar. Again the degree of accuracy obtained with four replications in four ranges would have been unattainable with five replications in 16 ranges.

The oats variety test and strain test in 1921 were contiguous, occupying 24 ranges, with 120 check plots of Kherson oats, or one in every sixth plot. The variability of these check plots in sections of

Table 27.-Relation of Plot Variability to Size of Experimen't Field. Check Plots in Oats Variety and Strain Test, 1921.

\begin{tabular}{lcccr}
\hline Size of field & $\begin{array}{c}\text { No. of } \\
\text { plots }\end{array}$ & $\begin{array}{c}\text { Yield } \\
\text { per acre }\end{array}$ & $\begin{array}{c}\text { Standard deviation } \\
\text { bu. }\end{array}$ & $\%$ \\
\hline Four ranges (1st) & 20 & 35.81 & 4.75 & 13.26 \\
Four ranges (2nd) & 20 & 34.95 & 2.90 & 8.30 \\
Four ranges (3rd) & 20 & 38.14 & 4.21 & 11.04 \\
Four ranges (4th) & 20 & 39.60 & 4.66 & 11.77 \\
Four ranges (5th) & 20 & 38.91 & 4.14 & 10.65 \\
Four ranges (6th) & 20 & 40.31 & 4.14 & 10.27 \\
$\quad$ Mean & 20 & 37.95 & 4.13 & 10.88 \\
Eight ranges (1st) & 40 & 35.38 & 3.96 & 11.19 \\
Eight ranges (2nd) & 40 & 38.87 & 4.50 & 11.58 \\
Eight ranges (3rd) & 40 & 39.60 & 4.21 & 10.62 \\
$\quad$ Mean & 40 & 37.95 & 4.22 & 11.13 \\
Twelve ranges (1st) & 60 & 36.30 & 4.25 & 11.71 \\
Twelve ranges (2nd) & 60 & 39.60 & 4.36 & 11.01 \\
$\quad$ Mean & 60 & 37.95 & 4.31 & 11.36 \\
Twenty-four ranges & 120 & 37.95 & 4.61 & 12.15 \\
\hline
\end{tabular}


four, eight, and twelve ranges, and in the whole field of 24 ranges, is shown in Table 27.

The variability of the whole field of 24 ranges was 12 per cent greater than the average variability of sections of four ranges each. In this case again, five replications in the larger field would have given less accurate results than four replications in the smaller.

In each of the cases cited above a steady increase in variability is apparent as the size of the experiment field is increased. It is obvious that the substitution of 3-row plots with discarded borders for single rows will result in greater variability, and will require increased replication for the same degree of accuracy.

From the foregoing statements it will be clear that the number of replications necessary for a given degree of accuracy may vary considerably with conditions. The number to be used in any specific experiment should be determined from the variability of the field in question and the degree of accuracy required. The variability of the check plots is usually considered a measure of the variability of the field. But when the number of replications to be used or the extent of experimental error is determined from the variability of the check plots, it is assumed that the variability of different varieties of the same crop is approximately the same under the same conditions. This of course is not strictly true. The yield of two varieties may be determined by very different factors, as has been stated, and their relative variability may also be quite different. The variability of 120 plots

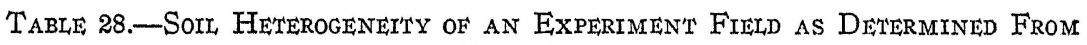
YIELDS of Two Check Varietires.

Oats Variety and Strain Tests. 1921.

\begin{tabular}{lcccccc}
\hline \multirow{2}{*}{ Check variety } & \multirow{2}{*}{$\begin{array}{c}\text { Number } \\
\text { of plots }\end{array}$} & $\begin{array}{c}\text { Average } \\
\text { yield } \\
\end{array}$ & & bu. & $\begin{array}{c}\text { Standard deviation } \\
\text { bu. }\end{array}$ & \multicolumn{3}{c}{$\begin{array}{c}\text { Probable error of a } \\
\text { single yield determination } \\
\text { bu. }\end{array}$} & $\%$ \\
\hline Kherson & 120 & 37.95 & 4.61 & 12.15 & 3.11 & 8.20 \\
Red Rustproof & 120 & 22.44 & 3.99 & 17.78 & 2.69 & 11.99 \\
\hline
\end{tabular}

each of Kherson and Red Rustproof oats, grown side by side as check plots in the oats variety and strain test of 1921, illustrate the possibility of a serious error in the use of the standard deviation of check plots as a measure of the variability of an experiment field. These determinations are shown in Table 28.

The field would have been considered decidedly less variable if Kherson had been used as the check variety than if Red Rustproof had 
been used. Both of these are standard recommended varieties for the region, though they differ decidedly in their characteristics. Both have been used frequently as check varieties at the Missouri station in past seasons. From the variability of the Kherson check plots the mean yield of four replicate plots in this experiment would be considered to have a probable error of 4.10 per cent; from the Red Rustproof plots the same determination would be given a probable error of 6.00 per cent. A degree of precision for which we would assume four replications necessary, judging from the Kherson check, would require nine replications according to the yields of the Red Rustproof check.

The importance of choosing a check variety typical of the varieties tested, if its variability is to be considered a criterion of the variability of the field, is obvious. Whether it is possble to choose a "typical variety" for the purpose, in the case of ordinary variety tests, remains to be seen.

\section{ADJUSTMENT OF YIELDS BY IMEANS OF CHECK PLOTS}

Adjustment of plot yields by the use of check plots has been a common practice in field experiments during recent years. It is recognized that no experiment field is perfectly uniform in productivity, and the attempt is made, by means of the check plot adjustment, to compensate the varieties or treatments which chance to be located on the less productive plots for the resulting loss in yield. The common method, in variety tests, is to distribute over the field, as frequently as practicable, check plots planted to the same variety and similarly handled in every way. The variation in yield among these check plots is then considered a measure of the productivity of the soil. By various methods, differing only in detail, the yields of the test plots in parts of the field giving high check yields are reduced, and those of test plots in parts giving low check yields are increased, in proportion to the productivity of the soil, as indicated by the yields of neighboring check plots.

Previous Investigation.-Several investigations of the effect of such adjustment on the variability of replicate plots have been reported. The majority of these have been conducted in connection with experiments of the type discussed in the preceding section, in which uniformly handled fields have been harvested in small sections. Certain of these sections, or plots, have been considered check plots, and on the basis of their yields the yields of the remaining plots have been 
adjusted. The reduction of variability of the adjusted plot yields is the measure of the efficiency of the method.

Morgan $^{15}$ reports an experiment of this sort, in which 63 plots, planted first to wheat and then to fodder corn, in the same season, were used. The variability of the plot yields was steadily reduced as the number of check plots was increased.

In a similar experiment reported by Lyon ${ }^{11}$, in which 37 replicate $1 / 100$ acre plots of corn were harvested, the use of checks in every second or third plot was found to reduce variability, but they were of little value when farther apart.

Montgomery $^{1 *}$ states that alternating check plots with test plots gives a high degree of accuracy, but the total number of plots required when this method is used is greater than when the same degree of accuracy is attained by the use of replication.

Kiesselbach ${ }^{5}$ reports a comprehensive trial of three methods of adjusting yields by means of check plots in a uniform field of 207 $1 / 30$-acre plots of Kherson oats. The effect on plot variability is shown in Table 29.

Table 29,-Eitrict on Plot Variability of Adjusting Yieldos by Check Pl,OTS (KIESSELBACH).

\begin{tabular}{ccc}
\hline $\begin{array}{c}\text { Method of } \\
\text { adjustment }\end{array}$ & $\begin{array}{c}\text { Coefficient } \\
\text { of variability } \\
\text { Actual } \\
\text { yields }\end{array}$ & $\begin{array}{c}\text { Adjusted } \\
\text { yields }\end{array}$ \\
\hline $\begin{array}{c}\text { Alternate check plots. } \\
\text { Correction based on } \\
\text { average of two ad- } \\
\text { jacent checks }\end{array}$ & 7.85 & 7.01 \\
$\begin{array}{c}\text { Checks every third plot. } \\
\text { Correction based on one } \\
\text { adjacent check plot }\end{array}$ & 7.79 & 7.35 \\
$\begin{array}{c}\text { Checks every third plot. } \\
\text { Correction by progres- } \\
\text { sive method, based on } \\
\text { two nearest checks }\end{array}$ & & \\
\hline
\end{tabular}

From these results Kiesselbach concludes "The yield of systematically distributed check plats cannot be regarded as a reliable measure for correcting and establishing correct theoretical or normal yields for the intervening plats."

It should be noted at this point that even if adjustment by check yields were found invariably effective in experiments of this sort, 
its value in ordinary variety testing would not be definitely established. The practice involves not only the assumption that the yields of the check plots are a fair indication of the productivity of the intervening plots for the check variety, but the further assumption that different varieties respond similarly to differing growing conditions. Adjustment of yields should therefore give better results in such experiments as those cited above than it could be expected to give in actual variety tests.

This point is well illustrated by observations reported by Salmon ${ }^{10}$. Two varieties of barley, Gatami and Odessa, were grown side by side in fiftieth-acre plots in five distributed portions of a field. Gatami gave an average yield of 18.3 bushels per acre, with quite uniform yields in the five plots, as evidenced by their probable error of 0.68 bushel, while Odessa yielded 13.3 bushels per acre in the first plot, 6.35 bushels per acre in the second, and a negligible yield in the other three. Obviously the adjustment of the yield of either of these varieties on the basis of the other variety as a check, would enormously increase rather than decrease the experimental error. As Salmon points out, an error similar in kind though less in degree may occur commonly in variety tests, when the yields of varieties are determined by different limiting factors. And if this is generally the case, adjustment by check yields will be of doubtful value, even if it were found to eliminate variability completely in uniform plot tests.

There is a growing tendency, consequently, to discontinue the use of check plots for adjusting yields in variety tests, and to use them only to measure soil variability and to indicate the degree of error in yield determinations of the tested varieties. Adjustment of yields has never been as common in preliminary tests as in tests on larger plots, principally because of the great amount of computation necessary in adjusting the yields of ten or twenty replicate rod-rows of a large number of varieties, and because the yield of a single rod-row, exposed to varying competition and materially affected by small mechanical errors, is at best a very unreliable measure of productivity on which to base the adjustment of the yields of several other plots.

Experimental Results.-It would of course be very desirable to use check plots for reducing plot variability, if the method could be relied on, because of the economy of the practice. The only certain method of reducing plot variability is by means of replication, and it may be considered a fairly general rule that the variability of plots on a given field, as measured by the standard deviation or the probable error, will in general be reduced by replication in proportion to the square root of the number of replications. In other words, the 
variability of the mean of 16 replicate plots will be about half that of the mean of 4 replicate plots. Now the maximum use of check plots, that is, the practice of alternating check plots and test plots, requires the same land and labor as would be required by doubling the number of replications, if no check plots were used. As doubling the number of replications will in general give a standard deviation about equal to the original standard deviation divided by the square root of

2 , it will reduce variability about $30 \%\left(\frac{1}{\sqrt{2}}=.7071\right)$. If alternating with check plots will consistently reduce variability more than 30 per cent it will be generally a more economical way to control error. Similarly, the use of check plots in every third plot requires as much land as would be required by increasing the number of replications by 50 per cent (using three replications instead of two, or fifteen instead of ten). From this relation the reduction of variability necessary if this practice is to equal replication in effectiveness can be easily computed. Such determinations for check plots at various intervals are shown in Table 30.

Table 30.-Reduction of Variability by The USE of Check Plots Equivalent to That Probably Attainable With the Same Number

OF PLOTS BY REPLICATION.

\begin{tabular}{lcc}
\hline $\begin{array}{c}\text { Distribution of } \\
\text { check plots }\end{array}$ & $\begin{array}{c}\text { Equivalent increase in } \\
\text { number of replications } \\
\%\end{array}$ & $\begin{array}{c}\text { Redundard deviation to } \\
\text { be expected by such } \\
\text { increase in replication } \\
\%\end{array}$ \\
\hline Alternate plots & 100.00 & 29.29 \\
Every third plot & 50.00 & 18.35 \\
Every fourth plot & 33.33 & 13.50 \\
Every fifth plot & 25.00 & 10.55 \\
Every sixth plot & 20.00 & 8.71 \\
Every seventh plot & 16.67 & 7.41 \\
Every eighth plot & 14.29 & 6.47 \\
Every ninth plot & 12.50 & 5.75 \\
Every tenth plot & 11.11 & 5.12 \\
\hline
\end{tabular}

If protected single-row or 3-row plots are used in preliminary experiments a more reliable measure of soil productivity is available, and consequently the adjustment of yields is more likely to be of value, than when unprotected single-row plots are used. By the use of planting plans of the sort employed in these experiments, it is pos- 
sible to adjust the yields by a somewhat shortened method. If adjustment of yield is effective in reducing plot variability in this sort of test it can be accomplished with but little increase in labor. In each of the tests reported in this paper a trial of the effectiveness of adjusting yields by means of check plots was made, the criterion of accuracy being in each case the variability of the yields of the replicate plots of each variety. Since the number of replicate plots was only three or four the average deviation was determined instead of the standard deviation.

Method Used in Adjusting Yields. - The method employed in adjusting yields may be described as follows: The average yield of all check plots and the relative yield of each check plot in terms of this average (that is, the quotient obtained by dividing the yield of the individual check plot by the average yield of all check plots) were determined. The relative yield of each check plot, expressed in percentage of the mean check yield, is designated hereafter as the "plot value" of that check plot. When the average yield of all check plots is 25 bushels per acre, the plot value of a check plot yielding 30 bushels per acre is 120 per cent-in other words it is 20 per cent more productive than the average. Now assuming gradual change in the productivity of the soil between check plots, each test plot is assigned a plot value by interpolation. The adjusted yield of each plot is then determined by dividing the actual yield by the plot value.

The short method for adjusting yields, referred to above, is based on the fact that the varieties occur in the same order in each series. Thus in the field diagrammed in figure 1 , the following sequence of plots occurs in each of the four series:

\section{$\begin{array}{llllllll}c k & 1 & 17 & 33 & 49 & 65 & 81 & \mathrm{ck}\end{array}$}

Now if the average yield of the four check plots adjoining variety 1 , and the average yield of the four check plots adjoining variety 81 are each given a plot value, corresponding plot values for the mean yields of varieties $1,17,33,49,65$, and 81 may be interpolated, and the mean yields may be adjusted in one operation. The same method may be used, of course, regardless of the number of replications. The result will not be exactly the same as that of averaging the adjusted yields determined individually, but will in most cases approximate it closely, the slight difference being caused by the disproportion of yield and plot value in the plots averaged. It is doubtful that either method is consistently more accurate than the other.

When the check plot yield is used in the adjustment of the yields of other plots it is of course essential that it should be a reliable determination, not unduly affected by factors not affecting the neighbor- 
ing plots. For example if the yield of a check plot is reduced 20 per cent by a poor stand, the adjusted yields of neighboring plots will be increased to the same extent as if the check plot yield had been low because of poor soil, and will consequently be considerably higher than they should be. It is important therefore that conditions be made as favorable as possible for accurate yield testing when this method is used. One cause for poor results in the adjustment of yield in some of the experiments reported in this paper was failure to protect the outside strip of check plots by means of border rows, in a few of the tests, be-

Table 31.-Relatrve Variability of Actual and Adjusted Yinids. Average Deviation in Percentage of Yield.-Barley Variety Test 1919.

\begin{tabular}{rlrrrr}
\hline & & \multicolumn{4}{c}{ Average deviation } \\
Planting \\
number & Variety & Actual & yields & Adjusted yields \\
& & interior rows & 5 rows & 3 interior rows & 5 rows \\
& & $\%$ & $\%$ & $\%$ & $\%$ \\
\hline 1 & Hanna 906 & 19.81 & 17.82 & 13.15 & 10.80 \\
2 & Steigum 907 & 15.17 & 18.79 & 13.48 & 8.40 \\
3 & Luth 908 & 29.97 & 28.17 & 5.51 & 4.62 \\
4 & Eagle 913 & 26.14 & 29.79 & 9.71 & 12.98 \\
6 & Servian 915 & 18.37 & 17.97 & 7.36 & 5.59 \\
7 & Odessa 916 & 2.31 & 4.33 & 23.99 & .17 .01 \\
8 & Lion 923 & 14.65 & 12.10 & 11.37 & 11.03 \\
10 & Horn 926 & 4.08 & 2.00 & 16.45 & 12.74 \\
11 & Odessa 927 & 13.62 & 9.16 & 21.62 & 13.76 \\
12 & Summit 929 & 5.28 & 6.45 & 14.23 & 11.59 \\
13 & Mariout 932 & 11.02 & 11.57 & 18.68 & 14.31 \\
14 & Odessa 934 & 13.73 & 13.91 & 11.18 & 10.31 \\
15 & Peruvian 935 & 13.25 & 17.87 & 12.42 & 16.82 \\
16 & Trebi 936 & 11.27 & 12.53 & 18.78 & 18.28 \\
18 & Oderbrucker 940 & 10.77 & 14.46 & 13.60 & 15.98 \\
19 & Frankish 953 & 20.53 & 19.65 & 22.63 & 18.49 \\
20 & Manchuria 956 & 6.88 & 6.33 & 13.89 & 10.68 \\
21 & Oderbrucker 957 & 17.88 & 13.62 & 1.97 & 3.27 \\
22 & Manchuria x Champion & 39.47 & 39.19 & 21.93 & 20.35 \\
& of Vermont & & & & \\
23 & Luth 972 & 16.77 & 18.61 & 7.05 & 7.48 \\
24 & Red River 973 & 13.94 & 11.02 & 12.37 & 12.33 \\
25 & Featherston 1118 & 21.40 & 20.89 & 8.47 & 13.39 \\
26 & Featherston 1119 & 16.59 & 15.25 & 4.78 & 12.26 \\
27 & Featherston 1120 & 15.91 & 13.64 & 2.48 & 6.44 \\
28 & Hanna x Champion & 16.00 & 16.81 & 28.36 & 28.50 \\
& of Vermont 1121 & & & & \\
29 & Manchuria 1125 & 6.79 & 14.42 & 7.78 & 1.55 \\
30 & Malting 1129 & 12.86 & 10.40 & 5.40 & 9.02 \\
& $\quad$ Mean & 15.35 & 15.44 & 12.91 & 12.15 \\
\hline & & & & &
\end{tabular}


cause of lack of space. The check plots growing on the border of the field were materially reduced in yield, in some cases, notably the oats strain test of 1919 and the wheat variety test of 1921 . In these cases the variability of the actual and adjusted yields has been computed both for all series and for the remaining series when the one affected by an unreliable check is discarded.

Relative Variability of Actual and Adjusted Yields.-The relative variability of actual and adjusted yields of both 3-row and 5-row plots in the barley variety test is shown in Table 31 . In this test there were three replications, and the check variety was Oderbrucker, in every

Table 32.-Relative Variability of Actual and Adjusted Yinids. Average Deviation in Percentage of Yield

Oats Variety Test 1919.

\begin{tabular}{|c|c|c|c|c|c|}
\hline \multirow{3}{*}{$\begin{array}{l}\text { Planting } \\
\text { number }\end{array}$} & \multirow{3}{*}{ Variety } & \multicolumn{4}{|c|}{ Average Deviation } \\
\hline & & \multicolumn{2}{|c|}{$\begin{array}{c}3 \text { Series } \\
\text { (3 interior rows) }\end{array}$} & \multicolumn{2}{|c|}{$\begin{array}{c}4 \text { Series } \\
\text { (3 interior rows) }\end{array}$} \\
\hline & & $\begin{array}{c}\text { Actual } \\
\text { yields } \\
\%\end{array}$ & $\begin{array}{c}\text { Adjusted } \\
\text { yields } \\
\%\end{array}$ & $\begin{array}{c}\text { Actual } \\
\text { yields } \\
\%\end{array}$ & $\begin{array}{c}\text { Adjusted } \\
\text { yields } \\
\%\end{array}$ \\
\hline 1 & A. sterilis nigra & 4.32 & 1.46 & 9.18 & 5.02 \\
\hline 2 & Black Mesdag & 9.03 & 9.69 & 7.29 & 12.90 \\
\hline 3 & C. I. 602 & 13.72 & 16.00 & 16.30 & 13.63 \\
\hline 3 & C. I. 603 & 4.72 & 3.09 & 5.84 & 3.88 \\
\hline 5 & C. I. 620 & 4.73 & 10.14 & 11.24 & 13.67 \\
\hline 6 & Early Champion & 18.63 & 15.18 & 14.97 & 14.65 \\
\hline 7 & Early Gothland & 14.20 & 4.67 & 11.55 & 4.18 \\
\hline 8 & Garton 473 & 5.99 & 6.25 & 8.42 & 9.42 \\
\hline 9 & Garton 585 & 14.08 & 19.44 & 16.92 & 19.95 \\
\hline 10 & Golden Giant & 9.44 & 14.31 & 14.40 & 15.09 \\
\hline 11 & Irish Victor & 9.69 & 3.29 & 7.72 & 16.40 \\
\hline 12 & Japanese Selection & 6.87 & 4.71 & 11.85 & 5.20 \\
\hline 13 & June & 18.37 & 11.19 & 17.53 & 10.37 \\
\hline 14 & Kherson Selection & 17.01 & 9.20 & 15.06 & 20.36 \\
\hline 15 & Fulghum & 9.69 & 11.36 & 13.06 & 17.32 \\
\hline 16 & Lincoln & 21.07 & 12.54 & 16.56 & 11.83 \\
\hline 17 & Monarch & 6.12 & 4.55 & 9.06 & 33.36 \\
\hline 18 & North Finnish & 8.69 & 5.17 & 7.84 & 27.03 \\
\hline 19 & Scottish Chief & 5.05 & 4.28 & 5.10 & 15.42 \\
\hline 20 & Sparrow bill (Missouri) & 10.98 & 10.82 & 12.38 & 13.15 \\
\hline 21 & Sparrow bill (Cornell) & 4.45 & 3.25 & 12.11 & 3.85 \\
\hline 22 & Tobolsk 1 & 6.17 & 3.85 & 13.92 & 5.38 \\
\hline 23 & Tobolsk 2 & 11.56 & 9.24 & 20.35 & 13.96 \\
\hline 24 & White Tartar & 10.94 & 4.75 & 9.51 & 4.54 \\
\hline & Mean & 10.23 & 8.27 & 12.01 & 12.94 \\
\hline
\end{tabular}


sixth plot. As a result of the adjustment of yields, the average deviation of 3-row plots was reduced from 15.35 per cent to 12.91 per cent, a reduction of 16 per cent, and that of 5-row plots from 15.44 per cent to 12.15 per cent, a reduction of 21 per cent.

The relative variability of actual and adjusted yields in the oats variety test of 1919 is shown in Table 32. In this field the check, Red Rustproof, was in every ninth plot. When the series affected by the faulty check yields of the border plots is included the variability of the adjusted yields is slightly higher than that of the actual yields, but when this series is discarded the average variability as measured by the mean deviation is reduced 19 per cent.

It might be expected that the oats strains grown on the same field would show a greater reduction of variability than the varieties, since practically all of them were of the same variety as the check, and since

Table 33.-Relative Variability of Actual and Adjustet Yifidds. Average Deviation in Percentage of Yield.

Oats Strains Test 1919.

\begin{tabular}{|c|c|c|c|c|c|}
\hline \multirow{3}{*}{$\begin{array}{l}\text { Planting } \\
\text { number }\end{array}$} & \multirow{3}{*}{$\begin{array}{l}\text { Accession } \\
\text { number }\end{array}$} & \multicolumn{4}{|c|}{ Average deviation } \\
\hline & & \multicolumn{2}{|c|}{ Actual yields } & \multicolumn{2}{|c|}{ Adjusted yields } \\
\hline & & $\begin{array}{c}3 \text { interior rows } \\
\%\end{array}$ & $\begin{array}{l}5 \text { rows } \\
\%\end{array}$ & $\begin{array}{c}3 \text { interior rows } \\
\%\end{array}$ & $\begin{array}{l}5 \text { rows } \\
\%\end{array}$ \\
\hline 1 & 0119 & 10.30 & 7.75 & 11.22 & 8.81 \\
\hline 2 & 0120 & 4.70 & 6.58 & 3.01 & 1.76 \\
\hline 3 & $0121 *$ & 5.76 & 3.25 & 4.57 & 4.14 \\
\hline 4 & 0122 & 4.62 & 3.52 & 6.46 & 3.82 \\
\hline 5 & 0123 & 9.91 & 8.25 & 11.47 & 9.62 \\
\hline 6 & 0125 & 3.18 & 3.34 & 5.39 & 6.60 \\
\hline 7 & 0126 & 7.62 & 5.95 & 10.56 & 16.58 \\
\hline 8 & $0127 *$ & 6.76 & 5.09 & 6.92 & 9.85 \\
\hline 9 & $0124^{*}$ & 6.13 & 6.34 & 4.92 & 4.59 \\
\hline 10 & 0133 & 7.07 & 4.77 & 3.92 & 5.36 \\
\hline 11 & 0128 & 4.17 & 3.56 & 3.58 & 3.36 \\
\hline 12 & 0129 & 5.02 & 7.07 & 5.94 & 6.35 \\
\hline 13 & 0130 & 4.20 & 2.62 & 6.74 & 9.72 \\
\hline 14 & 0131 & 2.59 & 2.59 & 4.98 & 2.94 \\
\hline \multirow[t]{2}{*}{15} & 0132 & 7.38 & 5.81 & 12.38 & 12.08 \\
\hline & Mean & 5.96 & 5.10 & 6.80 & 7.04 \\
\hline
\end{tabular}

* Not taxonomically Red Rustproof.

the check plots were more frequent, being in every sixth plot. The results of adjusting yields in this test, both for protected 3-row plots and for unprotected 5-row plots in four series are shown in Table 33. Contrary to expectation, the variability was not reduced by adjustment 
TABle 34.-Reilative Variability of Actual and Adjusted Yields.

Average Deviation in Percentage of Yield.-Wheat Variety Test 1920.

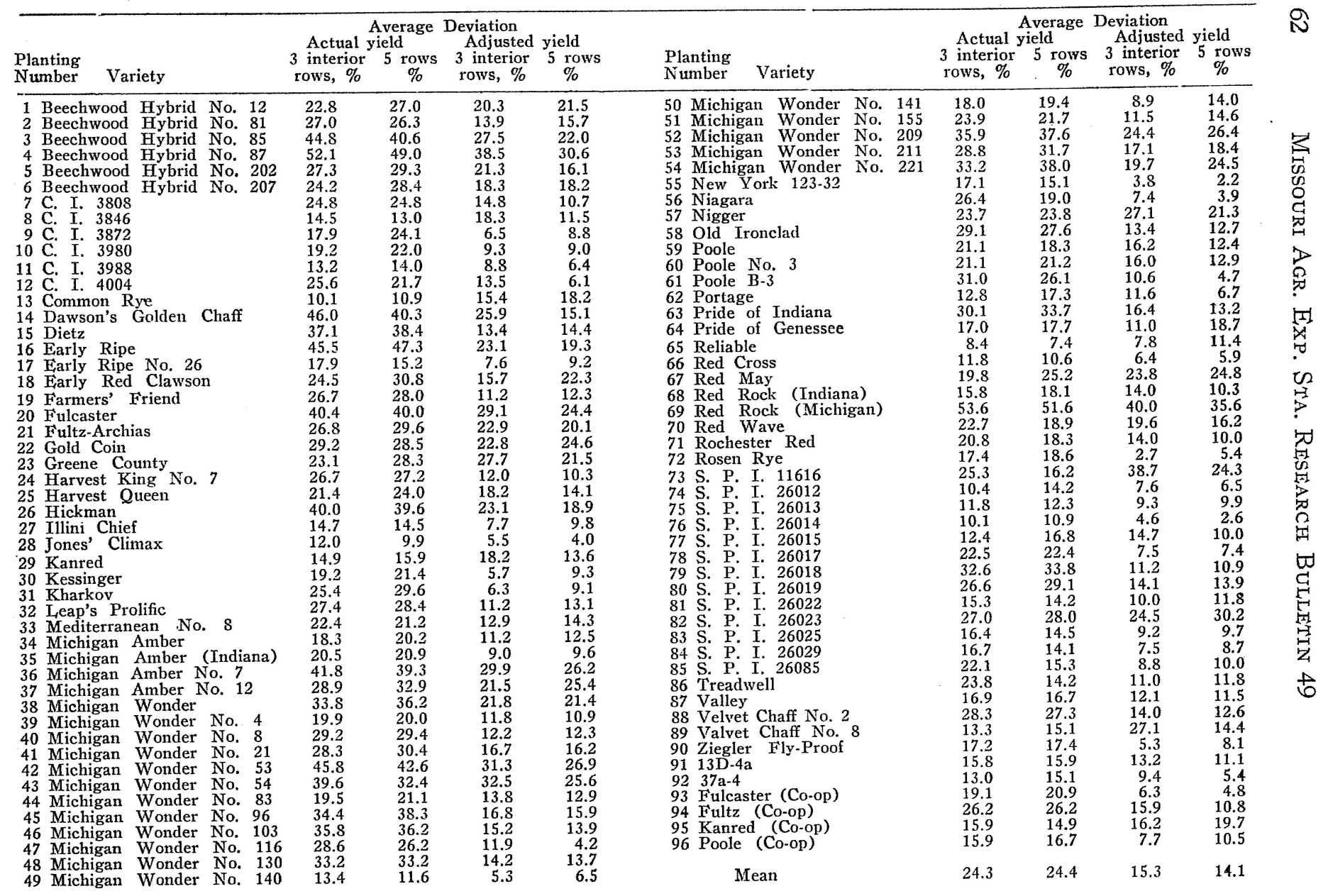


of yield. A possible explanation is the extremely low variability of the actual yields, indicating that the field, which was quite small, was relatively uniform. Any gain in uniformity from a check adjustment of yields would of course be expected to be greater in highly variable than in more uniform fields. The relative uniformity of this field is indicated not only by the low mean deviation of the test plots, but also by the low standard deviation of the check plots, which was only 11.68 per cent, as compared with a standard deviation of 22.59 per cent in the check plots of the adjoining oats variety test.

The effect of adjusting yields on the variability of 3-row and 5-row plots in the wheat variety test of 1920 is shown in Table 34 . In this test the check variety, Fultz, was grown in every seventh plot. There were four series of the ninety-six varieties.

The reduction in variability was very marked, being 37 per cent for 3-row plots and 42 per cent for 5 -row plots. The variability of almost every variety was reduced, and the reliability of the results was undoubtedly much increased.

The wheat variety test of 1921 , occupying an equal area on a neighboring field, and with similar varieties and the same planting plan, gave decidedly different results. In this field the check variety was Poole. Several check plots on the border were abnormal, and the computations are therefore given both for three series and for four, the series affected by the abnormal check yields being discarcled in the former case. The relative variability of actual and adjusted yields is shown in Table 35 .

Although the check yields are somewhat less variable for three series than for four, the adjustment was not effective in either case in reducing variability. The adjusted yields are 10 per cent more variable than the actual yields for the three series and 34 per cent higher for the four.

Similar results were obtained in the wheat mixture test of the same season, in which several of the same varieties were included, and the same check variety was used. In this test the check variety was in every sixth plot, and four replications were used. The results of adjusting yields are shown in Table 36. Variability was increased from 9.84 per cent to 13.81 per cent, an increase of 40 per cent. Thus the results of adjusting yields of wheat varieties in 1921 are directly contrary to the results of the same practice in 1920 .

Difference in Results Obtained by Adjustment with Different Check Varieties.-In the oats variety and strain tests of 1921, two check varieties, Kherson and Red Rustproof, were grown. In these tests 96 strains were included, 32 of Kherson, 32 of Red Rustproof, and 
Table 35.-Reilative Variability of Actual and Adjusted Yifids.

Average Deviation in Percentage of Yield.-Wheat Variety Test 1921.

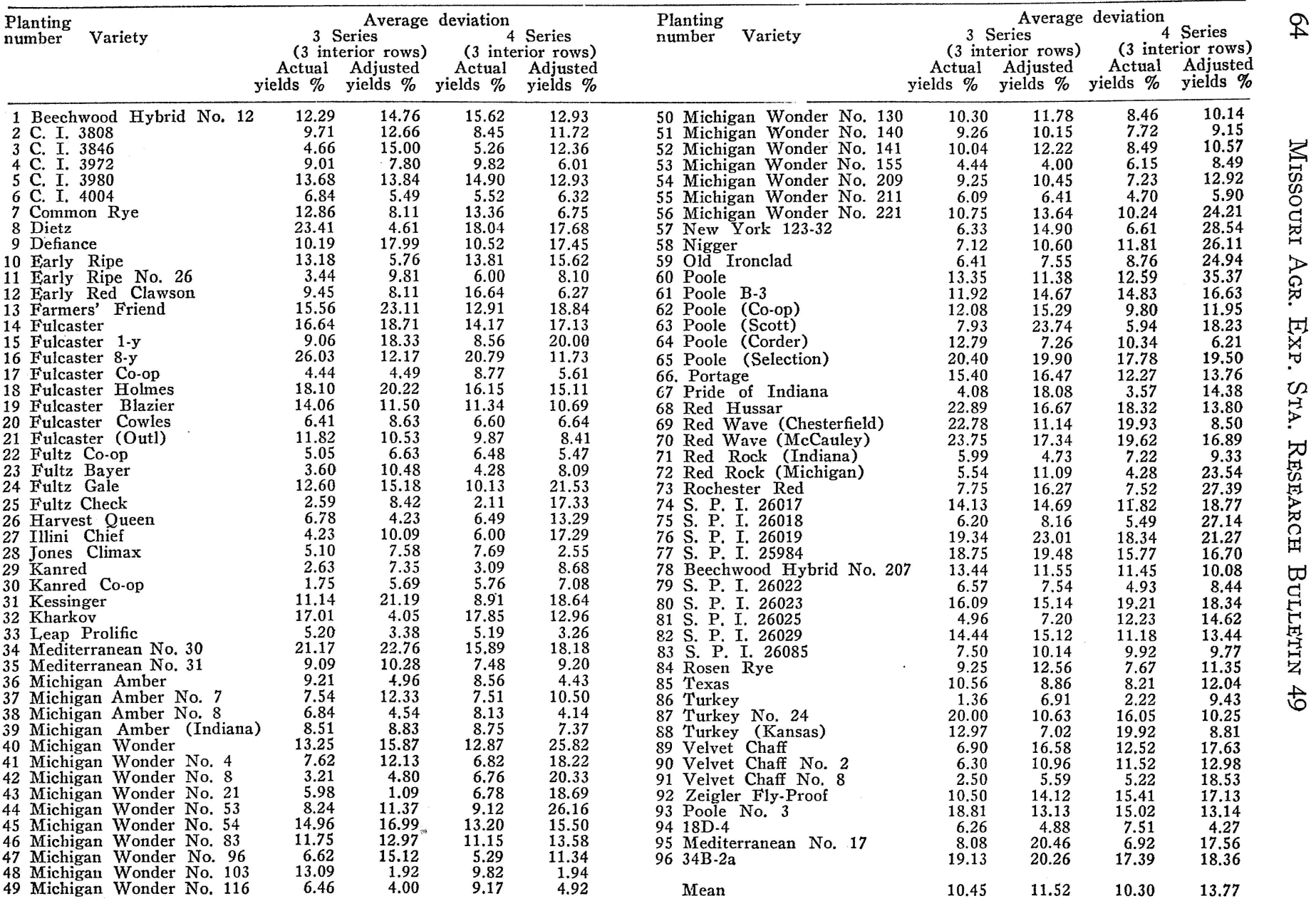


Tabie. 36-Relative Variability of Actual and Adjusted Yields. Average Deviation in Percentage of Yield. Wheat Mixture Test 1921

\begin{tabular}{|c|c|c|c|}
\hline \multirow[b]{2}{*}{$\begin{array}{l}\text { Planting } \\
\text { number }\end{array}$} & \multirow[b]{2}{*}{ Variety } & \multicolumn{2}{|c|}{ Average Deviation } \\
\hline & & $\begin{array}{c}\text { Actual yields } \\
\text { (3 interior } \\
\text { rows) } \\
\%\end{array}$ & $\begin{array}{c}\text { Adjusted yields } \\
\text { (3 interior } \\
\text { rows) } \\
\%\end{array}$ \\
\hline 1 & Fulcaster & 9.67 & 16.90 \\
\hline 2 & Harvest Queen & 9.35 & 21.47 \\
\hline 3 & Mixture No. 1 & 6.12 & 20.11 \\
\hline 4 & Michigan Wonder & 7.88 & 20.51 \\
\hline 5 & Nigger & 2.33 & 20.16 \\
\hline 6 & Michigan Wonder No. 31 & 4.93 & 13.86 \\
\hline 7 & Michigan Wonder No. 54 & 12.96 & 16.03 \\
\hline 8 & Mixture No. 2 & 15.38 & 17.86 \\
\hline 9 & Michigan Wonder No. 96 & 4.99 & 13.88 \\
\hline 10 & Michigan Wonder No. 209 & 5.30 & 14.83 \\
\hline 11 & Beechwood Hybrid No. 12 & 9.04 & 11.01 \\
\hline 12 & Beechwood Hybrid No. 85 & 14.98 & 15.49 \\
\hline 13 & Mixture No. 3. & 16.76 & 10.47 \\
\hline 14 & Beechwood Hybrid No. 87 & 10.16 & 11.94 \\
\hline 15 & Beechwood Hybrid No. 207 & 20.80 & 11.81 \\
\hline 16 & Michigan Wonder No. 221 & 7.13 & 8.90 \\
\hline 17 & Kanred & 10.09 & 12.86 \\
\hline 18 & Mixture No. 4 & 10.39 & 8.44 \\
\hline 19 & New York 123-32 & 16.73 & 12.09 \\
\hline 20 & Red Rock & 14.04 & 10.68 \\
\hline 21 & Red Hussar & 12.71 & 17.42 \\
\hline 22 & Turkey (Kansas) & 17.32 & 13.74 \\
\hline 23 & Mixture No. 5 & 2.87 & 12.73 \\
\hline 24 & Michigan Amber & 3.39 & 10.71 \\
\hline 25 & Nigger & 4.09 & 10.47 \\
\hline 26 & Fulcaster (Co-op) & 2.09 & 14.25 \\
\hline 27 & Fulcaster (Out1) & 11.97 & 17.18 \\
\hline 28 & Mixture No. 6 & 11.19 & 7.75 \\
\hline 29 & Fulcaster (Blazier) & 11.41 & 6.77 \\
\hline \multirow[t]{2}{*}{30} & Fulcaster (Cowles) & 9.09 & 14.11 \\
\hline & Mean & 9.84 & 13.81 \\
\hline
\end{tabular}

32 of other varieties. The yields were adjusted by means of each check variety separately, to determine the relation between the effectiveness of yield adjustment and the similarity of the check to the tested variety. The results of this adjustment on plot variability are shown in Tables 37 and 38.

The variability of the yields of the Red Rustproof strains was somewhat reduced ( 6 per cent) by adjustment according to the yields 
Table 37.-Relative Variability of Actual and Adjusted Yields. Average Deviation in Percentage of Yield. Oats Variety Test 1921

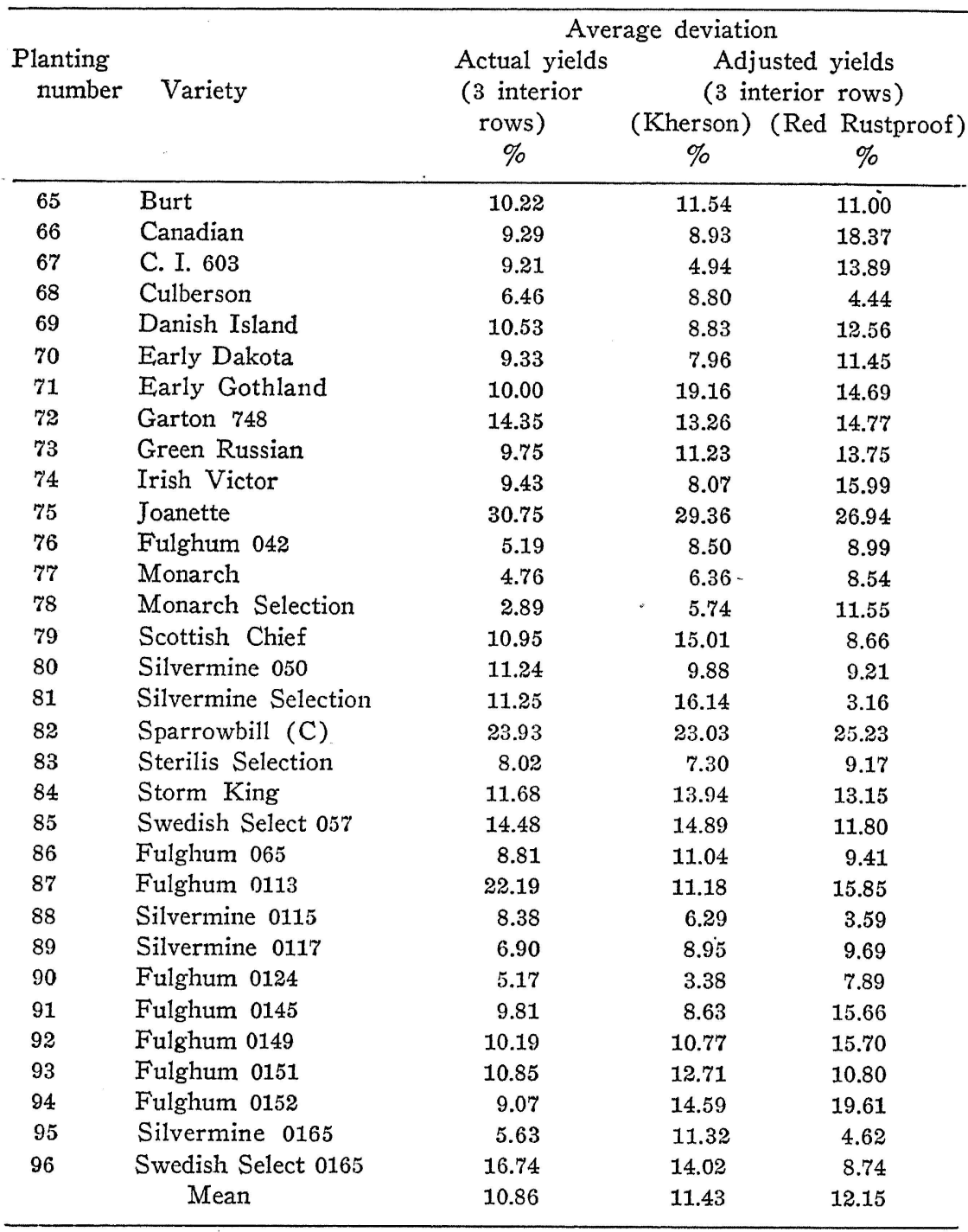

of the Red Rustproof check, but was slightly increased (2 per cent) when the Kherson check was used. On the other hand, the variability of the yields of the Kherson strains, though not reduced by either check, was increased only 4 per cent by the Kherson check, while it was increased 48 per cent by the Red Rustproof check. Neither check was effective in adjusting the yields of the other varieties, the Kherson 
Table 38.-Relative Variability of Actual and Adjusted Yields.

Average Deviation in Percentage of Yield.-Oats Strain Test 1921.

(Red Rustproof and Kherson)

\begin{tabular}{|c|c|c|c|c|c|c|c|c|c|}
\hline \multicolumn{5}{|c|}{ Red Rustproof strains } & \multicolumn{5}{|c|}{ Kherson strains } \\
\hline \multirow{3}{*}{ 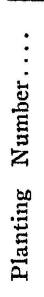 } & \multirow{3}{*}{ Strain } & \multicolumn{3}{|c|}{ Average deviation } & \multirow{3}{*}{ 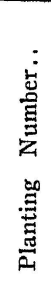 } & \multirow{3}{*}{ Strain } & \multicolumn{3}{|c|}{ Average deviation } \\
\hline & & \multirow{2}{*}{ 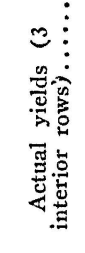 } & \multicolumn{2}{|c|}{$\begin{array}{l}\text { Adjusted yields } \\
\text { ( } 3 \text { interior rows) }\end{array}$} & & & \multirow{2}{*}{ 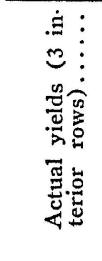 } & \multicolumn{2}{|c|}{$\begin{array}{l}\text { Adjusted yields } \\
\text { ( } 3 \text { interior rows) }\end{array}$} \\
\hline & & & $\begin{array}{l}\text { (Kher- } \\
\text { son) } \ldots\end{array}$ & $\begin{array}{l}\text { (Red } \\
\text { Rust-- } \\
\text { proof) }\end{array}$ & & & & $\begin{array}{l}\text { (Kher- } \\
\text { son)... }\end{array}$ & $\begin{array}{l}\text { (Red } \\
\text { Rust- } \\
\text { proof) }\end{array}$ \\
\hline & & $\%$ & $\%$ & $\%$ & & & $\%$ & $\%$ & $\%$ \\
\hline 1 & 066 & 18.13 & 15.48 & 13,04 & 2 & 023 & 15.80 & 7.59 & 12.93 \\
\hline 3 & 067 & 12.89 & 14.19 & 11.36 & 4 & 040 & 3.86 & 5.59 & 10.45 \\
\hline 5 & 068 & 23.14 & 21.34 & 12.47 & 6 & 041 & 9.50 & 5.82 & 4.07 \\
\hline 7 & 069 & 21.55 & 20.54 & 11.70 & 8 & 052 & 3.46 & 2.83 & 10.49 \\
\hline 9 & 072 & 14.29 & 12.26 & 10.34 & 10 & 053 & 6.26 & 5.97 & 10.14 \\
\hline 11 & 074 & 12.18 & 17.23 & 13.94 & 12 & 079 & 11.49 & 9.91 & 10.20 \\
\hline 13 & 075 & 13.40 & 18.28 & 18.80 & 14 & 080 & 1.72 & 7.02 & 13.20 \\
\hline 15 & 0118 & 28.77 & 32.06 & 26.92 & 16 & 082 & 6.19 & 8.74 & 15.01 \\
\hline 18 & 0119 & 10.32 & 13.47 & 13.62 & 17 & 083 & 5.31 & 5.88 & 9.26 \\
\hline 20 & 0120 & 7.28 & 6.11 & 12.32 & 19 & 085 & 8.69 & 10.65 & 7.30 \\
\hline 22 & 0122 & 17.16 & 12.32 & 14.20 & 21 & 086 & 11.73 & 7.45 & 8.45 \\
\hline 24 & 0125 & 10.91 & 11.52 & 8.40 & 23 & Mixture $e^{* *}$ & 4.87 & 3.84 & 9.19 \\
\hline 26 & 0126 & 10.41 & 10.24 & 4.66 & 25 & $088^{* *}$ & 13.04 & 13.79 & 9.16 \\
\hline 28 & 0128 & 14.48 & 17.36 & 2.76 & 27 & 089 & 4.69 & 6.77 & 12.89 \\
\hline 30 & 0129 & 7.89 & 6.31 & 7.44 & 29 & 090 & 2.84 & 4.85 & 10.64 \\
\hline 32 & 0130 & 7.99 & 11.78 & 9.17 & 31 & 091 & 12.46 & 14.67 & 10.84 \\
\hline 33 & 0131 & 12.43 & 13.96 & 13.23 & 34 & 094 & 4.59 & 6.43 & 6.57 \\
\hline 35 & 0132 & 17.77 & 14.67 & 12.11 & 36 & 095 & 4.36 & 4.96 & 14.62 \\
\hline 37 & 0133 & 14.07 & 11.63 & 13.55 & 38 & 096 & 4.39 & 7.71 & 4.66 \\
\hline 39 & 0134 & 29.91 & 30.37 & 29.50 & 40 & 097 & 5.53 & 6.97 & 11.80 \\
\hline 41 & 0135 & 14.36 & 17.58 & 13.11 & 42 & 098 & 9.09 & 10.03 & 13.18 \\
\hline 4.3 & $0136^{*}$ & 7.80 & 7.59 & 12.69 & 44 & 099 & 6.89 & 6.26 & 10.20 \\
\hline 45 & 0141 & 12.58 & 13.30 & 11.11 & 46 & 0100 & 6.90 & 4.65 & 8.55 \\
\hline 47 & 0163 & 2.70 & 1.82 & 14.28 & 48 & 0155 & 12.75 & 4.49 & 23.56 \\
\hline 50 & 0169 & 21.95 & 17.79 & 23.03 & 49 & 0157 & 6.34 & 7.40 & 14.18 \\
\hline 52 & 0181 & 9.95 & 7.62 & 9.69 & 51 & 0158 & 10.81 & 12.24 & 6.26 \\
\hline 54 & 0182 & 26.12 & 21.76 & 20.84 & 53 & 0159 & 6.33 & 10.82 & 8.26 \\
\hline 56 & $0183^{*}$ & 4.52 & 5.51 & 8.99 & 55 & 0160 & 4.98 & 6.12 & 12.52 \\
\hline 58 & 0383 & 10.10 & 15.60 & 20.18 & 57 & 0161 & 5.55 & 9.19 & 9.27 \\
\hline 60 & 0391 & 9.55 & 11,37 & 6.47 & 59 & 0162 & 11.28 & 13.38 & 9.47 \\
\hline 62 & 0.394 & 13.03 & 11.52 & 10.29 & 61 & 0167 & 2.65 & 3.37 & 4.41 \\
\hline 64 & 0395 & 8.69 & 11.40 & 17.96 & 63 & 0174 & 10.74 & 8.96 & 15.67 \\
\hline & & 14.47 & 14.70 & 13.55 & & Mean & 7.16 & 7.44 & 10.59 \\
\hline
\end{tabular}

* Not taxonomically Red Rustproof. Fixclucled from average.

* Not taxonomically Kherson. Excluded from average.

***Mixture of strains 082, 094, 0100, 0174.

check increasing their variability 7 per cent, and the Red Rustproof check 20 per cent. These results indicate the importance of using a check variety typical of the varieties tested, when adjustment of yields is to be made; and the danger of increasing rather than decreas- 
ing error by this practice when the tested varieties are quite different in habit from the check variety.

The use of an unsuitable check variety not only increases the margin of error, but it may cause very deceptive comparative results. For example, the average yields of the Kherson strains 0155 and 0157 , unadjusted and adjusted according to the yields of both check varieties, are shown below:

\begin{tabular}{|c|c|c|c|c|}
\hline \multirow{3}{*}{ Method } & \multicolumn{4}{|c|}{ Strain } \\
\hline & \multicolumn{2}{|c|}{0155} & \multicolumn{2}{|c|}{0157} \\
\hline & Yield & $\begin{array}{c}\text { Average } \\
\text { Deviation }\end{array}$ & Yield & $\begin{array}{l}\text { Average } \\
\text { Deviation }\end{array}$ \\
\hline Unadjusted & 37.50 & 12.75 & 43.69 & 6.34 \\
\hline Adjusted by Kherson check & 34.50 & 4.49 & 43.69 & 7.40 \\
\hline Adjusted by Red Rustproof check & 39.94 & 23.56 & 39.38 & 14.18 \\
\hline
\end{tabular}

The 17 per cent advantage in yield of strain 0157 is increased to 27 per cent by the Kherson adjustment, and since the variability of the replicate yields is reduced by the adjustment we may fairly assume that the latter is the more reliable figure. But when the Red Rustproof check is used for adjusting yields, the advantage of strain 0157 disappears entirely. The inaccuracy of the yields adjusted by Red Rustproof is indicated by the increase in plot variability resulting from this adjustment. Thus the adjustment of yields by means of check plots may mask considerable differences in yields between the varieties under test.

Although Kherson and Red Rustproof are decidedly different in type, both are commonly grown in Missouri, and both have been used frequently here as check varieties in oats variety tests. It is interesting

Table 39.-Relative Variability of Actual and Adjusted Yield of Kherson and Red Rustiproof Oats, Each in 120 Distributed Plots.

Oats Variety and Strain Tests 1921.

\begin{tabular}{|c|c|c|c|c|}
\hline \multirow[b]{3}{*}{ Variety } & \multirow{2}{*}{\multicolumn{2}{|c|}{ Yield }} & \multicolumn{2}{|c|}{ Standard deviation } \\
\hline & & & \multirow{2}{*}{$\begin{array}{l}\text { Actual } \\
\text { yield } \\
\%\end{array}$} & \multirow{2}{*}{$\begin{array}{l}\text { Adjusted } \\
\text { yield } \\
\%\end{array}$} \\
\hline & Actual & Adjusted & & \\
\hline Kherson & 37.95 & 39.04 & 12.15 & 20.79 \\
\hline Red Rustproof & 22.44 & 22.80 & 17.78 & 19.92 \\
\hline
\end{tabular}


to determine the effect on variability of adjusting the yields of the 120 plots of Kherson, on the basis of those of the 120 plots of Red Rustproof adjoining them, and those of the 120 plots of Red Rustproof, on the basis of the yields of the adjoining Kherson plots. In this adjustment the yield of each plot is divided by the plot value of the adjoining plot, and the method corresponds to method II used by Kiesselbach in the experiment cited above (see Table 29). The results of the yield adjustment are shown in Table 39.

The adjustment of plot yields by means of check plots of a variety distinctly different in type resulted in a decided increase in plot variability, even though the plot values used were determined in each case by the yield of the immediately adjacent plot. If the yields of the Kherson and the Red Rustproof plots had been perfectly accurate measures of the productivity of the soil, the plot values of the adjacent plots would have been almost the same in each of the 120 locations, and the adjustment of the yields of either variety by those of the other would have reduced variability almost to zero. Instead, variability was actually and yery decidedly increased, because the sections of the field which gave relatively high yields of Kherson, gave relatively low yields of Red Rustproof, and vice versa, in many cases. In fact, there was very little relation between the productivity of a portion of the field as determined by a Kherson check, and the pro-

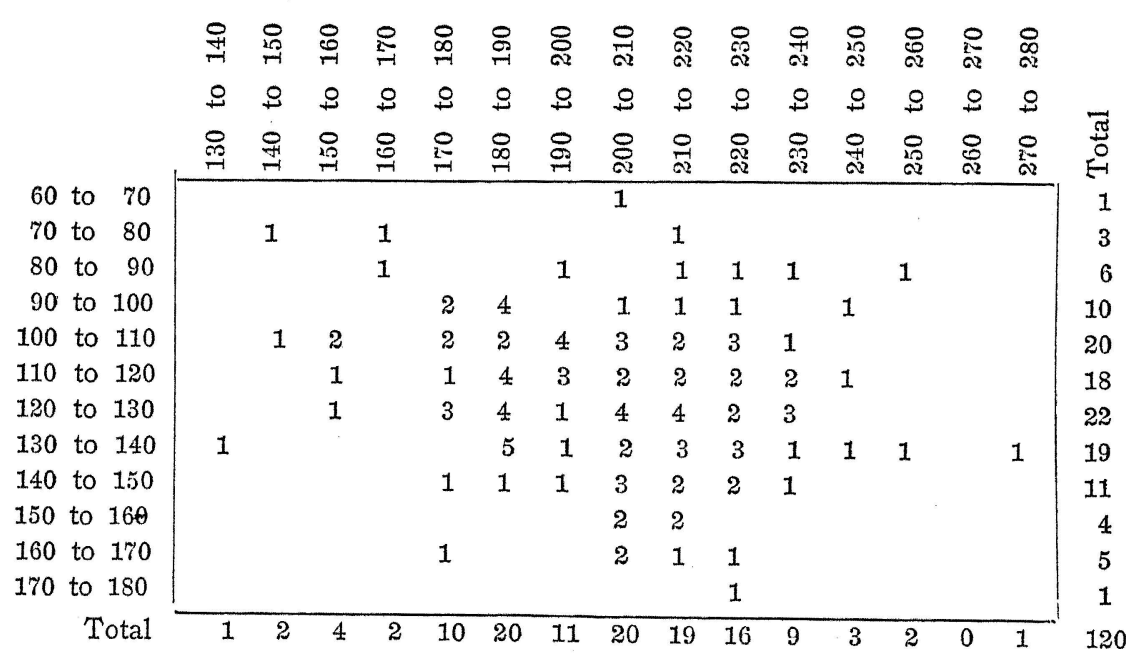

Figure 7.-Correlation Between Yiefds of Kherson Check Plots and YinLDS of Adjacent Red Rustproof Check Plots, in OATS Variety and STRAIN TESTS 1921.

$$
\mathrm{r}=+.162 \pm .060 \text {. }
$$


ductivity of the same portion of the field as determined by an adjacent Red Rustproof check plot. This correlation is shown in figure 7. The coefficient of correlation is less than three times its probable errorthe correlation has not even statistical significance! The relative productivity of different portions of the field, as indicated by the two check varieties, is shown in figure 8 . If Kherson had been used as a check
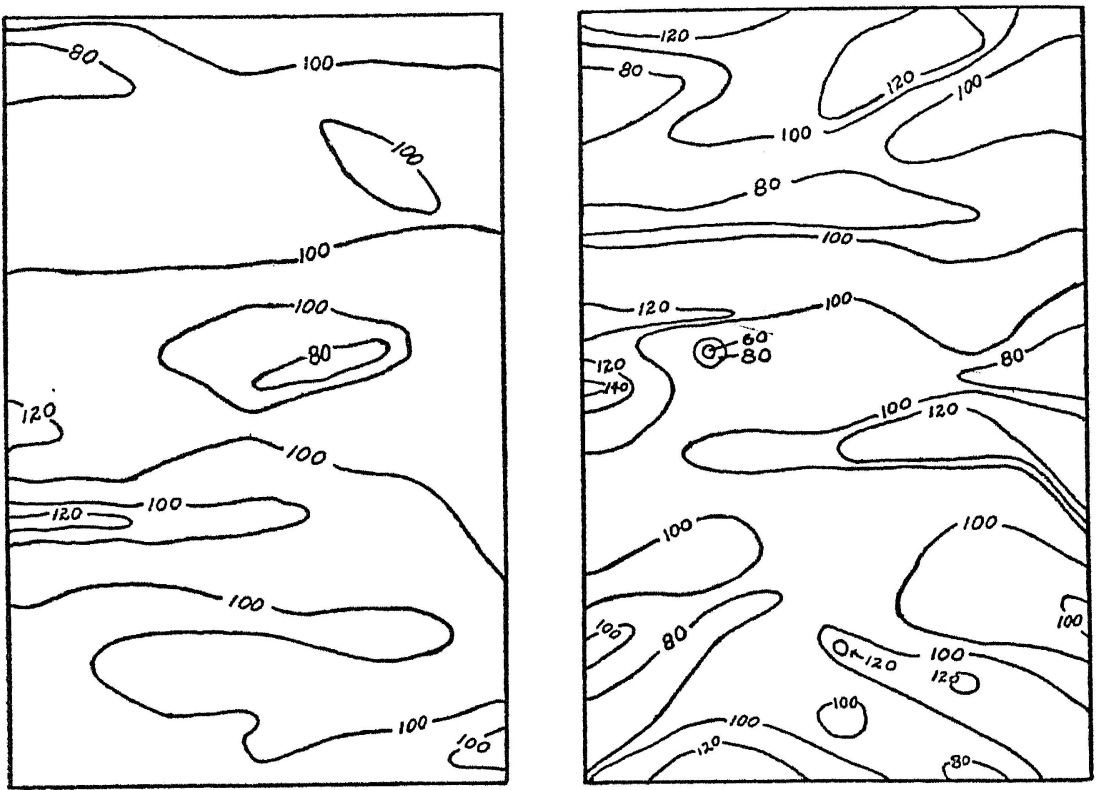

Figure 8.-Relative Variability of Different Parts of an Experiment Field, as indicated by the Yields of AdjackN'́ Check Plots of Kherson and RED Rustrpoof OATS. OATS Variety and Strain Tests 1921. In the diagram on the left, points of equal productivity, as indicated by the yields of the Kherson check plots, are connected by lines (as points of equal elevation are connected by lines on a contour map). In the diagram on the right, the same field is similarly mapped according to the yields of the Red Rustproof check plots. The numbers indicate the plot values of the points concerned.

variety for adjusting yields, the yields of certain plots would have been increased to compensate for the low productivity of the soil; if Red Rustproof had been used the yields of the same plots would have been decreased to compensate for the high productivity of the same soil. The fact is that certain parts of the field were actually more productive than the average for Kherson oats and less productive for Red Rustproof, as is indicated by the fact that each variety of check was considerably more effective in the adjustment of the yields of strains of the same variety than of strains of the other. But neither check was a very accurate measure of the productivity of the soil, even for its own variety, as indicated by the failure of adjustment to reduce variability consistently even when Kherson strains were ad- 
justed according to the Kherson check and Red Rustproof strains according to the Red Rustproof check.

Value and Limitations of Adjusting Yields by Means of Check Plots.-The effect on plots variability of adjusting yields by means of check plots in all of the tests is shown in summary form in Table 40. The variability of the test plots was reduced by adjustment in three tests and was increased in the other five. It is noteworthy that the three tests in which plot variability was reduced by adjustment were characterized by high plot variability, as indicated by the standard deviation of check plots, while the tests in which adjustment was not

Table 40.-Summary of Relative Variability of Actual and Adjusted YIFLDS OF INTERIOR ROWS IN ALL TESTS.

\begin{tabular}{|c|c|c|c|c|c|}
\hline Test & Season & $\begin{array}{l}\text { Number } \\
\text { of var- } \\
\text { eties or } \\
\text { strains }\end{array}$ & $\begin{array}{l}\text { Number } \\
\text { or rep- } \\
\text { lica- } \\
\text { tions }\end{array}$ & $\begin{array}{l}\text { Average } \\
\text { Actual } \\
\text { yields }\end{array}$ & $\begin{array}{l}\text { deviation } \\
\text { Adjusted } \\
\text { yields }\end{array}$ \\
\hline & & & & $\%$ & $\%$ \\
\hline Barley Variety & 1919 & 27 & 3 & 15.35 & 12.91 \\
\hline Oats Variety & 1919 & 24 & 3 & 10.23 & 8.27 \\
\hline Oats Strain & 1919 & 15 & 4 & 5.96 & 6.80 \\
\hline Wheat Variety & 1920 & 94 & 4 & 24.27 & 15.32 \\
\hline Wheat Variety & 1921 & 94 & 3 & 10.45 & 11.52 \\
\hline Wheat Mixture & 1921 & 30 & 4 & 9.84 & 13.81 \\
\hline Oats Variety & 1921 & 32 & 4 & 10.86 & $11.43^{*}$ \\
\hline Oats Strain & 1921 & 64 & 4 & 10.82 & $11.07 *$ \\
\hline
\end{tabular}

*Adjustment by Kherson check.

effective were in general low in plot variability. In 1919 adjustment was quite effective in reducing variability in the oats variety test, while it increased variability in the oats strain test, which was conducted on the same field and similarly handled in every way. In fact, conditions were considered more favorable for the effectiveness of the practice in the strain test than in the variety test, for the check plots were closer together and 12 of the 15 strains tested were taxonomically identical with the check. But the standard deviation of check plots on the part of the field on which varieties were grown was almost twice as great as on the part of the field on which the strains were grown. Apparently the high variability of the plots in the variety test was caused in large part by differences in actual soil productivity which were largely counteracted by the adjustment of yields, while there was little variation in soil productivity in the strain test and such plot variability as occurred was largely due to other factors. In general therefore the adjustment of yields will probably be found more ef- 
fective on fields highly variable in soil productivity than on more uniform fields, and for similar reasons the method will probably be found more effective in tests covering a rather large area than in tests covering a smaller area.

It is clear that the adjustment of yields by means of check plots entails several serious disadvantages, and may increase experimental error considerably. Not only is the yield of the check plot a far from perfect measure of soil productivity for the check variety, but the productivity of the same soil for other varieties may be decidedly different. The method is therefore more effective in tests of strains of the same variety as the check, than in tests of different varieties. When the yields of check plots are materially affected by factors not similarly affecting the neighboring test plots, adjustment of yields will increase experimental error. The check plots must therefore be effectively protected from competition, border effect, mechanical errors, and the like. Moreover, it is to be expected that the effectiveness of adjusting yields will vary with the season, since the relative influence of soil productivity on yield varies with the season. For example, in a season in which winter injury is exceptionally severe, actual soil fertility may have comparatively little to do with plot yields. Now, if the check variety is hardy, its yields may vary with the soil fertility, but when corresponding adjustments are made on the yields of tested varieties limited in yield by winter injury, a decrease in the variability of replicate plots is hardly to be expected. The same considerations apply of course to yields limited by many other factors.

But, although a multitude of objections may be made to the theoretical bases of the practice of adjusting yields in variety tests, and although in many cases it undoubtedly results in an increase rather than a decrease in experimental error, the practice offers promise of value and is worthy of further investigation. The effectiveness of the adjustment of yields in the wheat variety test of 1920 , in which the variability of replicate test plots was reduced about 40 per cent, is a demonstration of the possibilities of the method. An increase in replication of plots involving the same increase in land and labor would probably have reduced plot variability only about 7 per cent. A thorough knowledge of the value and limitations of yield-adjustment by means of check plots might enable us to reduce variability, at least in some types of plot tests, much more effectively by this means than by replication. The saving in area required is of particular significance in preliminary tests if border rows must be used for the elimination of competition, since in this case the area required for a large number of replications is in many cases prohibitive. 


\section{CONCLUDING REMARTS}

The best method for preliminary variety testing is one which will permit the accurate determination of the relative value of the varieties under field conditions, with the use of a small area of land for each variety. Some precision must be sacrificed to save land, and in so far as the errors involved are of such nature that their extent can be approximately determined, and conclusions drawn accordingly, this sacrifice of precision is permissible. In many cases it is advisable, for example, to reduce the number of replications and to increase the least difference in yield regarded significant to a sufficient degree to compensate for the decrease in precision.

But these considerations do not apply to systematic errors, which, since they affect the yields of replicate plots similarly, and consequently have little effect on plot variability, cannot be accurately measured. Typical systematic errors commonly involved in preliminary testing are (1) modification of growing conditions favoring some varieties more than others, such as hand planting or wide spacing between rows, and (2) competition between varieties of different type, resulting from the use of single-row plots. The relative value of varieties under such conditions may be vastly different from their relative value under typical field conditions. Even should measurable experimental error be reduced to the absolute minimum, such a variety test might give results entirely misleading. The error cannot be counteracted, as can non-systematic errors, by increasing the least difference considered significant, nor can the extent of error of this sort be measured or estimated by a study of the experimental results.

Systematic error must therefore be reduced by every practicable means. Growing conditions in the preliminary test should be made as similar to ordinary field conditions as possible. The effect of varietal competition must be reduced to the minimum. If this can be accomplished without increasing the size of plots, it is desirable to do so. On the other hand, if larger plots are necessary for the control of competition, larger plots should be used. If the area to be used for preliminary testing cannot be correspondingly increased, the number of replications can be reduced sufficiently to permit the use of the larger plots required on the area available. This will necessitate a decrease in the degree of precision of the test, and will reduce the rapidity of elimination of the less valuable varieties. But is it not better to eliminate the undesirable varieties slowly than to risk the elimination of desirable ones by a more rapid analysis? 
The error from competition is greater when different varieties are compared than when different strains of the same variety are compared, and the extent of error is roughly in proportion to the degree of difference in type of the varieties tested. Competition was not found to be correlated closely enough with earliness of heading, earliness of maturity, height, or grain-straw ratio in these experiments to permit its control by grouping varieties in respect to these characters. The factor found most closely correlated with competitive value was yield, but the correlation even in this case was not close enough to permit of effective control by grouping varieties. Moreover, it would be impossible in practice to group varieties with regard to yield, since the relative yield of varieties varies so widely with the season. The variety expected to yield poorly is not ordinarily included in the variety test.

When different strains of the same variety are grown, the error from competition, in some cases at least, may be slight enough to justify the use of single-row plots. However, competition in such cases is not wholly absent, and may occasionally be quite marked. The importance of competition as a source of error in tests of pure line selections of the same variety merits detailed investigation. If it is found that the effects of competition between pure lines is slight it may be practicable to use single-row plots, or at any rate to use 3-row plots without discarding border rows. The latter method will reduce the error from competition materially, without necessitating the loss of any of the experimental area. When the same total area is used, however, single row plots are somewhat more reliable than 3-row plots, because more replications can be used. The best size of plot for ordinary variety testing, as indicated by this investigation, is probably the 3-row plot with border rows discarded. The length of the plot as harvested is assumed to be 16 feet, but the same considerations will apply for any other convenient length. The number of replications will vary with the heterogeneity of the field and the degree of precision required (and, to some extent, with the season and the variety).

Check plots have been used in preliminary variety tests mainly for the following purposes:

(1) For the adjustment of the yields of the test plots, and

(2) To provide a measure of plot variability for the field used, and thus to determine the degree of precision of the experimental results, or the number of replications which would be required for a given degree of precision.

In both cases the behavior of the check variety is the basis for conclusions regarding the tested varieties. This involves the assumption that different varieties of the same crop respond similarly 
to varying conditions. In one case, reported in this paper, two standard varieties, used as duplicate checks, and grown side by side in 120 distributed sections of a field, showed no significant correlation in relative yield of adjoining plots, and differed so widely in plot variability that the number of replications necessary for a given degree of accuracy was more than twice as great for one check variety as for the other. Further investigation is necessary to determine how generally such.cases may occur, but this single case indicates at least a possible source of extreme error in the use of check plots, either for adjustment of yield or for the determination of the probable error of the experimental results.

For this and various other reasons the adjustment of yields by means of check plots is at present of doubtful value as a general practice. In some cases, however, such adjustment accomplishes a great improvement in the precision of an experiment, with a relatively slight increase in expense. The practice is more promising for tests of strains or selections of the same variety than for tests of different types. A thorough study of the use of check plots in variety and strain testing may discover methods of overcoming the disadvantages, and thus make available an economical and effective method of increasing precision. Meanwhile, check plots should be used cautiously. Methods for adjusting yields and for determining the extent of plot variability without the use of check plots are available ${ }^{17}$, and check plots must demonstrate actual value if they are to continue in use in variety tests.

\section{SUIMIMARY}

1. In variety and strain tests of barley, oats, and wheat, in fiverow blocks, the competing border rows of adjacent sorts gave relative yields often widely different from those of the interior rows of the same plots.

2. Such competitive effects were much more extreme between different varieties than between different commercial strains of the same variety.

3. A considerable error from competition affected tests in rows running north and south, as well as those in rows running east and west.

4. Although in general the higher yielding varieties were favored in competition, the reverse frequently occurred. In some cases a material advantage in yield in the interior rows was converted to a material disadvantage in yield in the border rows. 
5. Competing quality was correlated fairly consistently with yield and with earliness of heading and maturity. No relation to grain-straw ratio was found in the one season in which this character was determined. A significant correlation between competition and height was found in the wheat variety test of 1921, but the relation of competition to height was not determined in the other tests.

6. In the oats tests competition was most closely related to earliness of heading and maturity, but was also related to yield. In the wheat, competition was related fairly closely to both yield and earliness. In the barley it was not significantly correlated with any of the characteristics studied, though the relation to yield was considerably closer than the relation to any of the other characteristics.

7. In the wheat and oats tests in which earliness and yield were correlated with competition, earliness and yield were correlated quite closely with one another.

8. Single-row plots, protected from competition by border rows discarded at harvesting, were somewhat more variable in yield than 3-row plots similarly protected, but the difference was not great enough to outweigh their advantage in size. The mean yield of five replicate protected single-row plots is therefore more reliable, under the conditions of these tests, than the mean yield of three replicate protected 3-row plots, which would occupy the same area and require considerably more labor in harvesting and threshing.

9. There was no consistent difference in variability between 3row and 5-row plots.

10. Plot variability was increased with increase in the size of the experiment field. The number of replications required for a given degree of precision, as measured by the variability of plot yields, is therefore increased somewhat when border rows are added for the control of competition.

11. The variability of 120 distributed check plots of Kherson oats differed widely from that of 120 distributed plots of Red Rustproof oats, adjacent to them. If the variability of the check yields were considered a measure of the precision of the test, entirely different conclusions would be drawn on the basis of the yields of these two check varieties.

12. Adjustment of plot yields on the basis of the yields of check plots resulted in a decrease in plot variability in three tests and in an increase in five tests. In general the practice was effective on fields of high plot variability, and was ineffective on fields of low plot variability. 
13. In the oats strain test in which both Kherson and Red Rustproof check plots were included, the Kherson check was more effective than the Red Rustproof check as a basis for adjusting the yields of the Kherson strains, while the Red Rustproof check was more effective as a basis for adjusting the yields of the Red Rustproof strains.

14. The correlation between the yields of adjacent Kherson and Red Rustproof check plots was not statistically significant. Adjustment of the yields of the Kherson check plots on the basis of the yields of the adjacent Red Rustproof plots, and of those of the Red Rustproof plots on the basis of the Kherson yields increased variability.

\section{ACKNOWLEDGMENT}

The writer is indebted to Professors M. F. Miller and W. C. Etheridge for a critical reading of the manuscript, and to $\mathrm{O}$. W. Letson for preparing: figure 8. 


\section{REFERENCES CITED.}

1. Day, James W. The relation of size, shape, and number of replications of plats to probable error in field experimentation. In Journ. Amer. Soc. Agron. 12, 3; pp. 100-105. 1920.

2. Etheridge, W. C. A classification of the varieties of cultivated oats. Cornell Univ. Agr. Expt. Sta. Memoir 10; pp. 85-172. 1916.

3. Hall, A. D. and E. J. Russell. Field trials and their interpretation. In Jour. Bd. Agr. (London) Supplement: pp. 5-14. 1911.

4. Hayes, H. K. and A. C. Arny. Experiments in field technic in rod-row tests. In Jour. Agr. Res., 11, 9: pp. 399-419. 1917.

5. Kiesselbach, T. A. Studies concerning the elimination of experimental error in comparative crop tests. Nebr. Agr. Expt. Sta. Res. Bul. 13: pp. 3-95. 1918.

6. Kiesselbach, T. A. Experimental error in field trials. In Journ. Amer. Soc. Agron. 11, 6: pp. 235-241. 1919.

7. Kiesselbach, T. A. Plat competition as a source of error in crop tests. In Journ. Amer. Soc. Agron. 11, 6: pp. 242-247. 1919.

8. Love, H. H. The experimental error in field trials. In Journ. Amer. Soc. Agron. 11, 5: pp. 212-216. 1919.

9. Love, H. H. and W. T. Craig. Methods used and results obtained in cereal investigations at the Cornell Station. In Journ. Amer. Soc. Agron. IO, 4: pp. 145-157. 1918.

10. Lyon, T. L. A comparison of the error in yield of wheat from plats and from single rows in multiple series. In Proc. Amer. Soc. Agron. 2: pp. 38, 39. 1911.

11. Lyon, T. L. Some experiments to estimate errors in field plat tests. In Proc. Amer. Soc. Agron. 3: pp. 89-114. 1912.

12. Mercer, W. B. and A. D. Hall. The experimental error in field trials. In Journ. Agr. Sci. 4, 2: pp. 107-132. 1911.

13. Montgomery, E. G. Variation in yield and methods of arranging plats to secure comparative results. In 25th Ann. Rpt. Nebr. Agr. Expt. Sta. pp. 164-180. 1911.

14. Montgomery, E. G. Experiments in wheat breeding. Experimental error in the nursery and variation in nitrogen and yield. U. S. Dept. Agr. Bur. Plant Indus. Bul. 269 : pp. 5-61. 1913.

15. Morgan, J. O. Some experiments to determine the uniformity of certain plats for field tests. In Proc. Amer. Soc. Agron. 1: pp. 58-67. 1910.

16. Salmon, C. Check plats as a source of error in varietal tests. In Journ. Amer. Soc. Agron. 6, 3: pp. 128-131. 1914.

17. Surface, F. M. and Raymond Pearl. A method for correcting for soil heterogeneity in variety tests. In U. S. Dept. Agr. Journ. Agr. Res. 5, 22: pp. 1039-1049. 1916.

18. Wood, T. B. \& F. J. M. Stratton. The interpretation of experimental results. In Journ. Agr. Sci. 3, 4: pp. 417-440. 1910. 